\title{
Propriedades Estruturais e Óticas de Nanopartículas de Silício
}

Tese Apresentada ao Instituto de Física da Universidade de São Paulo para obteção do Título de Doutor em Ciências

Doutorando:Rogério José Baierle

Orientador:Prof ${ }^{\underline{a}}$. Dr $\stackrel{a}{a}$. Marília Junqueira Caletas

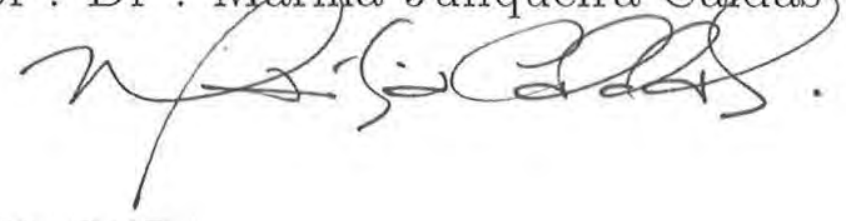

BANCA EXAMINADORA

Prof. Dr: Hélio Chachan (UFMG)

Prof. Dr. Pierre Basmadji (IFSCarlos/USP)

Prof. Dr. Omar Tecshke (IFGW/UNICAMP)

Prof. Dr. Adalberto Fazzio (IF/USP)

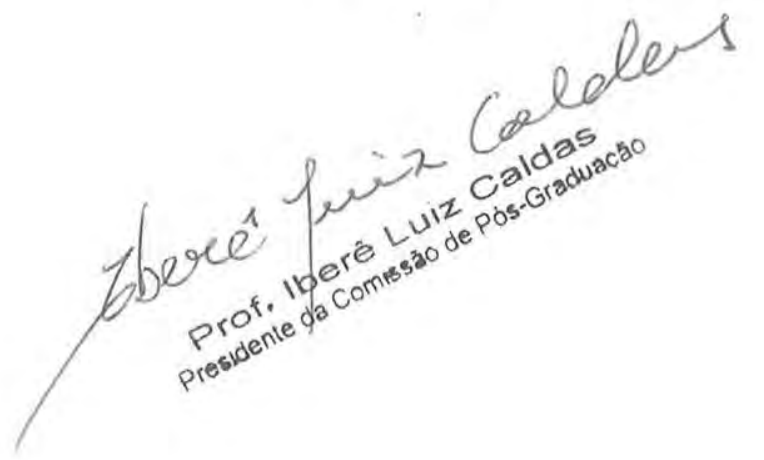

São Paulo

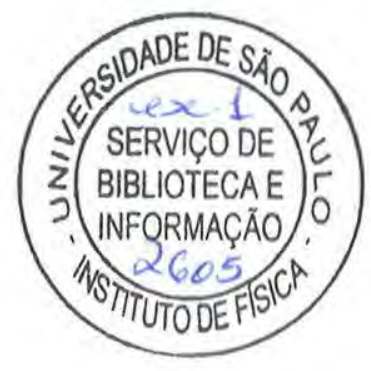




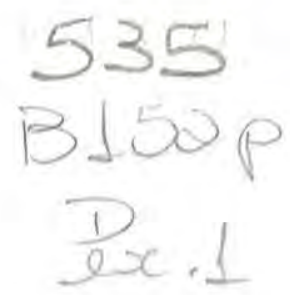

FICHA CATALOGRÁFICA

Preparada pelo Serviço de Biblioteca e Informação

do Instituto de Física da Universidade de São Paulo

Baierle, Rogério José

Propriedades Estruturais e Óticas de Nanopartículas de Silicio. São Paulo, 1997.

Tese (Doutoramento) - Universidade de São Paulo. Instituto de Fisica - Departamento de Fisica dos Materiais e Mecânica.

Área de Concentração: Fisica do Estado Sólido Orientador: Profa. Dra. Marilia Junqueira Caldas

Unitermos: 1. Partículas de Silício; 2. Propriedades Estruturais e Óticas; 3. Silicio Poroso;

4. Hartree-Fock LCAO; 5. NDO/Cristal. 


\section{Agradecimentos}

Às Prof. ${ }_{S}$ Dr. ${ }_{S}$ Marília Junqueira Caldas (Orientadora) Elisa Molinari (Colaboradora) pelas orientações amigas.

Aos Prof.s Dr.s Adalberto Fazzio, Stefano Ossicini e Sylvio Canuto pela ajuda com as discusões envolvendo problemas dia física.

À minha familia que mesmo distante sempre me incentivon.

Aos amigos Wagner, Edvaldo, Alex, Fernando, Fabio e a todos os colegas do DFMT pelo incentivo e amizade.

À FAPESP e ao CNPq pelo apoio financeiro concedido. 


\begin{abstract}
We study the properties of hydrogenated Si nanoparticles, also under surface oxidation, as a model-material to understand porous Silicon. To do that we developed a procedure designed to calculate geometries, vibrational properties and optical spectra for complex semiconductor systems, using semiempirical Quantum Chemistry techniques. The adopted techniques were thoroughly reparametrized for the $\mathrm{Si}$ and $\mathrm{O}$ atoms, and we thus present here the new parametrizations that we call AM1/Crystal and ZINDO/Crystal.

Contrary to the bulk crystal, porous Si is known to emit visible light efficiently, with bands in the red-orange and green regions. This behavior has been ascribed to quantum confinement in crystalline nanostructures created by the porosity, which should account both for the blue shift of the optical thereshold and for the emission efficiency.

Our results for different nanoparticles confirm the crystallinity of the structures. and show a blue shift of the first absorption peak with decreasing diameter. However the absorption peak energy for nanoparticles with effective diameter aromnd $15 \AA$ lies around $3 \mathrm{eV}$, much higher than the red-orange emission.

A study of structural relaxation in the first excited state reveals a strong local distortion that creates a surface defect, in which an hydrogen atom "bridges" a pair of surface silicon atoms. In this Si-H-Si configuration the nanoparticles emit light of much lower energy (red-orange), which is virtually independent of diameter. Surface oxidation also has very little influence on the energy of the emitted light.

Based on our results, we associate the optical activity of porous silicon to quasispherical nanocrystalline regions in the material. Both the absorption and the green emission occur in the core of the crystallites, and shows blue-shift with decreasing size; the red-orange luminescence occurs at the surface, through photogenerated defects, being thus pinned in energy.

The blue shift of absorption with oxidation we interpret as being due to decrease in crystallite size, and the decrease in luminescence intensity as being due to "hardening" of the oxidized surface, which decreases the total number of sites for photogeneration of defects.
\end{abstract}




\section{Resimo}

Neste trabalho nós estudamos as propriedades de nanopartículas de Si lidergenadas, limpas e com oxidação da superfície, como simulação do material silíciu poroso. Para tal, desenvolvemos $11 m$ procedimento para o cálculo da geometria. propriedades vibracionais e espectro ótico de sistemas semicondutores complexos. usando as técnicas semiempíricas de Química Quântica. As técnicas escolhiclats foram completamente reparametrizadas para os átomos de Si e O, e assim apresentamos as novas parametrizações que chamamos AMI/Cristal e Zindo/Ciristal.

Contrariamente ao silício cristalino, o material poroso emite eficientemente lı\% no visível, com duas bandas, no vermelho-laranja e no verde. Esse comportamento tem sido atribuido ao confinamento quântico em estruturas nanocristalinas criadas pela porosidade, confinamente esse que deve ser responsável tanto pela eficiencia da emissão, quanto pelo deslocamento do limiar ótico para energias mais allas.

Nossos resultados para nanopartículas de diferentes diâmetros confirmam it cristalinidade das estruturas, e mostram um deslocamento para o azul do primeiro pico de absorção, conforme diminui o diâmetro. Entretanto, a energia dessa

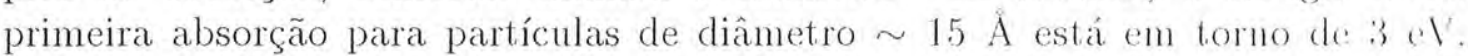
muito mais altas do que a emissão vermelho-laranja.

O estudo da relaxação estrutural no primeiro estado excitado mostra uma distorção forte e localizada, criando $u m$ defeito de superfície em que 1 m átomo de hidrogênio coloca-se numa configuração de "ponte" Si-H-Si. Nessa configuração as partículas emitem numa região de energia mais baixa (vermelho-laranja), inclependentemente do diâmetro. A oxidação da superfície influencia muito pouco as propriedades óticas, e em particular não afeta a energia da linha de emissão.

À luz destes resultados, associamos a atividade ótica do silício poroso a regiões nanocristalinas quase esféricas. A absorção (que varia consideravelmente em energia) e a emissão no verde ocorreu no "core" cristalino, e a emissão vermelho-laranja na região de superfície, atraves desses defeitos fotocriados, sendo portanto "lixa" em energia. O deslocamento para o azul da absorção com a oxidação interpretamos como sendo devido à diminuição do diâmetro efetivo dos cristalitos presentes no material, e o decréscimo da intensidade de luminescência como devida a 1 m enrijecimento da superfície oxidada, que reduz o número de sítios favoráveis à fotocriação de defeitos. 


\section{Índice}

1 Introdução 2

2 Método I: Arcabouço Teórico 11

2.1 A Equação para a Energia Tolal . . . . . . . . . . . . . . . . . 1:3

2.2 Obtenção das equações de Hartree-Fock-Roothaan . . . . . . . . 17

2.3 Correção de orbital virtual . . . . . . . . . . . . . . . . . I!

2.4 Método de Interação de Configurações . . . . . . . . . . . . . . . . 23

2.5 Extensão para Cristais: Sistema Periódico Infinito . . . . . . . . . 22(i

2.6 Modelo para Estados Excitados de Cristais na Teoria de Ilartree-

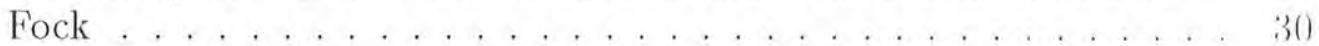

3 Método II: Implementação Utilizada 32

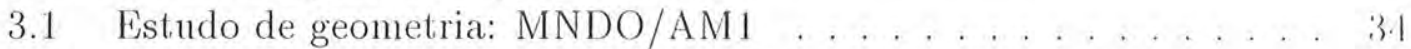

3.2 Estudo de Espectroscopia: ZINDO/CI . . . . . . . . . . . . . 3!)

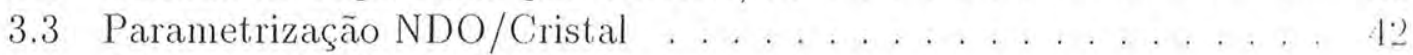

3.3.1 AM1/Cristal . . . . . . . . . . . . . . 43

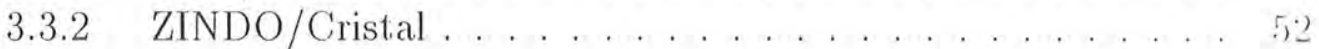

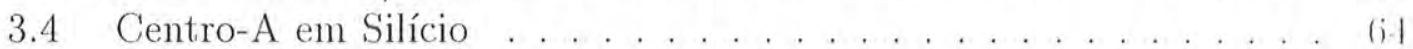

4 Propriedades de Nanopartículas de Si Hidrogenadas 71

4.1 Introdução . . . . . . . . . . . . . . . . . . . . . . . 72

4.2 Absorção Ótica de Nanopartículas de Si Hidrogenadas . . . . . . . 81

4.3 Espectro de Emissão de Pequenas Partículas de Si Hidrogenadas 89

5 Efeitos da Oxidação de Superfície $\quad 96$

5.1 Introdução: Incorporação de oxigênio em Superfícies de Si . . . . . 97

5.2 Absorção Ótica de Nanopartículas Fracamente Oxidadas . . . . 103 
5.3 Emissão Luminescente de Partículas de Si-H fracamente oxidadas . II

6 Conclusões

A Matrizes de Fock para somas de Bloch: Si e SiO.2

A.1 Simetria tetraédrica com dois átomos na célıla unitária e interaçu apenas entre primeiros vizinhos . . . . . . . . . . . . . 12!)

A.2 Simetria tetraédrica com oito átomos na base e interação de até segundos vizinhos . . . . . . . . . . . . . . . . . . . . . . . . . .

A.3 Simetria $D_{3 h} \operatorname{com} 9$ átomos na célula unitária e interação até seguıdos vizinhos . . . . . . . . . . . . . . . . (33)

B Parametrização NDO/Cristal para os átomos de Si e O 139

$\begin{array}{ll}\text { Bibliografia } & 143\end{array}$ 


\section{Capítulo 1 \\ Introdução}


O material semicondutor mais usado hoje em dia na construcan de disponilines eletrônicos ainda é o Si cristalino, dadas as suas notáveis e bem conluccidas pm

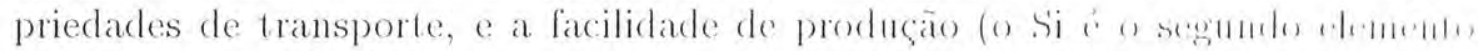
químico mais abundante na crosta terreste). Assim nos filtimos anos muitur an forços vem sendo realizados no sentido de produzir estrulmas hatseadas cun fi a pazes de emitir luz de maneira eficiente; entretanto, por ser $11 m$ semicondutor de gap indireto é dificilmente utilizável: a recombinação de um elétron na laixa de condução com um buraco na faixa de valência requer a participação de um fônon. para a conservação do momento. Isto faz com que este tipo de transição seja geralmente ineficiente, e a maior parte dos portadores excitados recombinam-se de maneira não radiativa produzindo calor (no bulk do Si apenas cerca de I fóton í gerado para cada $u$ milhão de portadores excitados)[1].

Para construir dispositivos optoeletrônicos a pesquisa em física de semicondutores tem se voltado principalmente para estruturas semicondutoras do lipo IIIV[2] ou estruturas de baixa dimensionalidade (poços quânticos, fios quânticos c pontos quânticos)[3], obtendo sucesso relativo. Pesquisas em materiais organicos tem também obtido algum sucesso na construção de materiais emissores de luz, e: se postula a utilização destes materias em substituição aos materias inorgânicos cristalinos, entretanto o interesse em construir um dispositivo opto-eletrônico lotalmente à base de silício persiste.

Recentemente Canham[4] e Lehmann[5] ao mesmo tempo e de maneira independente demonstraram que nanoestruturas de Si com alta porosidade podem emitir luz no vermelho visível com alta eficiencia. Este material é conhecido como silício poroso (porous silicon ou simplesmente po-Si). Emissões em outras regiões do espectro visível foram também detectadas e a eficiência apresentada foi de cerca de uma centena de vezes superior àquela apresentada pelo bulk de $\mathrm{Si}{ }^{1}$.

O material é geralmente preparado por anodização de substratos de Si do tipo $p$ em suspensão eletrolítica de $\mathrm{HF}+\mathrm{H}_{2} \mathrm{O}$, que provoca a dissolução do Si na suspensão, e produz material com porosidade que pode variar de 25 a $90 \%$. D):pendendo da intensidade da corrente, do tempo de tratamento, e da composição da suspensão, o tamanho e a distribuição dos poros varia[7, 8], como visto em um microscópico de transmissão, desde poros pequenos ( $20 \AA$ de diâmetro) em uma dis-

\footnotetext{
${ }^{1}$ O silício poroso foi incialmente descoberto em 1956 por Ulli[6] nos laboratórios Bell durante estudos de eletropolimento de superfícies de Si. Naqueles estudos observou-se que sob certas condiçóes um filme escuro nào desejado, aparecia sobre as amostras de Si. Esse material foi posteriormente utilizado na manufatura de estruturas de silício sobre óxido (silicon on insulator. $\mathrm{SOI})$
} 
tribuição homogênea, que podem estar ou não associados a uma superestrutura|i| de dimensões muito maiores $(\sim 600 \mathrm{~mm})$, até poros grandes $(\sim 500 \mathrm{~nm})$ em แma estrutura de canais $[9]$ ao longo, grosseiramente, das direções $\langle 100\rangle$; 0 diâme dos poros ou canais é normalmente acompanhado pelo diâmetro do material interveniente (maior diâmetro $\longmapsto$ maior espaçamento).

A luminescência observada em po-si pode alcançar a mesma eficiência datcucla produzida, por exemplo, em GaP:N[7], ou mesmo chegar à orden de grandeza (3 vezes maior) da luminescência em GaAs, um semicondutor de gap direto, e o máximo de intensidade pode ser variado desde o infravermelho longínquo até o visível em um forte deslocamento para o azul da luminescência esperada para o Si cristalino. A magnitude do deslocamento e mesmo a eficiência da luminescência são fortemente dependentes do método de preparação[9, 7, 10].

Entre as hipóteses consideradas prováveis para a origem da luminescência estâuo efeitos de confinamento quântico[4], e o material pode ser pensado como $11 m$ conjunto de fios quânticos ou cristalitos de dimensões nanoscópicas (foi sugericla a dimensão de alguns nanometros, $\geq 2 \mathrm{~nm}$, para cristalitos com luminescencia cliciente). Entretanto, apesar do número enorme de estudos sobre o material. o mecanismo de luminescência ainda é controverso: mesmo se relacionada à redução) do tamanho físico do cristal, alguns autores afirmam que a transição luminescente provavelmente se dá entre estados localizados[7]; e, se alguns autores postulam a existência de estruturas altamente ordenadas como fios quânticos[4], outros encontram evidências de que as estruturas emissoras no po-Si são de fato amorfas[1 I] ou por exemplo siloxanos.

Resultados mais recentes indicam que a luminescência pode ser obtida mesmo em amostras onde não estão presentes $\mathrm{H}$ e $\mathrm{O}[12,13,14]$ o que descartaria a possibilidade de que sejam estes agentes químicos os responsáveis pela luminescência, porém a influência que estes exercem sobre a luminescência ou em outras propriedades do po-Si ainda não é perfeitamente entendida.

A presença de $\mathrm{H}$ como passivador da superfície dos poros é inferida da observação $[15,16,17]$ de linhas Raman e de espectroscopia no infravermelho características de ligações $\mathrm{Si}-\mathrm{H}, \mathrm{Si}-\mathrm{H}_{2}$ e mesmo $\mathrm{Si}-\mathrm{H}_{3}$. A formação de óxido na superfície dos poros é em geral associada à degradação da luminescência[18], mas foram detectadas diferenças de comportamento para o po-Si oxidado em ar e oxidado em reação eletroquímica em $\mathrm{KNO}_{3}$, e até mesmo entre amostras com predominância de grupos $\mathrm{Si}-\mathrm{H}_{2}$ sobre grupos $\mathrm{Si}-\mathrm{H}[16]$.

Recentemente Allan a colaboradores[19] propuzeram um mecanismo para a luminescência de po-Si em que defeitos localizados, provocados pela falta de hidrogênio 
em terminações de superfície, são responsáveis pela "captura de excitons", ou scja. pelo decaimento ótico de excitações induzidas que viajem até o defeito. O trabalho é feito com dois tipos de método, $11 m$ deles ab initio na aproximação (a I)ensidade Local, enfocando clusters pequenos ( 30 átomos de Si) que representamo defeito superficial; e outro tight-binding chegando a clusters com 180 átomos de: Si . Os resultados são bastantes convincentes, apesar de baseados em 1 m defcito "provocado teoricamente" (além da falta de hidrogênio, é necessária mma tensâo local).

Entretanto, o que é importante destacar ao compararmos todos os resultidos teóricos existentes, veja tabela 1.1 (fios quânticos) e tabela 1.2 (nanocristais), ć a grande disparidade de valores obtidos para a transição luminescente de objetos quânticos semelhantes (entre fios, on entre cristalitos), e a consequente diferença de interpretação dos resultados experimentais. Assim, se o estudo de objetos ideais indicaria que fios quânticos teriam provavelmente uma emissão mais próxima ao valor experimental do que nanocristais, a proposta de Allan e colaboradores não pode de modo algum ser descartada em 11 m material de processamento tão complexo quanto o po-Si.

\begin{tabular}{|c|c|c|c|c|c|}
\hline fios quânticos & \multicolumn{5}{|c|}{ Energia do gap ótico (eV) } \\
\hline diâmetro $(\AA)$ & ref.[20] & ref.[21] & ref.[22] & ref.[23] & ref.[24] \\
\hline 7.70 & - & 2.48 & - & 3.85 & 2.35 \\
\hline 11.50 & - & 2.08 & - & - & 1.82 \\
\hline 12.20 & 1.95 & - & - & - & 1.50 \\
\hline 15.30 & - & 1.76 & 3.29 & 2.15 & - \\
\hline 16.35 & - & - & 3.08 & - & - \\
\hline 17.50 & 1.30 & - & - & - & - \\
\hline 23.00 & 0.90 & - & - & 1.80 & - \\
\hline
\end{tabular}

Tabela 1.1: Valores calculados com diferentes métodos para o gap de fios quânticos de silício passivados por $\mathrm{H}$. 


\begin{tabular}{|c|c|c|c|c|}
\hline cristalitos & \multicolumn{5}{|c|}{ Energia do gap ótico $(\mathrm{eV})$} \\
\hline $\mathrm{N}$ & ref.[25] & ref.[26] & ref.[27] & ref.[28] \\
\hline 10 & 4.62 & 5.10 & 3.43 & - \\
\hline 17 & - & 5.05 & 3.10 & - \\
\hline 29 & 3.32 & 4.95 & 2.76 & - \\
\hline 35 & - & 4.9 & 2.74 & 2.95 \\
\hline 66 & 2.95 & 3.98 & 2.62 & - \\
\hline 87 & - & 4.05 & 3.10 & - \\
\hline 123 & 2.45 & 3.60 & 2.45 & - \\
\hline 239 & - & 3.50 & - & 1.68 \\
\hline
\end{tabular}

Tabela 1.2: Valores calculados com diferentes métodos para o yap de nanopartículas de Si saturadas por H. Na primeira coluna indicamos o número $\mathrm{N}$ de átomos de Si na partícula.

Nosso questionamento de toda essa problemática é que, mesmo descontando a diferença de métodos, tal disparidade é inesperada e pode ter sua justificativa no fato de que estamos estudando objetos em dimensōes limítrofes entre moléculas o cristais. Uma indicação disso, vinda do laboratório, é a diferença entre as curvas de absorção e de luminescência para a mesma amostra, e entre curvas de absor(çio para a mesma amostra, como pode ser visto na figura 1.1 (da referência |7|).

Ora, um fator importante que deve ser investigado nessa região é a influência do tratamento da correlação eletrônica, que é incluida de modo completamente diverso em cada método teórico (desprezada completamente na maioria deles, mas em geral superestimada em cálculos dentro da aproximação da densidade local).

Os poucos estudos teóricos de po-Si disponíveis estão sempre baseados ent modelos altamente idealizados: fios quânticos regulares de Si terminados con $\mathrm{H}[23,29,24]$ e cristalitos[29] esféricos (clusters em simetria tetraédrica) também terminados com H. Estes estudos geralmente utilizam aproximações de campo médio parametrizadas mostrando que a luminescência é compatível com as dimensões nanoscópicas propostas, sem nenhum estudo estrutural.

Quanto mais sofisticada a técnica de cálculo das propriedades eletrônicas, mais rudimentar o estudo das propriedades estruturais ([24, 81]).

O único trabalho de que temos conhecimento que faz uma tentativa de tratar partículas de Si com diferentes terminações, fora da aproximação de campo médio, 


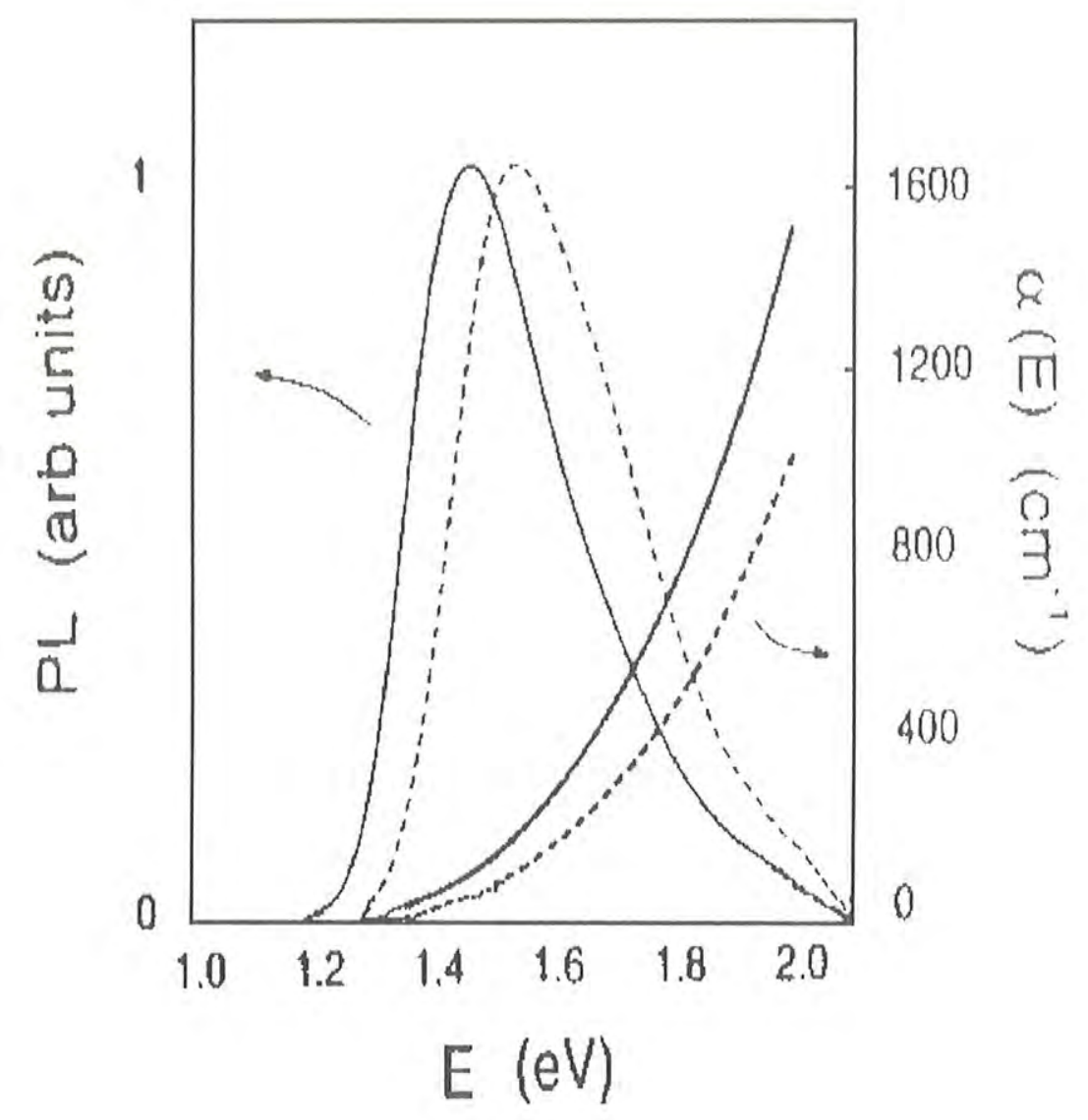

Figura 1.1: Diferenças entre a absorção e a luminescência para uma mesma amostra de po-Si : Vemos o pico de luminescência e o limiar da curva de absorçâ. As linhas sólidas e tracejadas são para duas amostras diferentes (da R J./7/) 
é o trabalho de Kumar e colaboradores [27]. Estes autores utilizam a hamiltoniana semiempírica PM3, em uma parametrização que é ideal apenas para a geometria de moléculas e não para as propriedades óticas não sendo, desta forma, apropriadi para o estudo concomitante da geometria e da ótica.

Neste trabalho apresentamos resultados para o cálculo da geometria de equilíbriu e propriedades óticas de pequenas partículas (até 131 átomos) de silício saturatas por hidrogênio, também com oxidação superficial. Fazemos assim uma análise da química da superfície, e sua influência nas propriedades óticas dessas partículats.

Ao mesmo tempo, ao escolhermos partículas finitas, estaremos investigando os efeitos específicos da correlação eletrônica sobre as propriedades óticas. P'ara tal adotamos técnicas de cálculo dentro da aproximação de Hartree-Fock (campo médio), com extensão para estados de muitos elétrons através do método de interação de configurações.

Dada a complexidade do problema, o estudo envolven o desenvolvimento de técnicas específicas, que introduzimos a seguir.

Existem na literatura diversos métodos que fornecem bons resultados para " cálculo, por exemplo, de defeitos em semicondutores. Entre esses métodos encontramos os métodos que usam a aproximação de Densidade Local (Local Density Approximation, LDA), ou métodos tight binding, que utilizam uma hamiltoniana parametrizada.

Os métodos que utilizam a aproximação LDA e que são bastante confiáves geralmente fazem uso de pseudopotenciais de primeiros princípios, o que torna o problema computacional complicado e muitas vezes impede que estes sejam aplicados para problemas complexos como o que vamos estudar. Já os métodos tighı binding existentes na literatura, apesar do baixo custo computacional, possuem confiabilidade menor pois foram parametrizados para problemas específicos. Outro fator importante é a inclusão de efeitos de correlação, uma vez que podem ser críticos quando trabalharmos com estruturas de dimensões muito reduzidas. Os métodos tight binding existentes na literatura, quando incluem estes efeitos, o fazem apenas parcialmente, já os métodos ab initio de LDA incluem o efeito de modo não separável.

Optamos por utilizar métodos dentro do formalismo Hartree-Fock, em detrimento aos métodos de LDA, por permitirem uma avaliação dos fítitos de correlação eletrônica. Entretanto, dado o carácter exploratório deste estudo, iremos trabalhar com hamiltonianas semiempíricas: isto nos permitirá tratar as estruturas complexas relevantes ao problema.

Escolhemos assim duas técnica semiempíricas: MNDO/AM1 (Modified Neglect. 
Diatomic Overlap - Anstin Model 1), desenhada especialmente para a obtençâu da geometria de moléculas[30, 3I], e ZINDO (Zerner Intermediate Neglect of I)iflerential Overlap) na parametrização espectroscópica, ideal para o estudo de excilaçós óticas[32].

Nas técnicas semiempíricas os parâmetros são definidos para os átomos indi. vidualmente, e são transferíveis às situações e ambientes em que os átomos sc encontram. É importante salientar que se preserva, do formalismo Hartree-fock, o método do campo autoconsistente, permitindo assim o estudo de rearranjo de: carga.

Ambos os métodos semiempíricos utilizados, em suas versões usuais, foram parametrizados para o ambiente molecular, que é um pouco diferente do ambiente cristalino. Assim não é imediato que os parâmetros usuais forneçam igualmentu. bons resultados para sistemas maiores. Realmente, uma revisão dos parâmetros se fez necessária. Nesta reparametrização calculamos propriedades de cristais (parâmetro de rede de equilíbrio, módulo de volume e alguns fônons dos pontos de mais alta simetria na Zona de Brillouin, principais características da banda de valência e o valor absoluto do gap), para isso foi necessário desenvolvermos a adaptação do método ao estudo de sistemas periódicos.

Para o cálculo do gap é essencial introduzir correlação eletrônica, pois a diferença entre os autovalores de Hartree-Fock para estados ocupados e virtuais não deve ser usada para fornecer o valor das transições óticas (gap). Ora, a inclusão do efeito de correlação eletrônica para sistemas infinitos, periódicos ou não, é um problema não trivial: o método da Interação de Configurações não pode ser utilizado, como discutiremos mais adiante, e como já dissemos o cálculo aproximado introduzido na aproximação da densidade local não é facilmente separável em contribuições de campo médio e não locais. Assim, propomos um procedimento para o cálculo do gup de sistemas cristalinos infinitos baseado no cálculo de propriedades de nanocristais finitos.

Todos os parâmetros foram obtidos para cristais mas tendo sempre como vínculo os resultados para pequenas moléculas envolvendo $\mathrm{Si}$, O e $\mathrm{H}$ em suas constituições. Obtivemos, assim, um método apropriado para fornecer resultados para partículas na região limítrofe entre moléculas e cristais.

Neste sentido, uma das contribuições deste trabalho é ofercer $11 m$ método de cálculo de propriedades de cristais dentro do formalismo de Hartree-FockRoothaan, para as técnicas MNDO-AM1 e ZINDO, e um conjunto de parâmetros para o Silício e o Oxigênio que produzem resultados en bom acordo com a experiência para as principais características estruturais e eletrônicas dos cristais de 
Si e $\alpha$-quartzo $\left(\mathrm{SiO}_{2}\right)$, enquanto reproduzindo ainda as propriedades relevantes de pequenas moléculas. A este método nós batizamos NDO/Cristal.

Este trabalho está organizado da seguinte forma: nos dois próximos capílulos descrevemos o procedimento teórico adotado, incialmente em termos mais gerais (capítulo 2) e depois específicamente para nossa aplicação (capítulo 3). Em seguida. no capítulo 4, apresentamos nossos resultados para o estudo de nanopartículas de. Si saturadas por hidrogênio, e logo após, no capítulo 5, descrevemos o efeito dia oxidação de superfície. Finalmente no último capítulo discutimos 1 m modelo para as propriedades óticas do Silício poroso. 
Capítulo 2

Método I: Arcabouço Teórico 
Neste capítulo faremos uma breve apresentação do método usado para derivar as equações de Hartree-Fock considerando uma combinação linear de orbitais atônicos (LCAO) para a expansão dos orbitais moleculares, de acordo com Roothaan|333|.

Para derivar as equações de Hartree-Fock algumas aproximaçōes são feitas: consideramos os núcleos atômicos em posições fixas (aproximação de Born-(Oppenheimer); trabalhamos a $\mathrm{T}=0$, não estaremos considerando efeitos relacionados à tenperatura; negligenciamos ainda efeitos relacionados ao acoplamento do spin eletronico ao movimento orbital do elétron.

Além disso, os elétrons são considerados como partículas independentes, e carla elétron é associado a uma função onda (de um elétron) ou orbital molecular (M()), que se estende por toda a molécula. A função de onda para $N$ elétrons é então escrita como $u$ m produto antissimétrico (AP) de todos os MO's (ao usar um produto antissimétrico garantimos que ao menos o princípio de exclusão de Pauli é obedecido).

Usando essas considerações escrevemos esse AP na forma de un "deteminante. de Slater":

$$
\Psi^{i}=\left|\begin{array}{cccccc}
\psi_{1}^{1} & \psi_{2}^{1} & \cdot & \psi_{N-1}^{1} & \psi_{N}^{1} \\
\psi_{1}^{2} & \psi_{2}^{2} & \cdot & \cdot & \psi_{N-1}^{2} & \psi_{N}^{2} \\
\cdot & \cdot & & \cdot & \cdot \\
\cdot & \cdot & & \cdot & \cdot \\
\psi_{1}^{N-1} & \psi_{2}^{N-1} & & \psi_{N-1}^{N-1} & \psi_{N}^{N-1} \\
\psi_{1}^{N} & \psi_{2}^{N} & & \psi_{N-1}^{N} & \psi_{N}^{N}
\end{array}\right|
$$

Agora os $\psi^{\prime} s$ são funções das coordenadas espaciais e das coordenadas de spin, ou seja

$$
\psi_{p}^{i}\left(x^{i}, y^{i}, z^{i}, \xi^{i}\right)=\varphi_{p}\left(x^{i}, y^{i}, z^{i}\right) \eta_{p}\left(\xi^{i}\right)=\varphi_{p}, \eta_{p}^{i}
$$

onde o superscrito $i$ indica as diferentes partículas, o subescrito $p$ indica os diferentes orbitais moleculares de spin (spinorbital molecular), e $\eta_{p}^{i}=\alpha^{i}$ ou $\eta_{p}^{l}=\beta^{2}$ são funções de spin.

Admitindo que os MO's são ortonormais, ou seja,

$$
\int \psi_{k}^{*} \psi_{l} d \tau=\delta_{k l}
$$


onde $d \tau$ é o elemento de volume de um elétron incluindo as coordenadas esparciais e de spin, exige-se

$$
\int \Psi^{*} \Psi d \tau=N
$$

ou seja, as funções de onda para $N$ elétrons estão normalizadas.

\subsection{A Equação para a Energia Total}

Para derivar as equações de Hartree-Fock-Roothaan, inicialmente devemos escrever a expressão para a energia total, já que as equações serão derivadas usando um procedimento variacional.

O operador hamiltoniano total para $u m$ sistema molecular de $\mathrm{N}$ elétrons tem a seguinte forma

$$
H_{T}=\sum_{A} \sum_{B<A} \frac{Z_{A} Z_{B}}{R_{A B}}+\sum_{A} \sum_{i} \frac{Z_{A}}{R_{A i}}+\sum_{i<i} \frac{1}{R_{i j}}+\sum_{i} K_{i l}
$$

onde $\mathrm{A}$ e $\mathrm{B}$ representam núcleos atômicos, $i$ e $j$ representam elétrons. $Z Z_{1}$ c $Z_{13}$ são a carga dos núcleos $\mathrm{A}$ e $\mathrm{B}$ respectivamente; $R_{A B}$ é a distância entre eles; $R_{A}$ é a distância do elétron $i$ ao núcleo $\mathrm{A} ; R_{i j}$ é a distância entre os elétrons $i$ e j; $K_{e l}$ é a energia cinética do elétron $i$. O termo correspondente à energia cinética dos núcleos atômicos foi desprezado de acordo com as considerações feitas na seção anterior.

Separando a parte eletrônica do termo de repulsão entre os núcleos atônicos essa expressão pode ser escrita como

$$
E_{T}=\sum_{A} \sum_{B<A} \frac{Z_{A} Z_{B}}{R_{A B}}+E_{1 \epsilon}+E_{2 e}
$$

onde $E_{1 e}=\int \Psi H_{1} \Psi d \tau$ e $E_{2 e}=\int \Psi H_{2} \Psi d \tau$, sendo

$$
\begin{gathered}
H_{1}=-\sum_{i}\left(\sum_{A} \frac{Z_{A}}{R_{A i}}+K_{e l}\right) \\
H_{2}=\sum_{i} \sum_{i<i} \frac{1}{R_{i j}}
\end{gathered}
$$


$H_{1}$ é conhecido como o operador hamiltoniano de $u m$ elétron e $H_{2}$ é conhecido como o operador hamiltoniano de dois elétrons.

Em seu estado fundamental a maior parte das moléculas possuem uma estrutura de camadas fechadas, e aqui admitiremos que estamos trabalhando com moléculats que possuem essa estrutura (moléculas com camadas abertas podem ser tratadas fazendo uma extensão dessa teoria); isto permite escrever os MO's como

$$
\psi_{2 i-1}=\varphi_{i} \alpha
$$

e

$$
\psi_{2 i}=\varphi_{i} \beta
$$

onde $\alpha=\left\{\begin{array}{l}1 \\ 1\end{array}\right\}$ e $\beta=\left\{\begin{array}{l}0 \\ 1\end{array}\right\}$ é a parte de spin e $\varphi_{i}$ é a parte espacial do MO.

A função de onda de $\mathrm{N}$ elétrons, que haviamos escrito na forma de um determinante de Slater geral, passa agora a ter a seguinte forma

$$
\Psi=\frac{1}{\sqrt{N !}}\left[\psi_{p}^{\alpha}(1) \psi_{p}^{\beta}(2) \ldots . . \psi_{z}^{\alpha}(n-1) \psi_{z}^{\beta}(n)\right] .
$$

Onde $\psi_{p}^{\alpha}(1)$ é a p-ésima função de onda molecular de partícula independente, para o elétron 1 de spin $\alpha ; \psi_{p}^{\beta}(2)$ descreve o elétron 2 , de spin $\beta$, e assim sucessivamente e $\frac{1}{\sqrt{N !}}$ é o fator de normalização.

Usando esta forma para a função de onda de $\mathrm{N}$ elétrons a energia de un elétron será

$$
E_{1 e}=\int \Psi H_{1} \Psi d \tau=2 \sum_{p} \int \psi_{p}^{*}(i) H_{1} \psi_{p}(i) d \tau_{i}
$$

e o termo de dois elétrons será então

$$
\begin{array}{r}
E_{2 e}=2 \sum_{p} \sum_{q}\left[\int \psi_{p}^{*}(i) \psi_{q}(j) H_{2} \psi_{p}^{*}(i) \psi_{q}(j) d \tau_{i} d \tau_{j}\right. \\
\left.-\frac{1}{2} \int \psi_{p}^{*}(i) \psi_{q}^{*}(j) H_{2} \psi_{p}(j) \psi_{q}(i) d \tau_{i} d \tau_{j}\right]
\end{array}
$$

Aqui as funções de onda $\psi_{p}$ e $\psi_{q}$ são funções apenas orbitais, ignais a $\psi_{p}^{\alpha \kappa}$ o॥ $\psi_{p}^{\beta,}$ e $\psi_{q}^{\alpha}$ ou $\psi_{q}^{\beta}$, respectivamente. 
Para resolvermos as integrais acima precisamos escolher mma base apropriatia para expansão dos $\psi^{\prime} s$. Uma das possíveis escollias, que faremos aqui, é usar a aproximação de Roothaan [33] de que os orbitais moleculares possam ser representados através de uma combinação linear de orbitais atômicos (LCAO)

$$
\psi_{p}(i)=\sum_{\mu} c_{\mu}^{\prime \prime} \phi_{\mu}(i)
$$

onde $\phi_{\mu}$ representa um orbital atômico individual e $c_{\mu}^{p}$ são parâmetrōs variacionais.

O termo de um elétron será então

$$
E_{1 e}=2 \sum_{\mu} \sum_{\nu}\left(\sum_{p}^{o c c} c_{\mu}^{p *} c_{\nu^{p}}^{p} \int \phi_{\mu}^{*}(i) H_{1} \phi_{\nu}(i) d \tau_{i}\right)
$$

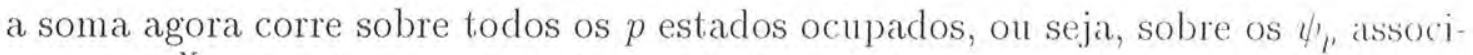
$\operatorname{ados} \operatorname{aos} \frac{N}{2}$ autovalores mais baixos.

Usando uma notação mais compacta temos

$$
E_{1 c}=2 \sum_{\mu} \sum_{\nu}\left(\sum_{p}^{o \omega} c_{\mu}^{p *} c_{\nu}^{p}\right) H_{\mu \nu}
$$

onde $H_{\mu \nu}=\int \phi_{\mu}^{*} H_{1} \phi_{\nu} d \tau$ é o elemento de matriz do operador hamiltoniano de $11 m$ elétron na base escolhida.

A energia de um elétron pode ser escrita de uma forma mais conveniente (ver a referência [34]) que será usada extensivamente para o caso de sistemas infinitos (sólidos):

$$
E_{1 e}=2 \sum_{\mu . \mu} \frac{1}{2} \sum_{p}^{o c c}\left[c_{\mu}^{p *} c_{\mu}^{p}+c_{\nu}^{p} c_{\nu^{\prime}}^{p *}\right] H_{\mu \nu}
$$

Definindo agora o elemento de densidade eletrônica

$$
P_{\mu \nu}=\frac{1}{2} \sum_{p}^{o c c}\left(c_{\mu}^{p *} c_{\mu}^{p}+c_{\nu}^{p} c_{\nu}^{p *}\right)
$$

a energia de um elétron poderá ser escritia como

$$
E_{1 e}=2 \sum_{\mu} \sum_{\nu} P_{\mu \nu} H_{\mu \nu}
$$

Usando o mesmo procedimento para o termo de dois elétrons, encontramos 


$$
\begin{aligned}
& E_{2 e}=\sum_{\mu} \sum_{\lambda} \sum_{\nu^{\prime}} \sum_{\sigma} \sum_{p} \sum_{\eta}\left[c _ { \mu } ^ { p ^ { * * } } c _ { \lambda } ^ { l * } c _ { \nu ^ { \prime } } ^ { \prime \prime } c _ { \sigma } ^ { q } \left\lceil\int \phi_{\mu}^{*}(i) \phi_{\lambda}^{*}(j) I_{2,} \phi_{\nu}(i) \phi_{\sigma}(j) d \tau_{,} d \tau_{,}\right.\right. \\
& \left.-\frac{1}{2} \int \phi_{\mu}^{*}(i) \phi_{\lambda}^{*}(j) H_{2} \phi_{\mu}(j) \phi_{\sigma}(i) d \tau_{,} d \tau_{1}\right)
\end{aligned}
$$

Usando uma notação compacta isso pode ser escrito como

$$
\begin{array}{r}
E_{2 e}=\sum_{\mu} \sum_{\lambda} \sum_{\nu} \sum_{\sigma}\left[\sum_{\nu} c_{\mu}^{p^{*} *} c_{\nu^{\prime}} \sum_{\eta} c_{\lambda}^{q *} c_{\sigma}^{q}[(\mu \nu, \lambda \sigma)\right. \\
\left.\left.-\frac{1}{2}(\mu \sigma, \nu \lambda)\right]\right]
\end{array}
$$

onde

$$
(\mu \nu, \lambda \sigma)=\int \phi_{\mu}^{*}(i) \phi_{\lambda}^{*}(j) H_{2} \phi_{\nu}(i) \phi_{\sigma}(j) d \tau_{1} d \tau_{,}
$$

é a integral de Coulomb e

$$
(\mu \sigma, \nu \lambda)=\int \phi_{\mu}^{*}(i) \phi_{\lambda}^{*}(j) H_{2} \phi_{\mu}(j) \phi_{\sigma}(i) d \tau_{1} d \tau_{\mu}
$$

é a integral de troca.

Usando novamento a definição da matriz densidade temos

$$
E_{2 \ell}=2 \sum_{\mu} \sum_{\nu} P_{\mu \nu} \sum_{\lambda} \sum_{\sigma} P_{\lambda \sigma}\left[(\mu \nu, \lambda \sigma)-\frac{1}{2}(\mu \sigma, \nu \lambda)\right]
$$

A primeira integral é a repulsão Coulombiana entre dois elétrons nas regiões de: sobreposição $\mu-\nu$ e $\lambda-\sigma$, respectivamente. A segunda integral é chamada de integral de troca, e não possui análogo clássico.

A expressão para a energia total torna-se deste modo

$$
\begin{array}{r}
E_{T}=\sum_{A} \sum_{B<A} \frac{Z_{A} Z_{B}}{R_{A B}}+2 \sum_{\mu} \sum_{\nu} P_{\mu \mu}\left\{H_{\mu \nu}+\right. \\
\left.\sum_{\lambda} \sum_{\sigma} P_{\lambda \sigma}\left[(\mu \nu, \lambda \sigma)-\frac{1}{2}(\mu \sigma, \nu \lambda)\right]\right\} .
\end{array}
$$

A seguir descreveremos o procedimento de obtenção das equações de HartreeFock-Roothaan através de $u$ procedimento variacional em termos da energia total. 


\subsection{Obtenção das equações de Hartree-Fock- Roothaan}

Uma vez obtida a expressão para a energia total a nossa pergunta é agora (fual u melhor conjunto de MO's para camadas fechadas, ou seja, qual o molhor I.('М() que irá formar os melhores MO's de camadas fechadas.

O procedimento para isto é minimizar a energia tolal, e, desta forma, encontrar os MO's que fornecem $14 m$ mínimo para a energia total. Gomo os parâmetros a variar são os $\mathrm{c}^{\mathrm{p}} \mathrm{s}$, podemos notar que minimizar a energia total é deste forma idêntico a minimizar a energia eletrônica, pois o termo de repulsão nuclear náo depende dos parâmetros variacionais.

Como temos um grande conjunto de variáveis iremos passar de agora em diant. a trabalhar com notação matricial, e a parte espacial dos MO's passa a ser escrit. como $\varpi=\left(\varphi_{1} \varphi_{2} \ldots \varphi_{n}\right)$, a parte de spin como $\eta=(\alpha, \beta)$ e os MO's como o produto direto de $\varpi$ e $\eta$, ou seja

$$
\psi=\varpi \otimes \eta .
$$

Um elemento do operador M será definido por seus elementos de matriz

$$
M_{\mu \prime}=\int \varphi_{\mu}^{*} \mathrm{M} \varphi_{\mu} \mathrm{d} \tau .
$$

Em particular, a matriz de sobreposição (Overlap)

$$
S_{\mu \nu}=\int \phi_{\mu}^{*} \phi_{\nu} d \tau
$$

corresponde nessa base ao operador identidade, de forma que

$$
\int \psi_{p}^{*} \psi_{q} d \tau=\mathrm{C}_{\mathrm{p}}^{+} \mathrm{SC}_{\mathrm{q}}=\delta_{\mathrm{pq}}
$$

onde os coeficientes $\left\{c_{\mu}^{p}\right\}$ foram reunidos no vetor $\mathbf{C}_{\mathbf{p}}$.

Introduzimos os operadores de energia e suas representações matriciais, a saber: hamiltoniano de um elétron $H_{p}$

$$
\mathrm{H}_{\mathrm{p}}=\mathrm{C}_{\mathrm{p}} \mathrm{HC}_{\mathrm{p}}
$$

hamiltoniano de Coulomb $J_{p}$

$$
\mathbf{J}_{\mathrm{pq}}=\mathrm{C}_{\mathrm{p}}^{+} \mathrm{J}_{\mathrm{q}} \mathrm{C}_{\mathrm{p}}=\mathrm{C}_{\mathrm{q}}^{+} \mathrm{J}_{\mathrm{p}} \mathrm{C}_{\mathrm{q}}
$$


hamiltoniano de troca $K_{\mu}$

$$
\mathrm{K}_{\mathrm{pq}}=\mathrm{C}_{\mathrm{p}}^{+} \mathrm{K}_{\mathrm{q}} \mathrm{C}_{\mathrm{p}}=\mathrm{C}_{\mathrm{q}}^{+} \mathrm{K}_{\mathrm{p}} \mathrm{C}_{\mathrm{q}} \text {, }
$$

todos hermiteanos, e finalmente a energia eletrônica pode ser escrita na segnintc. forma, que usaremos nos restantes capítulos:

$$
E_{e l}=2 \sum_{p} H_{p}+\sum_{p} \sum_{q}\left(2 J_{p q}-K_{p q}\right)
$$

O procedimento variacional sobre a energia, com o vínculo de ortonormalidade. dos MO's, leva à equação de Hartree-Fock-Roothaan

$$
\mathrm{FC}=\mathrm{SCE},
$$

onde introduzimos o operador de Fock

$$
\mathrm{F}=\mathrm{H}+\sum_{\mathrm{p}}\left(2 \mathbf{J}_{\mathrm{p}}-\mathrm{K}_{\mathrm{p}}\right)
$$

A equação matricial representa um conjunto de equações acopladas, que deve ser resolvida iterativamente: a partir de uma solução tentativa da equação acima, encontramos $u$ m conjunto de vetores $\mathrm{C}_{\mathrm{p}}$ que a satisfazem. A matriz $\mathbf{F}$ então será calculada a partir deste conjunto de vetores, e com esta nova matriz $\mathbf{F}$ poderemos encontrar um novo conjunto de autovetores $C_{p}$, e assim sucessivamente. A cada conjunto de novos vetores $\mathbf{C}_{\mathbf{p}}$ encontrados, fazemos a comparação com os anteriores, e guiados por esta comparação, um novo conjunto de vetores $\mathbf{C}_{\mathrm{p}}$ é escolhido. Este procedimento continua até que os $\mathrm{C}_{\mathrm{p}}$ escolhidos e os calculados concordem dentro de algun critério.

Este procedimento é conhecido como o método do campo autoconsistente (SelfConsistent-Field, SCF) de Hartree-Fock-Roothaan.

Ao final do procedimento autoconsistente teremos encontrado $u m$ conjunto de autoestados, todos ortogonais, que devem descrever o estado fundamental -de mais baixa energia- do sistema. Para un sistema de $\mathrm{N}$ elétrons, este estado será descrit.o pelos MO's associados aos $\frac{N}{2}$ autovalores de mais baixa energia ("ocupados").

A interpretação para os autovalores desses estados ocupados foi dada por Roothaan[33], que mostra que podem ser tomados como o negativo dos potenciais de ionização do sistema (não considerando a "relaxação orbital"que ocorre quando 
da ionização), como veremos adiante. Os autovalores de estados virtuais nẫo possuem nenhum significado físico, e para tratarmos estados excitados devemos fazer algumas correções.

A primeira correção foi introduzida por Roothaan[33] e é conhecida como correção de orbital virtual, outras correções foram introduzidas com o tempo e a mais utilizada é a correção de Interação de Configurações (Configuration Interaction. CI).

A seguir apresentamos uma curta descrição desses procedimentos adicionais ì teoria de Hartree-Fock.

\subsection{Correção de orbital virtual}

Essa correção dá em primeira aproximação as energias de excitação para ımı molécula. Inicialmente por completeza descreveremos como obter as energias d. ionização (também conhecidas como potenciais de ionização), e a seguir as encrgias de excitação.

A energia ou potencial de ionização deve ser obtida como a diferença das encrgias totais de sistemas a diferentes números de elétrons,

$$
E(N-1)-E(N)
$$

e demandaria $u m$ novo cálcuo autoconsistente para $\mathrm{E}(\mathrm{N}-1)$, o que resultaria em MO's diferentes ("relaxados" en relação à retirada de um elétron). I ma primeira aproximação entretanto, para sistemas com muitos elétrons, é considerar (juc os MO's não relaxam e continuam válidos para o sistema ionizado.

A função de onda para um estado ionizado positivamenté é então obtida on itimdo um (ou vários) dos MO's do AP para o estado fundamental.

Vamos considerar $11 m$ estado ionizado obtido pela "remoção" de $11 m$ dos dois elétrons ocupando o orbital molecular $\varphi_{i}$, e vamos primeiro considerar o (aso) (nu que $\varphi_{i}$ não pertença a um conjunto degenerado. A função de onda para esse estadu é em primeira aproximação

$$
\begin{gathered}
{ }^{2} \Psi_{i}=\left(\varphi_{1} \alpha\right)\left(\varphi_{1} \beta\right) \ldots .\left(\varphi_{i-1} \alpha\right)\left(\varphi_{i-1} \beta\right)\left[\begin{array}{l}
\varphi_{i} \alpha \\
\varphi_{i} \beta
\end{array}\right]\left(\varphi_{i+1} \alpha\right) \\
\left(\varphi_{i+1} \beta\right) \ldots\left(\varphi_{n} \alpha\right)\left(\varphi_{n} \beta\right) .
\end{gathered}
$$

Esse é um estado dupleto com as duas funções de onda de mesma energia 


$$
E\left({ }^{2} \Psi_{i}\right)=2 \sum_{i \neq i} H_{j}+H_{i}+\sum_{j \cdot k \neq i}\left(2 J_{i k}-K_{, k}\right)+\sum_{i \neq i}\left(2 J_{i,}-K_{i,}\right)
$$

que pode ser escrita como

$$
E\left({ }^{2} \Psi_{\imath}\right)=2 \sum_{j} H_{j}+\sum_{j \cdot k}\left(2 J_{j k}-K_{j k}\right)-H_{i}-\sum_{j}\left(2 J_{i,}-K_{i,}\right)
$$

Usando agora a definição para a energia eletrônica do estado fundamental temos que, em primeira aproximação a energia requerida para a remoção de $11 m$ dos elétrons "ocupando" $\varphi_{i}$ é dada por

$$
E\left({ }^{2} \Psi_{i}\right)-E\left({ }^{1} \Psi_{0}\right)=-H_{i}-\sum_{i}\left(2 J_{i j}-K_{i}\right),
$$

que pode ser escrita de uma forma mais conveniente se lembrarmos que

$$
\begin{aligned}
H_{i}+\sum_{i}\left(2 J_{i j}-K_{i, j}\right) & =\int \varphi_{i}\left[H+\sum_{i}\left(2 J_{i}-K_{i}\right)\right] \varphi_{i} d \tau \\
& =\int \varphi_{i} F \varphi_{i} d \tau \\
& =\epsilon_{i} \int \varphi_{i} \varphi_{i} d \tau \\
& =\epsilon_{i},
\end{aligned}
$$

finalmente

$$
E\left({ }^{2} \Psi_{i}\right)-E\left({ }^{1} \Psi_{0}\right)=-\epsilon_{i}
$$

ou seja, se ${ }^{1} \Psi_{0}$ e ${ }^{2} \Psi_{i}$ ( Hartree-Fock LCAO) são aproximações razoáveis para as funções de onda exatas dos correspondentes estados eletrônicos, $\epsilon_{i}$ deverá fornecer uma aproximação razoável para os potenciais de ionização experimentais.

Este desenvolvimento dota de significado físico os autovalores de estados ocupados. A idéia básica do método dos orbitais virtuais é que os MO's que foram obtidos para os estados desocupados (estados virtuais), quando da resolução do problema variacional para o estado fundamental, podem ser usados para deterninarmos o estado excitado.

Para os estados excitados mais baixos, funções de onda aproximadas são então obtidas substituindo $1 \mathrm{~m}$ dos spin-orbitais moleculares (MSO) do AP do estado 
fundamental por $11 \mathrm{~m}$ novo MSO que faça parte do conjunto de MSO's virtuais do problema, sendo portanto ortogonal a todos os MSO do estado findamental, c em particular àquele ao qual está substituindo. Vamos admitir que um elétron 6 "excitado" de $\varphi_{i}$ para $\varphi_{a}$, e que nenhum dos dois MSO's faz parte de um conjunto degenerado.

Devido às diferentes possibilidades con relação ao spin, devemos considerar 1 funções de onda simultâneamente:

$$
\left(\varphi_{1} \alpha\right) \ldots\left(\varphi_{i-1} \alpha\right)\left(\varphi_{i-1} \beta\right)\left|\begin{array}{c}
\left(\varphi_{i} \alpha\right)\left(\varphi_{a} \alpha\right) ;\left(\varphi_{i} \alpha\right)\left(\varphi_{a} \beta\right) \\
\left(\varphi_{i} \beta\right)\left(\varphi_{a} \alpha\right) ;\left(\varphi_{i} \beta\right)\left(\varphi_{a} \beta\right)
\end{array}\right|\left(\varphi_{i+1} \alpha\right)\left(\varphi_{i+1} \beta\right) \ldots\left(\varphi_{n} \beta\right)
$$

É sabido que essas quatro funções de onda dão origen a $u m$ estado singleto

$$
\begin{aligned}
{ }^{1} \Psi_{a a}= & \left(\varphi_{1} \alpha\right) \ldots\left(\varphi_{i-1} \beta\right)\left[\frac { 1 } { \sqrt { 2 } } \left[( \varphi _ { i } \alpha ) \left(\varphi_{a} \beta-\right.\right.\right. \\
& \left.\left.\left(\varphi_{i} \beta\right)\left(\varphi_{a} \alpha\right)\right]\right]\left(\varphi_{i+1} \alpha\right) \ldots\left(\varphi_{n} \beta\right),
\end{aligned}
$$

e um estado tripleto, para o qual as três possíveis funções de onda são

$$
\begin{gathered}
{ }^{3} \Psi_{u a}=\left(\varphi_{1} \alpha \ldots(\varphi-1 \beta)\left(\varphi_{i} \alpha\right)\left(\varphi_{a} \alpha\right)(\varphi i+1 \alpha) \ldots\left(\varphi_{n} \beta\right) ;\right. \\
{ }^{3} \Psi_{i a}=\left(\varphi_{1} \alpha\right) \ldots\left(\varphi_{i-1} \beta\right)\left[\frac { 1 } { \sqrt { 2 } } \left[\left(\varphi_{i} \alpha\right)\left(\varphi_{a} \beta\right)+\right.\right. \\
\left.\left.(\varphi 1 \beta)\left(\varphi_{a} \alpha\right)\right]\right]\left(\varphi_{i+1} \alpha\right) \ldots\left(\varphi_{n} \beta\right) ; \\
{ }^{3} \Psi_{i a}=\left(\varphi_{1} \alpha \ldots(\varphi-1 \beta)\left(\varphi_{i} \beta\right)\left(\varphi_{a} \beta\right)(\varphi i+1 \alpha) \ldots\left(\varphi_{n} \beta\right) ;\right.
\end{gathered}
$$

Os três estados tripleto possuem a mesma energia ( uma vez que estamos desconsiderando o acoplamento spin-órbita).

Agora retornamos à questão de como um MO para um estado excitado, $\varphi_{a}$, pode ser determinado. Se desejarmos encontrar a melhor função de onda para. uma excitação do estado $\varphi_{i}$ para o estado $\varphi_{a}$ temos que minimizar a energia média dos estados singleto e tripleto. Entretanto se quisermos usar o mesmo MO $\varphi_{a}$ para 
descrevermos excitações de diferentes $\mathrm{MO} \varphi_{i}$, devemos minimizar a energia mérlia de todos os singletos e tripletos em consideração, com isso muitas vezes equaçón para $\varphi_{a}$ tornam-se complicadas.

Porém se estivermos trabalhando com $11 n$ LCAO para moléculas de considerável simetria os MO excitados são muitas vezes basicamente determinados pela simetria e/ou a requerida ortogonalidade do MO excitado em relação aos MO's do estado fundamental, e dessa forma parece aceitável que os MO's de estidos virluais, encontrados a partir da equação de Hartree-Fock para o estado fundamental que já obedecem aos requisitos citados, possam ser aceitos para descrever os processos de excitação.

As energias dos estados singleto e tripleto são dadas por

$$
\begin{aligned}
E\left({ }^{1.3} \Psi_{i a}\right)= & 2 \sum_{i \neq i} H_{j}+H_{i}+H_{a}+\sum_{j \cdot k \neq i}\left(2 J_{j k}-K_{j k}\right)+\sum_{j \neq i}\left(2 J_{i,}-\Lambda_{1, j}\right)+1 \\
& \sum_{i \neq i}\left(2 J_{j a}-K_{j a}\right)+J_{i a} \pm K_{i a}
\end{aligned}
$$

onde o sinal "+" vale para oestado singleto e o sinal "." para o estado tripleto. Essa expressão pode ser reduzida a

$$
\begin{aligned}
E\left({ }^{1,3} \Psi_{i a}\right)= & \sum_{j} H_{j}+\sum_{j \cdot k}\left(2 J_{j k}-K_{j k}\right)-H_{i}-\sum_{j}\left(2 J_{i j}-K_{i,}\right)+H_{a}+ \\
& \sum_{j}\left(2 J_{j a}-K_{j a}\right)-\left(J_{i u}-K i a\right) \pm K_{i a}
\end{aligned}
$$

As somas agora correm sobre todos os MO's do estado fundamental. Comparando esse resultado à expressão para a energia do estado fundamental temos

$$
\begin{aligned}
E\left({ }^{1,3} \Psi_{i a}\right)-E\left({ }^{1} \Psi_{0}\right)= & H_{a}+\sum_{j}\left(2 J_{j a}-K_{j a}\right)-H_{i}- \\
& \sum_{i}\left(2 J_{i j}-K_{i j}\right)-\left(J_{i a}-K_{i a}\right) \pm K_{i a},
\end{aligned}
$$

assim, chegamos ao seguinte resultado

$$
E\left({ }^{1,3} \Psi_{i a}\right)-E\left({ }^{1} \Psi_{0}\right)=\epsilon_{a}-\epsilon_{i}-\left(J_{i a}-K_{i a}\right) \pm K_{i a} .
$$


Se $i$ descreve o último estado ocupado (Highest Occupied Molecular (Orbital (HOMO)) e a descreve o primeiro estado desocupado (Lowest Hnoccupied Molecular Orbital (LUMO)), em primeira aproximação esta relação poderá ser usada para determinarmos o "gup" de energia para mma molécula (em analogia ao termo) utilizado em cristais).

Se desejarmos correções de mais alta ordem devemos introduzir correçōes mais poderosas, e o método de interação de configurações (Cofiguration Interaction, ('I) parece ser o método mais apropriado. A seguir descrevemos os fundamentos (lo método CI.

\subsection{Método de Interação de Configurações}

Um conjunto base de dimensão $M$ define um subespaço de funções de onda de um elétron e um correspondente operador de projeção p: a diagonalização de 11 !n operador de um elétron, no caso o operador de Fock, produz un certo número $L=\frac{N}{2}$ MO's ocupados e (M-L) MO's virtuais. Os M MO's (ocupados + virluais) definem a base para $u$ projetor

$$
p=\sum_{i=1}^{M}\left|\psi_{i}><\psi_{i}\right| .
$$

Os MO's virtuais podem ser usados para construir M-L diferentes determinantes de $\mathrm{N}$ elétrons a partir do determinante do estado fundamental $\Psi_{0}$, pela substituição de um dos MO's ocupados; voltando a notação da seção 2.1,

$$
\Psi_{I}=\Psi_{i}^{a}=\left|\psi_{1} \ldots \ldots \psi_{a} \ldots \ldots \psi_{N}\right|,
$$

significa que foi criado um "buraco" $i$ abaixo do nível de Fermi e uma "partícula" a acima do nível de Fermi.

Introduzindo, dois, três, ou mais MO's virtuais no lugar de MO's ocupados obtemos determinantes duplamente, triplamente ... excitados. Esses determinantes podem interagir através da Hamiltoniana de $\mathrm{N}$ elétrons do problema $\left(<\Psi_{I}|H| \Psi_{J}>\neq 0\right)$,

pois, por exemplo, se considerarmos $\Psi_{0}$ e $u m$ estado duplamente ex camadas fechadas $\Psi\left(\frac{a \bar{a}}{i \bar{i}}\right)$, obtemos

$$
<\Psi_{0}|H| \Psi\left(\begin{array}{c}
a \bar{a} \\
i \bar{i}
\end{array}\right)>=<\varphi_{i}(1) \varphi_{i}(2)\left|\frac{1}{r_{12}}\right| \varphi_{a}(1) \varphi_{a}(2)>=K_{z a}
$$


que é necessariamente diferente de zero (exceto no caso em que $\varphi_{i}$ e $\varphi_{a}$ estiverum infinitamente separados). Isto significa que $\Psi_{(1)}$ a função de onda de Hartree-lock. não é um autovetor de H. Podemos admitir entretanto que a base dos determinantes $\Psi_{I}$ seja conveniente para obtermos esses antoestados de $\mathrm{N}$-elétrons, a partir de combinações lineares.

Para obtermos essa combinação linear construimos a matriz (:I, expressa na base de determinantes ortogonais de $\mathrm{N}$ elétrons, $\Psi_{0}$ e de estados excitados $\psi_{1}$, cujos elementos são dados por

$$
H_{1 . J}=\left\langle\Psi_{I}|H| \Psi_{J}>\right.
$$

Com essas considerações podemos enunciar o problema CI da seguinte forma: Um conjunto base de AO's definem um projetor p na base de um conjunto ortogonal de MO's. Esses MO's permitem a construção de funções de onda ortogonais de N elétrons, $\Psi_{I}$. O correspondente projetor de $\mathbf{N}$ elétrons, $\mathbf{P}$, será

$$
P(1, \ldots, N)=\sum_{I}\left|\Psi_{I}><\Psi_{I}\right|=\prod_{k=1}^{N} p(k) .
$$

Para um conjunto base definido, a melhor aproximação será obticla pela diagonalização do Hamiltoniano projetado, PHP,

$$
[P H P] \chi_{m}=E_{m} \chi_{m}
$$

o qual fornece funções de onda multideterminantais

$$
\chi_{m}=\sum_{I} C_{m I} \Psi_{I}
$$

O Hamiltoniano PHP toma a forma de 1 ma matriz finita

$$
\text { PHP }=\sum_{I} \sum_{I}\left|\Psi_{I}><\Psi_{I}\right| H\left|\Psi_{, I}><\Psi_{, I}\right|
$$

cujos elementos são $H_{I J}$.

Entretanto, a diagonalização da matriz rapidamente torna-se impossível devido ao grande número de possíveis $\Psi_{I}$ ls. Podemos notar que desde que I : 1 m operador de dois elétrons, $\Psi_{0}$ somente interage com determinantes simplesmente e duplamente excitados, com isso se estivermos interessados na descriçion do estado fundamental podemos restringir o CI para $\Psi_{0}$ e excitações simples e duplas. Além 
disso, se $\Psi_{0}$ é um determinante autoconsistente, o teorema de Brillouin assegura que todos os elementos de matriz de $\Psi_{0}$ com determinantes de excitações simples são nulos.

A prova para esse teorema pode ser obtida através de teoria de pertubaçâu. So $\Psi_{0}$ pode ser usada em primeira aproximação para a função de onda exata lemos

$$
\left|\chi_{0}>=C_{0}\right| \Psi_{0}>+\sum_{i a} C_{i}^{a} \mid \Psi_{i}^{a}>+O(2) .
$$

Se considerarmos apenas determinantes com excitações simples como correçoes. os coeficientes $C_{i}^{a}$ serão determinados através do princípio variacional pela diagonalização da Hamiltoniana na base de estados $\left\{\Psi_{o}\left\{\Psi_{i}^{u}\right\}\right\}$.

Consideremos a matriz dos autovalores envolvendo apenas $11 m$ estado excitado

$$
\left|\begin{array}{cc}
\left\langle\Psi_{0}|H| \Psi_{0}\right\rangle & \left\langle\Psi_{0}|H| \Psi_{i}^{a}\right\rangle \\
\left\langle\Psi_{i}^{a}|H| \Psi_{0}\right\rangle & \left\langle\Psi_{i}^{a}|H| \Psi_{i}^{a}\right\rangle
\end{array}\right| \begin{gathered}
C_{0}^{\prime} \\
C_{i}^{a}
\end{gathered}\left|=E_{0}\right| \begin{gathered}
C_{0}^{\prime} \\
C_{i}^{a}
\end{gathered} \mid
$$

A parte que leva em conta o acoplamento dos dois estados são os elementos fora da diagonal, que são expressos por

$$
<\Psi_{0}|H| \Psi_{i}^{a}>=<i\left|H_{1}\right| a>+\sum_{l}<i b\left|H_{2}\right| a b>
$$

$H_{1}$ e $H_{2}$ seguem as definições anteriores (Hamiltoniana de 1 e 2 elétrons ). Fissa equação pode ser simplificada se lembrarmos que

$$
\left.<\psi_{i}|F| \psi_{i}\right\rangle=\left\langle i\left|H_{1}\right| j\right\rangle+\sum_{b}\left\langle i b\left|H_{2}\right| j b\right\rangle
$$

Então,

$$
<\Psi_{0}|H| \Psi_{i}^{a}>=<\psi_{i}|F| \psi_{a}>,
$$

ou seja, os elementos de matriz que acoplam $\Psi_{()}$a determinantes de excitações simples são iguais aos elementos fora da diagonal da matriz de Fock. Agora por definição resolver o problema de autovalores de Hartree-Fock significa requerer que os elementos fora da diagonal da matriz de Fock satisfaçam $\left\langle\psi_{i}\left|F^{\prime}\right| \psi_{\text {,j }}\right\rangle=0$, 
para $i \neq j$. Com isso o teorema fica provado e podemos restringir o ( 1 para determinantes duplamente excitados (esta não é uma grande simplilicação, pois o número de determinantes com excitações duplas é muito superior).

Uma vez obtida a matriz CI o procedimento agora é o de diagonalizá-la, obtendo assim autovalores e os correspondentes autovalores. O autovalor mais baixo dará a energia corrigida para o estado fundamental, e a diferença entre esse antovalor a energia de Hartree-Fock será a correção de correlação.

No nosso caso estaremos sempre interessados en determinar o espectro ótico. com isso estaremos mais interessados na correção para a diferença de energia entre o estado fundamental e estados excitados. Em particular, a energia da primeira primeira transição do estado fundamental para um estado excitado que possui força de oscilador (oscillator strength ) não nula poderá ser interpretada como o gup do material.

As energias de transição podem ser obtidas por:

$$
E_{\text {trans }}=E_{m}-E_{i)}
$$

onde $\chi_{m}$ e $\chi_{0}$ são as funções de onda CI para o estado excitado e fundamential respectivamente, obtidas da diagonalização da matriz CI.

Estaremos neste trabalho interessados nas transições óticas: o acoplamento neste caso é inversamente proporcional à diferença de energia entre estado fundantental e excitado e, no caso de excitações múltiplas, essa dependência é multiplicativa. Como estaremos trabalhando com sistemas poliatômicos relativamente grandes, com centenas de elétrons de valência, o espectro de um-elétron é também relativamente denso. Além disso, os sistemas apresentam um gap de energia entre estados ocupados e virtuais, em geral mais de dez vezes maior que o espaçamento entre os estados ocupados mais altos. Assim, poderemos trabalhar apenas com excitações simples pois já excitações duplas terão muito pouca influência sobre o espectro ótico nas energias de interesse.

\subsection{Extensão para Cristais: Sistema Periódico Infinito}

Nas seções anteriores descrevemos o método usual para estudo de 1 m sistema poliatômico finito (sistema molecular). Aqui descrevemos a extensão para o estudo de um cristal, que é um problema um pouco diferente, isto é, queremos resolver as 
equações para $11 \mathrm{~m}$ sistema infinito, usando condições de fronteira periódicas sobre uma célula unitária. A função de onda de mma partícula deve se transformar d. acordo com as translações da rede $\mathbf{T}_{I}$ e vetores do espaço recíproco $\mathbf{K}$, de tal modo que é natural agora procurarmos bases de funções periódicas. Se partirmos de una base de orbitais atômicos $\left(\phi_{\mu}\right)$, e considerando que existem muitos átomos (A) na célula unitária, construimos funções periódicas $\left(\Phi_{\mu}^{A}(K, r)\right)$, também conlecidas como somas de Bloch, da seguinte forma

$$
\Phi_{\mu}^{A}(\mathbf{K}, \mathrm{r})=\sum_{I} e^{i \mathbf{K} \cdot \mathbf{R}_{I}} \phi_{\mu}\left(\mathrm{r}-\left(\mathbf{R}_{I}+\mathrm{d}_{A}\right) .\right.
$$

Nessa expressão, I corre sobre todas as células unitárias, $\mu$ designa 111 (ip) de orbital $(\mathrm{s}, \mathrm{p}, \ldots)$ e $A$ corre sobre todos os átomos em uma célula unitária. As somas de Bloch constituem a nova base para a expansão da função de onda de mma partícula, $u_{i}(\mathbf{K}, \mathbf{r})$, que tem as propriedades de simetria translacional desejaclas:

$$
u_{i}(\mathbf{K}, \mathbf{r})=\sum_{\mu \cdot A} C_{\mu A}^{i}(\mathbf{K}) \Phi_{\mu}^{A}(\mathbf{K}, \mathbf{r})
$$

sendo os $C_{\mu A}^{i}(\mathbf{K})$ os novos parâmetros variacionais.

A matriz de Fock é agora calculada em termos dessa nova base $\left\{\phi_{\mu}^{A}\right\}$, para cada ponto do espaço recíproco

$$
\mathrm{F}_{\mu \prime \prime}^{A \cdot B}(\mathrm{~K}, \mathrm{r})=<\Phi_{\mu}^{A}(\mathrm{~K}, \mathrm{r})|\mathbf{H}| \Phi_{{ }^{\prime}}^{B}(\mathrm{~K}, \mathrm{r})>
$$

onde $\mathbf{H}$ é o operador hamiltoniano eletrônico total, que é finalmente projetado sobre os elementos de matriz "moleculares":

$$
\begin{aligned}
\mathbf{F}_{\mu \nu}^{A . B}(\mathbf{K}, \mathbf{r})= & \frac{1}{N_{\nu}} \sum_{I . J} e^{i \mathbf{K} \cdot\left(\mathbf{R}_{,}-\mathbf{R}_{l}\right)} \\
& <\phi_{\mu}^{A}\left(\mathrm{r}-\left(\mathbf{R}_{I}+\mathrm{d}_{A}\right)\right)|\mathbf{H}| \phi_{\nu^{\prime}}^{B}\left(\mathrm{r}-\left(\mathbf{R}_{I}+\mathrm{d}_{B}\right)\right)>
\end{aligned}
$$

onde $N_{c}$ é o número de células no cristal (na aproximação de Born-Von Karman).

O procedimento para encontrarmos a melhor função de onda para o stiado fundamental do sistema cristalino é idêntico àquele para um sistema nolecular, apenas agora utilizando a simetria translacional e pontual da rede.

Admitindo uma matriz de Fock "molecular" inicial, construimos as interações para átomos internos à célula; usando as propriedades de simetria pontual obtemos 
as interações "extra-celulares", e montamos a matriz de Fock para diferentes pontos $\mathbf{K}$ do espaço recíproco. Usando a independência e ortogonalidade (pelo Hamilıniano) das funções a $\mathbf{K}$ diferentes diagonalizamos a matriz de Fock para cata ponto $\mathbf{K}$, independentemente e com isso vários conjuntos de autovetores $C(\mathbf{K})$ sãu obtidos, com seus correspondentes autovalores. Através destes autovetores podemos encontrar os elementos da matriz densidade cristalina, $P_{\mu \nu}(\mathbf{K})$. Tim elemento da matriz densidade total é então obtido fazendo a soma na Zona de Brillouin (ZB).

$$
P_{\mu \prime}=\sum_{\mathrm{K}}^{Z B} P_{\mu \nu}(\mathrm{K}) .
$$

Uma vez encontrada a matriz densidade, uma nova matriz de Fock é geracla c assim por diante até que se chegue à autoconsistência.

Dois problemas aqui merecem destaque especial. O primeiro concerne a convergência no processo autoconsistente. Como é amplamente sabido [35] o uso direto de uma matriz densidade "saida" de uma iteração como entrada na próxima itcração não necessariamente conduz à convergência esperada, e diversos algoritmos de "aceleração de convergência" (que mais apropriadamente deveriam ser chamados de asseguradores de convergência) podem ser usados. O mais simples a a mistura linear, onde à matriz $P_{\mu \nu}(N, S)$, que resulta da saida da iteração $\mathrm{N}$, se mistura a matriz $P_{\mu \nu}(N, E)$ que entrou naquela mesma iteração, para construir a matriz $P_{\mu \nu}(N+1, E)$.

$$
P_{\mu \nu}(N+1, E)=\alpha P_{\mu \nu}(N, S)+(1-\alpha) P_{\mu \nu}(N, E) .
$$

Esse método apresenta bons resultados para sistemas moleculares, sendo porém um pouco lento para sistemas grandes (mais de $\sim 30$ átomos). No caso cristalino as flutuações de $P_{\mu \nu}$ durante a autoconsistência são mais favorecidas pela delocalização natural dos orbitais, e podem produzir transferências de carga severas (e artificiais). Um algoritmo devido a Zerner [36] amplamente usado nos métodos de Hartree-Fock e que já apresentou bons resultados para clusters ciclícos [37] está baseado em uma mistura não linear das iterações anteriores (o número de iterações passadas que se integra à mistura depende da complexidade do sistema).

Para o caso cristalino esse procedimento de mistura não linear foi o que for necen melhores resultados, suprimindo uma possível tranferência de cargas entre átomos equivalentes.

Outro ponto que merece destaque é a soma na Zona de Brillouin. Esta soma torna-se necessária na medida em que queremos $u m$ método autoconsistente. Como 
o operador de Fock depende da matriz densidade, que deve ser conseguida pela soma sobre todos os (infinitos) estados ocupados, a dificuldade de resoluçaos do sistema de infinitos estados foi reduzida a essa soma, a única ainda a acoplar estados de diferentes simetrias $\mathbf{K}$.

Existem vários algoritmos alternativos a essa soma, sendo os mais conhecidos o método do ponto médio proposto por Baldereschi [38] e o método dos pontus especiais na BZ proposto por Chadi e Cohen [39].

No nosso trabalho adotamos em geral o método dos pontos especiais; ent alguns casos, em que a célula unitária usada é de dimensoões bastante grandes, IIn único ponto especial (ponto $\Gamma, K=0$ ) é já suficiente, pois como veremos aliante. os resultados praticamente ficaram inalterados quando aumentamos o número de pontos $\mathrm{K}$ na ZB.

Para um sistema molecular dentro do método Hartree-Fock obtivemos a seguinte expressão para a energia total

$$
E_{T}=\sum_{A} \sum_{B<A} \frac{Z_{A} Z_{B}}{R_{A B}}+\frac{1}{2} \sum_{\mu, \nu^{\prime}} P_{\mu \nu}\left[H_{\mu \nu}+F_{\mu \nu}\right]
$$

Para o caso de um sólido, a expressão para a energia total, por célıla unitíria, dentro do formalismo de Hartree-Fock pode ser escrita como

$$
E_{T}^{c}=E_{c o r c}^{c}+\frac{1}{N_{A}} \frac{1}{2} \sum_{\mu . \nu^{\prime}} P_{\mu \nu}\left[H_{\mu \nu}^{c}+F_{\mu \nu}^{\prime \prime}\right]
$$

onde $N_{A}$ é o numero de átomos na célula unitária e o superindice c especifica o fato de estarmos usando a forma cristalina, ou seja

$$
F_{k l}^{c}=\sum^{Z B} F_{k l}(\mathrm{~K})
$$

O problema claro aqui é que existem várias somas divergentes (atração elétronnúcleo, repulsão núcleo-núcleo, repulsão elétron-elétron) devido à infinitude do sistema. Diversos modos de resolver este problema foram propostos $[40,41]$, cada qual para um tipo de método de cálculo de estrutura eletônica. Nós seguiremos a aproximação de vizinhança (todas as somas são calculadas até uma determinada vizinhança ou distância de corte), adequada ao método de HFR, e is técnicas semiempíricas que serão adotadas para resolver as integrais de um e dois elétrons e. um e dois centros (detalhes sobre estas técnicas serão apresentados muis adiante).

Cabe ressaltar aqui que usando a equação de Hartree-Fock para cristais 


$$
F(\mathrm{~K}, \mathrm{r}) u_{i}(\mathrm{~K}, \mathrm{r})=\epsilon_{\mathbf{K}} u_{i}(\mathbf{K}, \mathrm{r})
$$

podemos obter os autovalores de estados ocupados e virtuais para cada ponto $\mathrm{K}$. com isso a estrutura de faixas do cristal poderá ser traçada. Contudo, deveremos ter o cuidado se desejarmos aplicar a equação 2.41 pois uma forte relaxação orbital é esperada se extrairmos $10 \mathrm{~m}$ elétron (principalmente se este se encontrar no funclo da faixa de valência).

\subsection{Modelo para Estados Excitados de Cristais na Teoria de Hartree-Fock}

Como descrito anteriormente a teoria de Hartree-Fock é válida para o estado fundamental. Para sistemas finitos (moléculas e átomos) existem métodos adicionais para tratarmos estados excitados, sem os quais não se consegue obter, por exemplo, espectros óticos. Para o caso de cristais, se desejarmos falar algo sobre a banda de condução ou excitações óticas deveremos enfrentar o mesmo problema.

Supondo ortogonalidade dos estados de N-elétrons a K diverso, poderíamos implementar uma "interação de configurações" para cada $K$, se tivessemos como partida bons resultados para as "configurações puras".

O problema é, entretanto, amplificado aqui pois a interação entre as somas de Bloch introduz uma repulsão eletrônica excessiva no autovalor virtual, que nãu pode ser removida apenas pela correção de orbital virtual (que tende de fato a zero) com o número de vizinhos incluido, pela delocalização dos orbitais cristalinos). Isto faz com que a "energia de configuração pura" não seja, de forma alguma, mma boa aproximação para a energia do estado real.

Poderíamos nesse momento ter optado por um método hibrido entre a teoria de Hartree-Fock e a teoria do Funcional Densidade, como fazem alguns autores: a densidade de carga obtida dentro da teoria de Hartree-Fock é usada para calcular a energia de correlação com o auxilio do Funcional Densidade[42]. Essa escolha impactaria a aplicabilidade do método a sistemas finitos, e com isso perderíamos parte do seu poder e flexibilidade.

Optamos então por um modelo complementar ao periódico de Blorii, já muito usado em física de semicondutores, que é conhecido como modelo de aglomerado molecular. Na verdade, aqui não nos restringimos ao estudo de um ínico aglomerado, mas analisamos estados de interesse para diferentes aglomerados on "na- 
nocristais", e sua tendência conforme o nanocristal anmenta. Cada nanocristal é constituido como $1 \mathrm{~m}$ "pedaço" de cristal, ou seja, um aglomerado de átomos dispostos na geometria cristalina, tendo as superfícies passivadas por pseudo-átomos que agem de forma a produzir uma cicatrização completa das ligações, e a manter equivalência entre os átomos internos do nanocristal. Estando essas características satisfeitas para o estado fundamental, os estados excitados são estudados pelo método de Interação de Configurações, normalmente.

Esse modelo é também particularmente útil [43] para o estudo de defeitos em cristais, superfícies, etc...(a técnica de pseudo-átomos[44] já tinha sido aplicadia. preliminarmente na aproxiamação INDO para estudar defeitos em (iaAs, mas só como investigação a nível de campo médio). 
Capítulo 3

Método II: Implementação Utilizada 
Da maneira como foram derivadas as equações de Hartree-Fock-Roothaan no capítulo anterior, nenhuma restrição foi imposta à base de funçöes $\phi_{\mu}$ utilizadas, que deve ser completa. Entretanto, a utilização do método de Hartree-Fock nessa forma ( ab initio) é extremamente trabalhosa exigindo enormes matrizes e, ao final do processo iterativo, um procedimento adicional do tipo de interação de configuraçoes se faz ainda necessário.

Nós estamos interessados em 11 m método que seja o mais simples possivel, porém com uma confiabilidade superior aos métodos tradicionais de tight binding. Para isso fazemos uso das técnicas semiempíricas da Química Quântica, que são aproximações ao método de Roothaan.

Os métodos semiempíricos utlizados aqui são o MNDO-AM1[30, 31] e o ZINI)() espectroscópico[32], simultaneamente, pois cada um deles foi criado para um fim específico: no caso do MNDO-AM1 o objetivo é o cálculo da geometria de moléculats, e no caso do ZINDO espectroscópico o espectro ótico dessas moléculas. I'sando os dois métodos paralelamente teremos um método bastante poderoso para tratarmos os problemas propostos.

A seguir faremos uma breve descrição dos dois métodos semiempíricos utilizados. com suas aproximações e parametrizações.

A primeira aproximação é praticamente padrão em todos os métodos de cálculo de estrutura eletrônica para física de semicondutores, e é conhecida como aproximação de caroço congelado (ou pseudopotencial, mas este termo é mais facilmente associado a calculos onde se usa expansão em ondas planas). Trabalha-se apenas com os elétrons de valência, e os elétrons de camadas atômicas internas são tomados juntamente com seu núcleo, e formam o caroço atômico, com carga efetiva ignal à carga de valência do átomo neutro.

Em seguida, usa-se um conjunto mínimo de funções-base (por exemplo apenas os orbitais $s$ e $p$ da camada de valência do Si ou O, s p e d para o Fe, et.c.), e se introduzem parâmetros em vários elementos de matriz, a serem ajustados a resultados experimentais ou ab initio.

Como aproximação seguinte (séria), nestes métodos semiempíricos a base atônica é suposta ortogonal, e a equação de Hartree-Fock assume a seguinte forma

$$
\sum_{\nu}\left(F_{\mu \nu}-\xi_{i} \delta_{\mu \nu}\right) C_{\mu \nu}^{i}=0
$$

e são assim conhecidas por NDO (Neglect of Differential Overlap).

A seguir descrevemos as aproximações adicionais impostas aos elementos do operador $\mathbf{F}$ e a forma das funções paramétricas contidas nestes métodos, conı a 
devida escolha dos parâmetros.

\subsection{Estudo de geometria: MNDO/AM1}

O método semiempírico AM1 sofre apenas uma pequena mudança na sua forma a partir do método MNDO (o mesmo não é valido para a parametrização), com isso faremos uma breve apresentação do método MNDO[30] (maiores detalles podem ser obtidos na referência [34]) e da modificação introduzida pelo AM1.

Para facilitar o desenvolvimento, separamos os elementos de matriz do operador de Fock na maneira usual, em

$$
\begin{gathered}
F_{\mu \mu}=U_{\mu \mu}+\sum_{B} V_{\mu \mu}^{B}+\sum_{{ }^{\prime}}^{A} P_{\mu \mu \nu}\left[(\mu \mu, \nu \nu)-\frac{1}{2}(\mu \nu, \mu \nu)\right]+ \\
\sum_{B} \sum_{\lambda \sigma}^{B} P_{\lambda \sigma}(\mu \mu, \lambda \sigma),
\end{gathered}
$$

para o elemento diagonal (ou seja, aqui o indice $\mu$ já especifica o tipo de orbital e o núcleo em que está centrado), e

$$
\begin{gathered}
F_{\mu \nu}=\sum_{B} V_{\mu \nu}^{B}+\frac{1}{2} P_{\mu \nu}[3(\mu \nu, \mu \nu)-(\mu \mu, \nu \nu)]+ \\
\sum_{B} \sum_{\lambda \sigma}^{B} P_{\lambda \sigma}(\mu \nu, \lambda \sigma),
\end{gathered}
$$

para orbitais $(\mu$ e $\nu)$ diferentes porém centrados no mesmo núcleo, e

$$
F_{\mu \lambda}=\beta_{\mu \lambda} S_{\mu \lambda}+P_{\mu \lambda}(\mu \mu, \lambda \lambda)
$$

no caso de orbitais $(\mu$ e $\lambda)$ centrados em núcleos diferentes.

No MNDO as integrais de um e dois elétrons são avaliadas de duas maneiras: analiticamente, ou ajustadas através de expressões semiempiricas, que reproduzam resultados experimentais.

Os termos de um centro: $U_{\mu \mu}$, energia cinética de um elétron no orbital atômico $\phi_{\mu}^{A}$ mais a energia potencial devido a atração pelo caroço do átomn $A ; g_{\mu \nu}^{\prime \prime}=$ $(\mu \mu, \nu \nu)$ (integral de Coulomb para um centro); $h_{\mu \nu}=(\mu \nu, \mu \nu)$ (integral de troca para um centro), são avaliados da mesma forma que no método semiempírico MINDO/3[45] (Modified Intermediate NDO/3). Esses termos são desenvolvidos usando um procedimento[46] baseado no método de Oleari [47], o qual permite que 
todos os $g_{\mu \nu}$ e $h_{\mu \nu}$ sejam avaliados independentemente. Nenhuma integral de um centro é desprezada, com isso temos 8 integrais a serem determinadas (para mma base $s$ e $p$ ), a saber: $U_{s s}, U_{p p}, g_{s s}, g_{s p}, g_{p p}, g_{p p^{\prime}}, h_{s p}, h_{p p^{\prime}}$.

Essas integrais são determinadas através de ajuste por mínimos quadráticos da energia total dos estados de valência $\left(E_{A}\right)$ de cada átomo, como mua função do número de ocupação de seus orbitais[46]

$$
E_{A}=\sum_{\mu} \eta_{\mu} U_{\mu \mu}+\frac{1}{2} \sum_{\mu} \sum_{\nu \neq \mu} \eta_{\mu} \eta_{\nu} g_{\mu \nu}^{\prime}+\frac{1}{2} \sum_{\mu} \eta_{\mu}\left(\eta_{\mu}-1\right) g_{\mu \nu}
$$

onde $g_{\mu \nu}^{\prime}=g_{\mu \nu}-\frac{1}{2} h_{\mu \nu}$.

Os cálculos de Oleari estão baseados nas energias dos estados de valência cstimados por Skinner e Pritchard [48]. Através deste procedimento foram obticlos valores para $U_{s s}, U_{p p}, g_{s s}, g_{p p}, g_{s p}^{\prime}, g_{p p^{\prime}}^{\prime}$, porém para resolvermos as integrais de: 1111 centro necessitamos de $g_{s p}^{\prime}$ e $g_{p p}^{\prime}$ em termos de suas componentes $g_{s p}-\frac{1}{2} h_{s p}$. $g_{p p}-\frac{1}{2} h_{p p}$.

A resolução de $g_{p p^{\prime}}^{\prime}$ é efetuada usando as relações de Slater Condon [49]:

$$
g_{s s}=g_{s p}=F^{(0} ; g_{p p}=F^{(1)}+\frac{4}{5} F^{2} ; g_{p p^{\prime}}=F^{(1)}-\frac{2}{2} 5 F^{2} ; h_{s p}=\frac{1}{3} G^{1} ; h_{p^{\prime} \prime^{\prime}}=\frac{3}{2} 5 F^{r^{\prime 2}-}
$$

junto com os parâmetros de Oleari

$$
g_{p p^{\prime}}=\frac{4}{5} g_{p p^{\prime}}^{\prime}+\frac{1}{5} g_{p p} ; h_{s p^{\prime}}=\frac{2}{5}\left(g_{p p}-g_{p p^{\prime}}^{\prime}\right) ; h_{s p}=\frac{1}{3} G^{1} ; g_{s p}=g_{s p}^{\prime}+\frac{1}{6} G^{1} .
$$

A resolução de $g_{s p^{\prime}}$ e $h_{s p^{\prime}}$ é efetuada usando os valores de Slater para $G^{1}$

$$
g_{p p^{\prime}}=\frac{1}{4} g_{p p^{\prime}}^{\prime} ; h_{p p^{\prime}}=\frac{2}{5}\left(g_{p p}-g_{p p^{\prime}}\right)
$$

Os valores usados para $F^{()}, F^{2}$ e $G^{1}$ são os mesmos usados por Pople e e colaboradores para derivar o método INDO[50] (Intermediate NDO)(detalhes sobre o método INDO serão apresentados adiante).

Os valores semiempíricos encontrados pelos autores[46] para as integrais de repulsão de um centro $g_{\mu \nu}$ e $h_{\mu \nu}$ derivadas usando esse procedimento são muito menores do que seus correspondentes valores analíticos. Esta redução é atribuida[5l] à correlação Coulombiana entre o movimento dos elétrons, que tende a mantê-los separados a todo o momento e diminuir a energia média de repulsão entre eles. Desta forma, na determinação das integrais de repulsão de um centro a partir 
de dados experimentais, automaticamente, foi compensado em parte o efeito do correlação que é formalmente excluído na aproximação de campo médio.

As integrais de repulsão de dois centros $(\mu \nu, \lambda \sigma)$ representam a energia de interação entre a distribuição de carga $e \phi_{\mu} \phi_{\nu}$, do átomo $A$ e a distribuição de carga $e \phi_{\lambda} \phi_{\sigma}$ do átomo $B$. Classicamente elas seriam iguais às somas sobre todas as interações de multipolo de duas distribuições de cargas, $M_{l m}$, onde os subíndices $/$ e $m$ especificam a ordem e a orientação dos multipolos. Baseado nesta analogia. as integrais de repulsão de dois centros são expandidas em termo de interaçóes semiempiricas multipolo-multipolo $\left[M_{l_{1} m}^{A}, M_{l_{2} m}^{B}\right]$

$$
(\mu \nu, \lambda \sigma)=\sum_{l_{1}} \sum_{l_{2}} \sum_{m}\left[M_{l_{1} m}^{A}, M_{l_{2} m}^{B}\right]
$$

onde $A$ e $B$ indicam caroços atômicos, das quais se exige o seguinte comportantento: para $R_{A B}$ tendendo a infinito estas expressões deven convergir para os valores clássicos de interação, e para $R_{A B}$ igual a zero estas devem reproduzir os valores semiempíricos das integrais de repulsão de $11 \mathrm{~m}$ centro. Ambos os requisitos são satisfeitos pela aproximação de carga pontual, cada multipolo $M_{l m}$ é representado por uma configuração apropriada $\left[M_{l m}\right]$ de $2^{l}$ cargas pontuais de magnitude $\frac{l}{l}$ com separação de carga $D_{l}$. A interação $\left[M_{l_{1} m}^{A}, M_{l_{2} m}^{B}\right]$ entre dois multipolos é entioo calculada aplicando fórmulas semiempiricas apropriadas para cada interação, e a seguir soma-se sobre todas essas interações. Denotando a distância entre as carga pontuais $i$ e $j$ dos átomos $A$ e $B$ por $R_{i j}$ obtemos

$$
\left[M_{l_{1} m}^{A}, M_{l_{2} m}^{B}\right]=\frac{e^{2}}{2^{l_{1}+l_{2}}} \sum_{i=1}^{2^{l_{1}}} \sum_{j=1}^{2^{l_{2}}} f_{1}\left(R_{i j}\right)
$$

onde $f_{1}\left(R_{i j}\right)$ é uma expressão semiempirica que possui o comportamento correto nos limites citados anteriormente.

A atração elétron-caroço, $V_{\mu \nu}$, e a repulsão caroço-caroço são usualmente expressas em termo das integrais de repulsão de dois elétrons e dois centros. No desenvolvimento do método semiempirico MNDO foram investigadas as seguintes expressões para a atração elétron-caroço e a repulsão caroço- caroço

$$
\begin{gathered}
V_{\mu \nu}^{B}=-Z_{B}\left(\mu^{A} \nu^{A}, s^{B} s^{B}\right)+f_{2}\left(R_{A B}\right) \\
E_{\text {core }}^{A B}=Z_{A} Z_{B}\left(s^{A} s^{A}, s^{B} s^{B}\right)+f_{3}\left(R_{A B}\right)
\end{gathered}
$$


Nas expressões acima podemos notar que o efeito de caroço atômico é simulado por uma distribuição de cargas $s$, ou seja, esférica. Se as funçōes $f_{2}\left(R_{A B}\right)$ e $f_{3}\left(R_{A B}\right)$ forem ambas iguais a zero a interação entre dois átomos neutros quase desaparcu para todos os valores de $R_{A B}$, já que a repulsão de dois elétrons e dois contros. a atração elétron-caroço e a repulsão caroço-caroço quase se cancelann fo cancelitmento total ocorre no método CNDO(Complete NDO[52]) e no método INI)()]. Isto não é razoável pois esperamos que haja repulsão eletrostática entre átomos neutros e que essa aumente suavemente com o decréscimo da distância interatônica. listc efeito pode ser reproduzido na própria escolha das funções $f_{2}\left(R_{A B}\right)$ e $f_{3}\left(R_{A B}\right)$. No método semiempírico MNDO os autores escolheram fazer mma das duas funçôes igual a zero, e investigaram diferentes expressões para a ontra. As expressões investigadas quase sempre continham o termo $e^{-r R_{A B}}$, com $\alpha>0$ e ajustável, (le maneira que a repulsão eletrostática entre átomos neutros desapareça no limit. $R_{A B}$ tendendo a infinito.

Ruedemberg[53] mostrou que a principal contribuição para a energia de ligação) de uma molécula provêm das integrais de ressonância de $u m$ elétron, $\beta_{\mu \lambda}$. No MNDO essas são tomadas como proporcionais às integrais de sobreposição correspondentes, $S_{\mu \lambda}$ :

$$
\beta_{\mu \lambda}=f_{4}\left(R_{A B}\right) S_{\mu \lambda}
$$

onde $f_{4}\left(R_{A B}\right)$ é uma função semiempírica, mas que pode, em princípio, depender dos orbitais atômicos, $\phi_{\mu}$ e $\phi_{\lambda}$, dos átomos $A$ e $B$ respectivamente.

Para determinar a melhor forma para as funções paramétricas $f_{1}$ a $f_{1}$, e o melhor valor para os parâmetros nelas contidos, o procedimento utilizado é puramente empírico, baseado em comparações entre propriedades calculadas e observadas para um "conjunto base" de moléculas cuidadosamente escolhido.

As funções de referência para as moléculas teste incluem calores de formação, variáveis geométricas, momentos de dipolo, e primeiros potenciais verticais de ionização.

Para a função semiempirica $f_{1}\left(R_{i j}\right)$ adota-se a fórmula de Dewar-Sabelli-Klop$\operatorname{mann}[54](\mathrm{DSK})$

$$
f_{1}\left(R_{i j}\right)=\left[R_{i j}^{2}+\left(\rho_{l_{1}}^{A}+\rho_{l_{2}}^{B}\right)^{2}\right]^{-1}
$$

Os termos $\rho_{l}$ são caracteristicos das interações de monopolo, dipolo e quadrupolo $(l=0,1,2)$ e são escolhidos de maneira que a fórmula semiempirica para a integral de repulsão de dois centros concorde com os valores semiempiricos no limile de 
$u m$ centro, entre dois monopolos $\left(g_{s s}\right)$, dois dipolos $\left(h_{s p}\right)$ e dois quadrupolos $\left(h_{1},{ }\right)$. Desta maneira temos para $\rho_{0}=\frac{c^{2}}{2 !}$, sendo os valores de $\rho_{1}$ e $\rho_{2}$ cálculados através de métodos numéricos.

Para a atração elétron-caroço, Dewar e Thiel[30] testaram muitis expressōes semiempíricas para a função $f_{2}\left(R_{A B}\right)$, encontrando resultados razoáveis para hídrocarbonetos. Entretanto o uso destas expressões para sistemas com heteroátomos (sistemas com fortes ligações polares) fornecen valores não realísticos para a clistribição de carga. Isto não é surpreendente, já que a atração elétron-caroço aparece nos elementos diagonais da matriz de Fock. Os autores concluiram que o uso de $f_{2}\left(R_{A B}\right)$ introduz valores não realísticos para a eletronegatividade dos átomos na molécula, e desta forma decidiram por excluir $f_{2}\left(R_{A B}\right)$, ou seja, tomar

$$
f_{2}\left(R_{A B}\right)=0
$$

e incluir a repulsão eletrostática entre átomos neutros somente na expressão para a repulsão caroço-caroço, que ficou com a seguinte forma

$$
f_{3}\left(R_{A B}\right)=Z_{A} Z_{B}\left(s^{A} s^{A}, s^{B} s^{B}\right)\left[e^{-r_{A} R_{A B}}+e^{-\tau_{B} R_{A B}}\right]
$$

onde $\alpha_{A}$ e $\alpha_{B}$ são parâmetros atômicos ajustáveis. Esta expressão é puramente empírica, porém apresenta o comportamento correto no limite $R_{A B}$ tendendo a infinito,

Para a expressão $f_{4}\left(R_{A B}\right)$ os autores decidiram não estudar qualquer expressão que contivesse uma dependência explícita nas distâncias interatônicas $R_{A l}$, enbora fosse possível, e assim

$$
f_{4}\left(R_{A B}\right)=\frac{\left(\beta_{\mu}^{A}+\beta_{\lambda}^{B}\right)}{2}
$$

onde $\beta_{\mu}^{A}$ e $\beta_{\lambda}^{B}$ são parâmetros ajustáveis e característicos dos orbitais atômicos $\phi_{\mu}$ e $\phi_{\lambda}$ dos átomos $\mathrm{A}$ e $\mathrm{B}$ respectivamente.

Com o surgimento do MNDO foi obtido grande progresso no cálculo de geometrias e calores de formação para uma grande variedade de moléculas. Porém em alguns casos o MNDO ainda deixava a desejar, especialmente no que diz respeito a ligações que envolvem o hidrogênio.

Um novo método foi então proposto por Dewar e colaboradores[31] y ara suprir as falhas do MNDO, que foi batizado AM1 (Austin Model One)[31].

O método AM1 parte da mesma escolha das funções paramétricas à exceção da repulsão entre os caroços, que passa a ter a forma 


$$
E_{c o r c}=Z_{A} Z_{B}\left(s^{A} s^{A}, s^{B} s^{B}\right)\left[1+F(A)+F^{2}(B)\right]
$$

onde

$$
\begin{aligned}
& F(A)=e^{-\alpha_{A} R_{A B}}+\sum_{i} K_{A_{i}} e^{L_{A i}\left(R_{A B}-M_{A+}\right)^{2}} \\
& F(B)=e^{-\alpha_{B} R_{A B}}+\sum_{j} K_{B_{j}} e^{L_{B}\left(R_{A B}-M_{B}\right)^{2}}
\end{aligned}
$$

À parte essa pequena modificação, foi feita para o AMl uma parametrização completa[31].

Mais recentemente, em 1989, Stewart e colaboradores[55] reparametrizaram novamente o MNDO batizando essa nova versão de MNDO-PM3 ( MNI)O parametric method 3; onde o 1 e o 2 seriam o MNDO e o AM1 respectivamente). No PMB os erros do MNDO e do AM1 no cálculo dos calores de formação são substancialmente. reduzidos, sem a perda da geometria molecular e dos momentos de dipolo.

Cabe ressaltar aqui que, apesar de muito cuidadoso e minucioso, esse procedimento não visa a obtenção de propriedades (geometrias, energias de ligação) para sólidos - que é o caso em que estamos interessados neste trabalho. Assim nào é imediato que os mesmos parâmetros, obtidos para sistemas finitos, prodızanm bons resultados para cristais.

Por outro lado, dado o número limitado de sólidos estáveis formados a partir dos mesmos dois ou três elementos (comparativamente a moléculas), o procedincuto de parametrização deve ser necessáriamente diferente no nosso caso, como veremos mais tarde.

\subsection{Estudo de Espectroscopia: ZINDO/CI}

O método semiempírico ZINDO/CI (Zerner Intermediate NDO)[32] é baseado na versão original do INDO que foi apresentado pela primeira vez por Pople, Beveridge and Dobosh[50]. O INDO, como o seu nome já diz, foi introduzido para manter parcialmente as integrais de troca

$$
(\mu \nu, \mu \nu)=\int \phi_{\mu}(1) \phi_{\mu}(2) \frac{1}{r_{12}} \phi_{\nu}(1) \phi_{\nu}(2) d \tau_{12},
$$


que eram todas desprezadas no método semiempírico CNDO[52] (Complete N1)( )). No INDO são mantidas as integrais de troca nos termos de $11 m$ centro, ou seja, para orbitais atômicos localizados sobre o mesmo átomo.

Uma vez que estaremos usando $u m$ conjunto base $s, p, d, \ldots$, (sem a presença do híbridos) podemos perceber que muitas das integrais de um centro irâo desaparcer por simetria. Da mesma forma temos apenas 1 morbital atômico de cada simetria. $s, p_{x}, p_{y}, p_{z}, \ldots$ no conjunto base, com isso todos os elementos de carogo fora da diagonal, $U_{\mu \nu}$, irão desaparecer. Com essas simplificações os elementos do operaulor de Fock se reduzem a

$$
\begin{gathered}
F_{\mu \mu}^{A \cdot A}=U_{\mu \mu}+\sum_{\lambda}^{A}\left[P_{\lambda \lambda}(\mu \mu, \lambda \lambda)-\frac{1}{2} P_{\lambda \lambda}(\mu \lambda, \mu \lambda)\right]+\sum_{B \neq A} \sum_{A}\left(P_{B B}-Z_{B}\right) \Gamma_{A B} \\
F_{\mu \nu}^{A . A}=\frac{3}{2} P_{\mu \nu}(\mu \nu, \mu \nu)-\frac{1}{2} P_{\mu \nu}(\mu \mu, \nu \nu) \\
F_{\mu \nu}^{A, A}=\sum_{\lambda . \sigma} P_{\lambda \sigma}(\mu \nu, \lambda \sigma)-\frac{1}{2} P_{\mu \lambda} \Gamma_{A B}
\end{gathered}
$$

onde $\Gamma_{A B}=(\mu \mu, \lambda \lambda)$ é a integral de dois elétrons e dois centros.

Como estamos interessados na parte que diz respeito a excitações óticas adotamos a parametrização voltada para a espectroscopia, proposta por Riclley c Zerner[32] e batizado como ZINDO/CI.

As integrais de caroço de $u m$ centro, $\mathrm{U}_{\mu \mu}$,

$$
U_{\mu \mu}=\left(\mu\left|\frac{1}{2} \nabla^{2}-\frac{Z_{A}}{R_{A}}+V\right| \mu\right)
$$

são obtidas (como é feito no caso do INDO/1 e do CNDO/1) a partir tão somente dos valores experimentais do potencial de ionização.

$$
U_{\mu \mu}=I_{\mu}-\left(Z_{A}-1\right) F^{0}(s s)+\frac{1}{6} m G^{1}(s p)
$$

para um orbital $s$, e

$$
U_{\mu \mu}=I_{\mu}-\left(Z_{A}-1\right) F^{(0}(s s)+\frac{1}{6} l G^{1}(s p)+\frac{2}{25}(m-1) F^{2}(p p)
$$

para um orbital $p$. Nestas expressões $\mu$ é um orbital centrado sobre o átomo $A, V$ é o pseudopotencial de caroço atômico, $I_{\mu}$ o potencial de ionização para o processo 
$s^{l} p^{m} \rightarrow s^{l-1} p^{m}+(\mathrm{s})$ ou $s^{l} p^{m} \rightarrow s^{l} p^{m-1}+(\mathrm{p})$. $C^{\prime}(s p)$ e $F^{\prime 2}(p p)$ são os parantuefros de Slater Condon[49].

Para a parte de atração elétron-caroço entre dois centros, se admite a forma

$$
V_{A B}=Z_{B} \Gamma_{A B}
$$

As integrais de dois elétrons e $u m$ centro são dadas em termo dos fatores semiempíricos de Slater Condon. Para átomos que possuem apenas orbitais s e $p$ na camada de valência temos

$$
\begin{gathered}
g_{s s}=g_{s p}=F^{(1)} \\
h_{s^{\prime}}=\frac{1}{3} G^{1}(s p) \\
g_{p p^{\prime}}=F^{(0)}(p p)+\frac{4}{25} F^{2}(p p) \\
g_{p p^{\prime}}=F^{(0)}(p p)-\frac{2}{25} F^{2}(p p) \\
h_{p p^{\prime}}=\frac{3}{25} F^{2}(p p)
\end{gathered}
$$

As integrais de dois elétrons e dois centros são avaliadas pela formula modificada. de Mataga-Nishimoto[56]

$$
\Gamma_{A B}=\frac{f_{y}}{\frac{2 f_{y}}{\Gamma_{A}+\Gamma_{B}}+R_{A B}}
$$

onde $R_{A B}$ é a distância entre os dois centros. $\Gamma_{A}$ e $\Gamma_{B}$ são obtidos da aproximação de Pariser[51]

$$
\Gamma_{A}=F^{(0)}(A)=I_{A}-A_{A}
$$

sendo $I_{A}$ o potencial de ionização e $A_{A}$ a afinidade eletrônica do átomo A.

A modificação espectroscópica é a introdução do parâmetro $f_{y j}$ sugeriua por Weiss[57] e traz como efeito aumentar a repulsão eletrônica. Note-se que ıảo se faz nenhuma distinção entre os orbitais atômicos $(s, p, \ldots)$ e o termo $f_{y}$ é totalmente arbitrário. No caso de moléculas orgânicas $f_{y}$ é tomado como igual a 1.2 , sendo 
esse o valor que melhor reproduziu o espectro do benzeno, em especial o segrundo estado singleto excitado $\left({ }^{1} B_{1 u}\right)$.

O termo de dois centros da matriz de Fock $I_{\mu \lambda}$ é calculado por

$$
\beta_{\mu \lambda}=\frac{1}{2}\left(\beta_{A}+\beta_{B}\right) \bar{S}_{\mu \lambda}
$$

onde $\beta$ é um parametro de ligação caracteristico do átomo. S̀ é um overlap especial. relacionado ao overlap tradicional por

$$
\begin{gathered}
\tilde{S}_{m s n s}=S_{m s n s} \\
\tilde{S}_{m s n p}=S_{m s n p} \\
\tilde{S}_{m p n p}=f_{\sigma} G \sigma S_{m p j \sigma n p \sigma}+f_{\pi} G_{\pi} S_{m p \pi n p \pi}
\end{gathered}
$$

onde $G_{\sigma}$ e $G_{\pi}$ são fatores geométricos apropriados, para transformar o overlap do sistema diatomico local para o sistema molecular, e $f_{\sigma}$ e $f_{\pi}$ são fatores empíricos.

Novamente fica claro que muitos dos parâmetros usados foram ajustados para fornecerem bons resultados para moléculas e dentro do conjunto base molecular a hibridização do tipo $s p^{3}$ (essencial em semicondutores covalentes) entra com $11 m$ peso pequeno.

\subsection{Parametrização NDO/Cristal}

Até aqui descrevemos rápidamente o método Hartree-Fock-Roothaan acoplado aos métodos semiempíricos da Química Quântica (AM1 e ZINDO).

Recapitulando, sendo nosso objetivo estudar sistemas relacionados aos semicondutores tetraédricos, o procedimento envolve o uso em paralelo do método de Hartree-Fock-Roothaan para sistemas com periodicidade de Bloch, e do modelo de nanocristais, o que nos permite principalmente inserir sistemas cristalinos no conjunto base de sistemas para ajuste de parâmetros.

Uma vez parametrizada a técnica específica (AM1 ou ZINDO), podemo utilizar qualquer dos dois modelos, ou ainda o modelo usual para moléculas, para estudo dos sistemas de interesse. 
Além disso, ao estudar qualquer sistema, as propriedades estruturais são obtidas através do AM1, cujo hamiltoniano é desenhado para melhor obtençâo de geometrias, calores de formação, e espectros vibracionais. A partir das geometrias obtidas com o AM1, as propriedades eletrônicas e óticas são obtidas através do ZINI)( )/('I.

Como descrito, as aproximações semiempíricas, com suas parametrizaçoes originais, estão voltadas às propriedades de pequenas moléculas. O nosso objetivo é aplicar o nosso método para sistemas mais complexos (cristais, nanocristais, defeitos em cristais, partículas, etc, ...), com isso, deve ser efetrada mma parametrização que além de descrever bem pequenas moléculas, descreva as principais propriedades de cristais.

Esta parametrização foi efetuada para os átomos de Si e O, que são as duas priıcipais espécies atômicas presentes nas amostras de silício poroso. Descreveremos agora a metodologia utilizada e listamos as novas parametrizações no apendice $B$.

Ainda neste capítulo apresentamos nossos resultados para "um sistema de teste", ou seja, sistema não incluido no conjunto base, mas que tem suas propriedades muito conhecidas e estudadas.

O conjunto base escolhido para obter os parâmetros para os átomos de Si e () foi: Si cristalino, cristal de $\alpha$-quartzo; pequenas moléculas $S i H_{1}, S_{2} I_{6}, O S_{1} i_{2} / I_{6}$. e finalmente, o O intersticial em Si; como sistema teste, escolhemos o centro- $\Lambda$ em Si (propriedades estruturais e eletrônicas).

\subsubsection{AM1/Cristal}

Iniciamos pela parametrização do silício e usamos como conjunto base para ajuste o cristal de Si e as moléculas de silano e disilano.

Em geral o conjunto base de parametrização inclui um número grande de moléculas, porém em nosso caso iremos dar preferência às moléculas que possuem mm ambiente tetraédrico muito similar àquele dos semicondutores tetraédricos.

Para o conjunto teste envolvendo cristais, no nosso caso, não nos é conveniente. usar estruturas cristalinas para o Si muito separadas em energia da estrutura tetraédrica (como Si bcc) que estão muito longe da situação estável. Assim, para ter um bom controle das propriedades elásticas e estruturais a partir da energia total, decidimos por outro caminho: comparar os nossos resultados com didos experimentais ligados à energia total que sejam bem conhecidos.

Entre esses resultados, escolhemos um conjunto de grandezas relevantes: parâmetro de rede de equilıbrio, e o módulo de compressibilidade volumétrica, on sim-

plesmente módulo de volume, que para o caso da estrutura do diamante é obtido 
através da seguinte relação [58]

$$
B=\frac{8}{9 a} \frac{\partial^{2} u}{\partial a^{2}}
$$

Outras grandezas que estão fortemente relacionadas com a estabilidade do cristal são os fônons, que equivalem às frequências vibracionais de moléculas. De novo. para um sistema poliatômico finito (moléculas) o número de modos normais é linito e em geral o espectro completo é calculado. Esse não é o caso para o cristal, e conı isso calculamos a frequência dos fônons de pontos de mais alta simetria na Z13 (pontos $\Gamma, X$ e $L$ ).

O cálculo para a frequência dos fônons foi feito com condições de periodicidade de Bloch, utilizando o método de fônons congelados ("frozen phonons"). Nesse método a energia total para o estado fundamental (sem a presença de fônons) e a. energia total com a presença de fônons são calculadas separadamente, para vários valores de deslocamento ao longo da coordenada normal correspondendo ao fônon; com isso a curva de energia para $11 m$ fônon assume a forma

$$
E^{\text {fonon }}(\mathrm{K}, \Delta \mathrm{x})=E_{t}(\mathbf{K}, \Delta \mathrm{x})-E_{t}(0)
$$

$\mathrm{O}$ vetor $\mathrm{K}$ aqui especifica a simetria de um determinado fônon, que corresponde a esse $\Delta \mathrm{x}$ particular efetuado (para cada $\mathrm{K}$, estudamos os modos ótico, acrístico, longitudinal e transversal).

Para o cálculo da frequência do fônon utilizamos a aproximação harmônica, em que a frequência é tomada como proporcional à parte linear da segunda derivada da energia:

$$
\nu(\mathbf{K})=\frac{1}{2 \pi} \sqrt{\frac{1}{m} \frac{\partial^{2} E(\mathbf{K}, \Delta \mathrm{x})}{\partial \Delta \mathrm{x}^{2}}} .
$$

O procedimento de parametrização é iterativo. Se partirmos de unı célula unitária com 2 átomos e interação apenas entre primeiros vizinhos (detallhes de como obter a matriz de Fock cristalina para este caso particular são apresentados no apêndice A) e com pontos especiais na ZB, teremos apenas uma primeira idéia (grosseira) da direção onde leva a mudança de parâmetros.

Para efetuarmos uma parametrização mais rigorosa devemos estender, alcance das interações, e para isso usamos a célula unitária de 8 átomos (re le cúbica simples) e incluimos interações de segundos vizinhos (detalhes de como a matriz de Fock cristalina é obtida para esta estrutura são apresentados no apendice A). 
Sabemos de cálculos de LDA[59] que para a frequência do lônon TAx ser reproduzida, são necessárias constantes de força de até quintia ordem, con isso a aproximação de interação de até segundos vizinhos somente, realmente não poderia reproduzir esta frequência.

Se analisarmos a estrutura do diamante veremos que (se a é o parâmetro do rede) cada átomo possui 4 primeiros vizinhos distanciados de $\sqrt{3} \frac{a}{4}, 12$ segundos vizinhos distanciados de $\sqrt{2} \frac{a}{2}, 12$ terceiros vizinhos distanciados de $\sqrt{11} \frac{u}{4}, 6$ quartos vizinhos distanciados de $a$, e assim por diante.

Com isso fica claro que estamos introduzindo um erro grosseiro se desprezarmos terceiros vizinhos em relação a segundos vizinho pois estes são em igual múmero e a distâncias muito proximas. Ao mesmo tempo vemos que o nímero de cultrtos vizinhos é apenas a metade do número de segundos e terceiros vizinhos, e estão at uma distância ligeiramente superior.

Introduzindo interação de até terceiros vizinhos, e efetuando mua minuciosa parametrização encontramos bons resultados para as grandezas calculadas, tinto para moléculas de silano e disilano como para o cristal de silício.

Dentro da aproximação AM1 é importante notar que os parâmetros de hoppung $\beta_{\mu}$ controlam, entre outras grandezas, a largura da faixa de valência: apesar de não incluirmos como grandezas de ajuste propriedades estritamente eletrônicas, esse valor não deve diferir muito do valor experimental inclusive por ser $u m$ rellexo da hibridização.

Um ajuste nos $\beta_{\mu}$ mostrou também ser eficiente em controlar o caráter $s p^{3}$ da distribuição de carga, fator que deve ser monitorado, pois é de fundanental importância para uma boa descrição de semicondutores covalentes. Assim procuramos controlar a largura de faixa de valência e monitorar a hibridização $s \mu^{3}$. ajustando os $\beta_{\mu}$.

Quanto à energia de repulsão de caroço, mantendo a forma geval do hamiltoniano efetivo AM1, introduzimos novas gaussianas e modificamos os parâmetros (expontes $\alpha$ ) das gaussianas já existentes no AM1 original.

Daqui em diante, e em todas as figuras e tabelas, designaremos os resultados obtidos com o procedimento e a parametrização aqui propostos por AM1/Cristal, ou seja, hamiltoniano "Austin Model One" para cristais.

Os resultados obtidos para o parâmetro de rede de equilíbrio e o mór nlo de volume do cristal de Si, usando uma célula unitária de 8 átomos com interaçâo de até terceiros vizinhos e 4 pontos especias da ZB estão apresentados na tabela 3.1 , comparados ao valor experimental e aos valores obtidos com a parametrização 
AM1 original. Vemos que tanto o parâmetro de rede quanto o módulo de volume obtidos com o AM1 está bastante distante do valor experimental, e particularmente. o erro do módulo de volume inviabilizaria qualquer estudo estrutural de sistemas tetraédricos de Si. Nossos resultados apresentam desvio muito menor, (claramente poderiam ser ainda diminuidos não fosse o compromisso com sistemas moleculares) que consideramos aceitável.

\begin{tabular}{|c|c|c|}
\hline $\begin{array}{c}\text { Si } \\
\text { cristal }\end{array}$ & $\begin{array}{c}\text { Parâmetro } \\
\text { de rede }(\AA)\end{array}$ & $\begin{array}{c}\text { Módulo de } \\
\text { volume }\left(10^{12} \mathrm{dy} / \mathrm{cm}^{2}\right)\end{array}$ \\
\hline AM1 & 5.562 & 1.827 \\
\hline AM1/Cristal & 5.453 & 1.125 \\
\hline Exp.[60] & 5.429 & 0.978 \\
\hline
\end{tabular}

Tabela 3.1: Resultados para o parâmetro de rede de equilíbrio e o módulo do volume do Si, obtidos com a parametrização AMl original e com a parametrizaçâo prposta neste trabalho, comparados aos valores experimentais.

Mostramos na tabela 3.2 o efeito das diferentes convergências do método periódico, ou seja, aumentamos a célula unitária, a soma na ZB e o número de vizinhanças incluidos. Vemos que já estamos muito próximos dos melhores valores com a escolha de $3^{\underline{a s}}$ vizinhos. Para obtermos bons valores de $a_{0}$ e $B$, a cada inclusão de vizinhanças os parâmetros são modificados, e a modificação é drástica ao passar de uma a duas e ainda de duas a três camadas de vizinhos. Entretanto a mudança já é muito pequena na passagem de três a cinco camadas. Este teste é importante pois ao estudarmos sistemas finitos é dispensável a aproximação de vizinhança, e assim, dada a boa convergência encontrada, não a adotamos.

Na tabela 3.3 apresentamos o resultado para as frequências de fônons, comparados a resultados experimentais[61]. O maior erro porcentual aparece na frequência do fônon TA(X), como já esperado. O limite da dispersão $\Gamma$ é bastante bem representado, como podemos ver. Aqui, resultados com a parametrização original sequer podem ser obtidos por dificuldade de convergência: a quebra de simetria causada pelo fônon traz uma grande dificuldade ao cálculo (no programa com periorlicidade de Bloch) por provocar transferência e polarização da carga. 


\begin{tabular}{|c|c|c|c|c|}
\hline Célula & $\begin{array}{c}\text { Soma } \\
\text { na ZB }\end{array}$ & Vizinhanças & $\begin{array}{c}\text { Parâmetro } \\
\text { de rede }\end{array}$ & $\begin{array}{c}\text { Módulo de } \\
\text { volume }\end{array}$ \\
\hline 8 & 4 & 3 & 5.453 & 1.125 \\
\hline 32 & 1 & 5 & 5.460 & 1.126 \\
\hline 32 & 2 & 5 & 5.453 & 1.115 \\
\hline 54 & 1 & 3 & 5.482 & 1.175 \\
\hline 54 & 1 & 5 & 5.475 & 1.124 \\
\hline 64 & 1 & 5 & 5.475 & 1.123 \\
\hline 64 & 4 & 5 & 5.454 & 1.120 \\
\hline
\end{tabular}

Tabela 3.2: Resultados para o módulo de volume $\left(10^{12} \mathrm{dy} / \mathrm{cm}^{2}\right)$ e o parâmetro de rede de equilíbrio $(A)$ do Si para diferentes células unitárias, diferentes múmero de pontos especiais na $Z B$ e diferentes alcances de interaçòes.

\begin{tabular}{|c|c|c|}
\hline Pto na ZB & AM1/Cristal & Exp. \\
\hline$L T O(\Gamma)$ & 522 & 517 \\
\hline$L A O(X)$ & 427 & 410 \\
\hline$T O(X)$ & 481 & 463 \\
\hline TA $(X)$ & 175 & 150 \\
\hline$L O(L)$ & 430 & 417 \\
\hline$L A(L)$ & 392 & 378 \\
\hline$T O(L)$ & 492 & 487 \\
\hline$T A(L)$ & 142 & 114 \\
\hline
\end{tabular}

Tabela 3.3: Resultados para a frequência dos fonons $\left(\mathrm{cm}^{-1}\right)$ do cristal de Si calculadas usando o método HF-LCAO periódico acoplado à aproximaçâo semi-empírica AM1/Cristal.

Vemos que temos uma descrição bastante confiável do cristal. Entretantó, é muito importante, para uma maior confiabilidade do método, que os pirâmetros reproduzam as principais propriedades estruturais do cristal de Si, possanı também reproduzir as propriedades estruturais de pequenas moléculas que contém átomos de Si. Com isso a geometria e as vibrações das moléculas de silano e disilano foram 


\begin{tabular}{|c|c|c|c|c|c|}
\hline $\mathrm{SiH}_{4}$ & $d_{S i-H}$ & $\mathrm{~A}$ & $T$ & $E$ & $T$ \\
\hline AM1 & 1461 & 2258 & 2254 & 854 & 770 \\
\hline AM1/Cristal & 1.453 & 2226 & 2223 & 883 & 819 \\
\hline Exp.[62] & 1.480 & 2185 & 2189 & 972 & 913 \\
\hline
\end{tabular}

Tabela 3.4: Resultados para a geometria (distância em Ä) e us frequèncius (cm $\mathrm{cm}^{-1}$ ) de vibração do silano

\begin{tabular}{|c|c|c|c|}
\hline $\mathrm{Si}_{2} \mathrm{H}_{6}$ & $d_{S i-H}(\AA)$ & $d_{S i-S i}(\AA)$ & $\Theta_{S i-S i-H}$ \\
\hline AM1 & 1.466 & 2.41 & 109.6 \\
\hline AM1/Cristal & 1.457 & 2.40 & 109.7 \\
\hline Exp.[63] & 1.480 & 2.33 & 109.4 \\
\hline
\end{tabular}

Tabela 3.5: Resultados para a geometria do disilano

também calculadas com o AM1/Cristal, e nas tabelas 3.4 e 3.5 apresentamos os resultados obtidos.

Aqui, percebemos algo que deverá aparecer futuramente, que é o fato da distância Si-H estar um pouco abaixo do valor experimental $(\sim 2 \%)$ e as frequências de estiramento (stretching) estarem um pouco acima do valor experimental $(\sim 5 \%)$. Isto ocorre pois quando reparametrizamos o método para o átomo de Si, foi como objetivo de reduzir a distância de ligação Si-Si; com isso é esperado que a distância entre o átomo de Si e outros átomos seja reduzida também. Para que a distância Si-H não fosse reduzida uma modificação dos parâmetros do átomo de H (interação entre caroços) deveria ser efetuada conjuntamente, o que não desejávamos. Assim, aceitaremos esta pequena dispersão, e estaremos conscientes que uma pequena dispersão para frequências e distância Si-H deverá ocorrer e que esta é carregada do processo de parametrização.

Para a parametrização do átomo de oxigênio procuramos $11 \mathrm{~m}$ ambiente en que este estivesse ligado a átomos de Si. Com isso escolhemos o cristal de a quartizo e a molécla de disiloxano $\left(\mathrm{H}_{3} \mathrm{SiOSiH}_{3}\right)$; usamos ainda a molécula d'água $\left(\mathrm{H}_{2} \mathrm{O}\right)$ pois assim teremos uma análise do comportamento dos parâmetros para a ligação $\mathrm{OH}$. 
Dada a maior complexidade do cristal, pudemos usar a própria célula unitária fundamental do quartzo: rede hexagonal com 9 átomos na base, 3 si e 6 (). Isamos neste caso uma aproximação de interação de até segundos vizinhos (detallıes de como a matriz de Fock cristalina é obtida para esta particular estrutura é apresentado no apendice $\mathbf{A}$ ).

A parametrização para o $O$ foi efetuada modificando as mesmas funções paramétricas que foram modificadas quando da parametrização do Sii, ou seja, parâmetro de hopping e os parâmetros da função que descreve a repulsão entre os caroços atômicos (expoentes e parâmetros das gaussianas).

Após um minucioso processo de parametrização, modificando apenas os parâmetros do oxigênio e usando os parâmetro do Si aqui propostos, conseguimos bons resultados para a geometria do cristal de quartzo e as moléculas usadis como referência.

Os principais resultados para as propriedades estruturais do cristal de (juartzo obtidas fazendo uso de 6 pontos especias na ZB e a célula mnitária convencional, junto com os respectivos valores experimentais, estão apresentados na tabela 3.(i.

\begin{tabular}{|c|c|c|c|}
\hline$\alpha$-quartzo & $a(\AA)$ & $c(\AA)$ & $c / a$ \\
\hline AM1/Cristal & 4.998 & 5.522 & 1.105 \\
\hline Exp.[60] & 4.903 & 5.394 & 1.100 \\
\hline
\end{tabular}

Tabela 3.6: Resultados obtidos para o cristal de quartzo com o método HF L(AC) periódico acoplado à aproximação AMI/Cristal.

\begin{tabular}{|c|c|c|c|c|}
\hline $\mathrm{OSiH}_{6}$ & $d_{S i-O}(\AA)$ & $\Theta_{S i-O-S i}$ & $f_{1}(S i-O-S i)$ & $f_{2}(S i-O-S i)$ \\
\hline AM1 & 1.725 & 154 & 574 & 1124 \\
\hline AM1/Cristal & 1.687 & 167 & 564 & 1154 \\
\hline Exp.[62] & 1.630 & 144 & 555 & 1089 \\
\hline
\end{tabular}

Tabela 3.7: Resultados para a geometria do disiloxano.

Na tabela 3.7 apresentamos os resultados obtidos para a geometria da molécula. de disiloxano, junto aos valores experimentais. Nossos valores estão ao menos na mesma qualidade que os do AM1 original neste caso. 
Nossos resultados entretanto não nos garantem que qualquer sistema molecular será descrito com essa mesma qualidade. Em particular, sistemas muito pequenos como a água, que não entrou com peso relevante na parametrização, poderian ser mal descritos. Apresentamos assim na tabela 3.8 os resultados para a molécula de $\mathrm{H}_{2} \mathrm{O}$. vemos que realmente neste caso a qualidade do ajuste é pior que a obtida com o AM1, e novamente para melhorar nossos resultados deveríamos alterar os parâmetros para o átomo de H. Entretanto, como os sistemas que nos interessam são muito diferentes dessas moléculas tão pequenas, nāo seria justificável dar peso de relevância à molécula de $\mathrm{H}_{2} \mathrm{O}$.

\begin{tabular}{|c|c|c|c|c|c|}
\hline água & $\begin{array}{c}d_{()-H} \\
(\AA)\end{array}$ & $\begin{array}{c}\Theta_{H-O-H} \\
\text { (graus) }\end{array}$ & $\begin{array}{c}\nu_{I-O-H} \\
\left(\mathrm{~cm}^{-1}\right)\end{array}$ & $\begin{array}{c}\nu_{H-0} \\
\left(\mathrm{~cm}^{-1}\right)\end{array}$ & $\begin{array}{c}\nu_{H-O} \\
\left(\mathrm{~cm}^{-1}\right)\end{array}$ \\
\hline AM1 & 0.961 & 103.61 & 1877 & 3543 & 3616 \\
\hline AM1/Cristal & 0.957 & 103.73 & 1901 & 3355 & 3438 \\
\hline Exp.[64] & 0.970 & 104.50 & 1595 & 3657 & 3756 \\
\hline
\end{tabular}

Tabela 3.8: Resultados para a geometria da molécula de água.

Ainda para a parametrização do Si e do $\mathrm{O}$, calculamos as frequềncias de vilıração (dos modos de estiramento) do oxigênio intersticíal em silício cristalino, para as quais existem resultados experimentais. Este sistema requeren o nso do modelo de nanocristais.

Neste caso queremos estudar as características estruturais de $u m$ defeito em um cristal: selecionamos uma vizinhança $\left(r \leq R_{c}\right)$ em torno do defeito que seja representativa, ou seja, onde julgamos que esteja confinado o "potencial de defeito", a perturbação $\Delta V(\mathrm{r})$ causada ao hamiltoniano do sistema cristalino perfeito $V_{0}(\mathrm{r})$ pela presença do defeito $V_{D}(\mathrm{r})$

$$
\Delta V(\mathrm{r})=\mathrm{V}_{\mathbf{D}}(\mathrm{r})-\mathrm{V}_{\mathbf{0}}(\mathrm{r}) \approx 0, \quad \mathrm{r} \geq \mathbf{R}_{\mathrm{c}}
$$

Essa escolha define o tamanho e forma de um aglomerado representativo do cristal, que é então construido com átomos do cristal hospedeiro (no caso, Si) nas posições cristalinas "teóricas", ou seja, na simetria do cristal (no ca so, T $T_{d}$ ou $D_{3 d}$, dependendo da forma), com a distância interatomica $d_{10}$ dada pelo parâmetro de rede de equilíbrio obtida pelo AM1/Cristal, modelo HF com periodicidade de Bloch. A superfície do aglomerado é então saturada com pseudo-átomos do cristal 


\begin{tabular}{|c|c|c|}
\hline $\mathrm{O}_{\text {in } .}$ & $f_{1}\left(\mathrm{~cm}^{-1}\right)$ & $f_{2}\left(\mathrm{~cm}^{-1}\right)$ \\
\hline AM1/Cristal & 1152 & 582 \\
\hline Exp.[65][66] & $1136-1106$ & 515 \\
\hline
\end{tabular}

Tabela 3.9: Resultados para as frequências de vibração do oxigênio intersticial c.m silício.

hospedeiro (pseudo-Si), à mesma distância $d_{0}$. Assim construimos $u$ m nanocristal, finito.

Esses saturadores não são necessariamente únicos, ou seja, em $u m$ mesmo nanocristal pode haver mais de um saturador, e nanocristais diferentes quase certament. precisarão saturadores diferentes. O papel desses saturadores é garantir, o melhor possível, duas condições:

a) equivalência de carga para os diferentes átomos (átomos de diferentes camadas) do nanocristal;

b) hibridização igual à obtida com o modelo periódico infinito.

Uma vez que o nanocristal é testado e reproduz o ambiente cristalino, o defeito é incluido, no centro do nanocristal, e suas propriedades estudadas sem alteração posterior dos pseudo-átomos.

Para simularmos o O intersticial em Si utilizamos 1 m nanocristal de 86 átomos (44 átomos de Si e 42 psendo-Si) em simetria $D_{3} d$, com o oxigênio intersticial entre os dois átomos de Si centrais. O resultado obtido está apresentado na tabela 3.9, juntamente com os resultados experimentais.

Vemos que obtemos um resultado bastante próximo do valor experimental tanbém para estas frequências, o que nos permite confiança nos parâmetros tanto para o átomo de Si quanto para o de O. Veremos mais adiante o teste para o centro-A em Si. 


\subsubsection{ZINDO/Cristal}

Para a parametrização do Si no ZINDO, usamos como conjunto de ajuste novamente o cristal de Si e as moléculas de silano e disilano, partindo sempre das geometrias estáveis como determinadas com o AM1/Cristal.

As propriedades sob exame agora são os potenciais de ionização, e caracteristicas da faixa de valência no caso do cristal; e transiçōes óticas, sempre obticlis conı correção de Interação de Configurações. No caso do cristal, nos restringimos au ajuste do "gap" fundamental.

O processo de parametrização foi idêntico ao AM1, partimos de uma célıla unitária com dois átomos e interação apenas entre primeiros vizinlıos, com isso uma primeira visão dos parâmetros já era obtida, e aumentamos pouco a pouco a complexidade do sistema (células maiores, maior vizinhança).

Os parâmetros que foram ajustados são: $\beta_{\mu}$, para o ajuste da largura da laixa de valência; integrais de dois elétrons para o ajuste da hibridização desejacla $s p^{3}$ (ajustando apenas os $\beta_{\mu}$, não foi suficiente para produzir a hibridização $s \mu^{3}$ ); e finalmente os fatores de interação para fornecer o caráter indireto do gap. ${ }^{1}$.

Na figura 3.1 apresentamos a estrutura de faixas do cristal de Si obtida com o método ZINDO/Cristal. Podemos constatar que as principais características (que julgamos necessária) para os estados eletrônicos do cristal de Si foram obtidos: topo da faixa de valência em $\Gamma$ e o fundo da faixa de condução na direção $\Gamma-X$ (obtendo assim gap indireto); as degenerescência ao longo das direçōes $\Gamma-X$ e $\Gamma-L$ estão corretas.

Como vemos (figura 3.1) a largura da faixa de valência esta acima do valor obtido por cálculos de LDA e do valor experimental. Poderíamos ter privilegiado a descrição da largura da faixa de valência mas teríamos perdido a caráter indireto do gap, e como estaremos interessados em descrever com o ZINDO/Cristal, as primeiras transições é de extrema necessidade que o método descreva o caráter indireto do gap. Por outro lado, os potenciais de ionização tão altos como o fundo da faixa de valência provavelmente não serão conseguidos sem o uso de relaxação orbital e interação de configurações.

Uma vez obtidas as características da faixa de valência, hibridização, e distribuição de carga além do caráter (indireto) do gap, sabemos que o cristal está bem descrito, e o espectro ótico deve ser obtido de outra forma.

\footnotetext{
${ }^{1}$ Tentamos a modificação de outros parânetros mas nenhuma modificaçào foi capaz de fornecel um gap indireto
} 


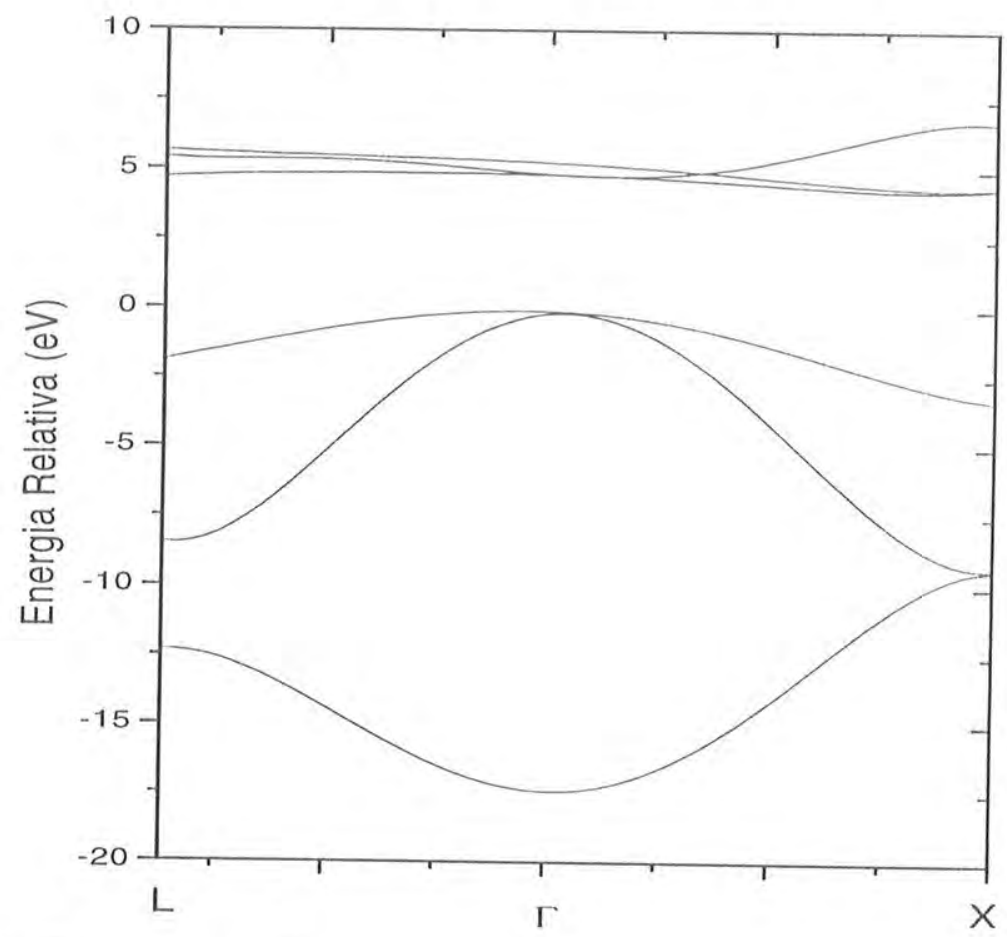

Figura 3.1: Estrutura de faixas do cristal de Si obtida com o ZINDO/Cristal na versão com periodicidade de Bloch. Notar a forma correta da degenerescência ao longo das linhas $\Gamma-X$ e $\Gamma-L$, e o caráter indireto do gap. 
Para estimarmos o valor absoluto do gap usamos três nanocristais ( 71 átomos, 86 átomos e 131 átomos, figuras 3.2, 3.3 e 3.4 ) e calculamos o espectro ótico.

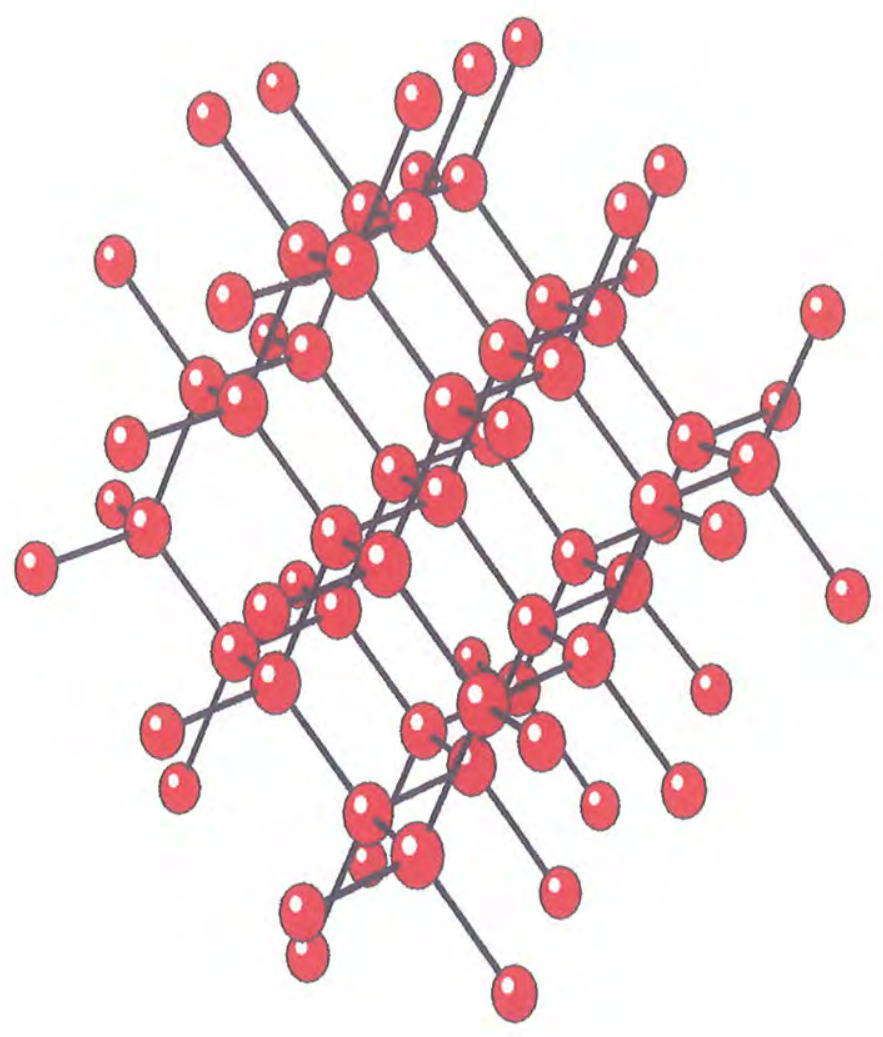

Figura 3.2: Nanocristal de 71 átomos $\left(S i_{35} \mathrm{p}\right.$-Si36) utilizado para representar o $\mathrm{Si}$ cristalino: p-Si são pseudoátomos de Si. 


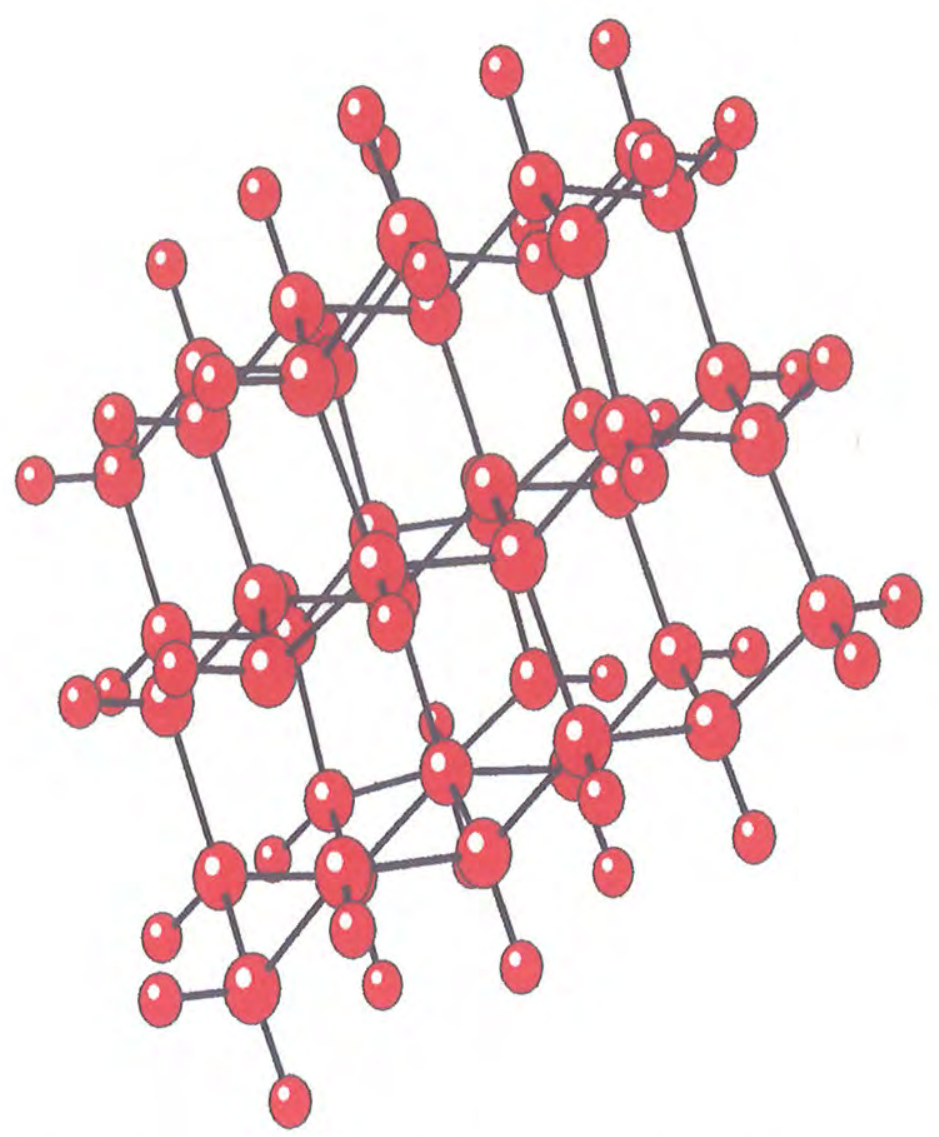

Figura 3.3: Nanocristal de 86 átomos $\left(S i_{44} \mathrm{p}-S i_{42}\right)$ utilizado para representar o $\mathrm{Si}$ cristalino. 


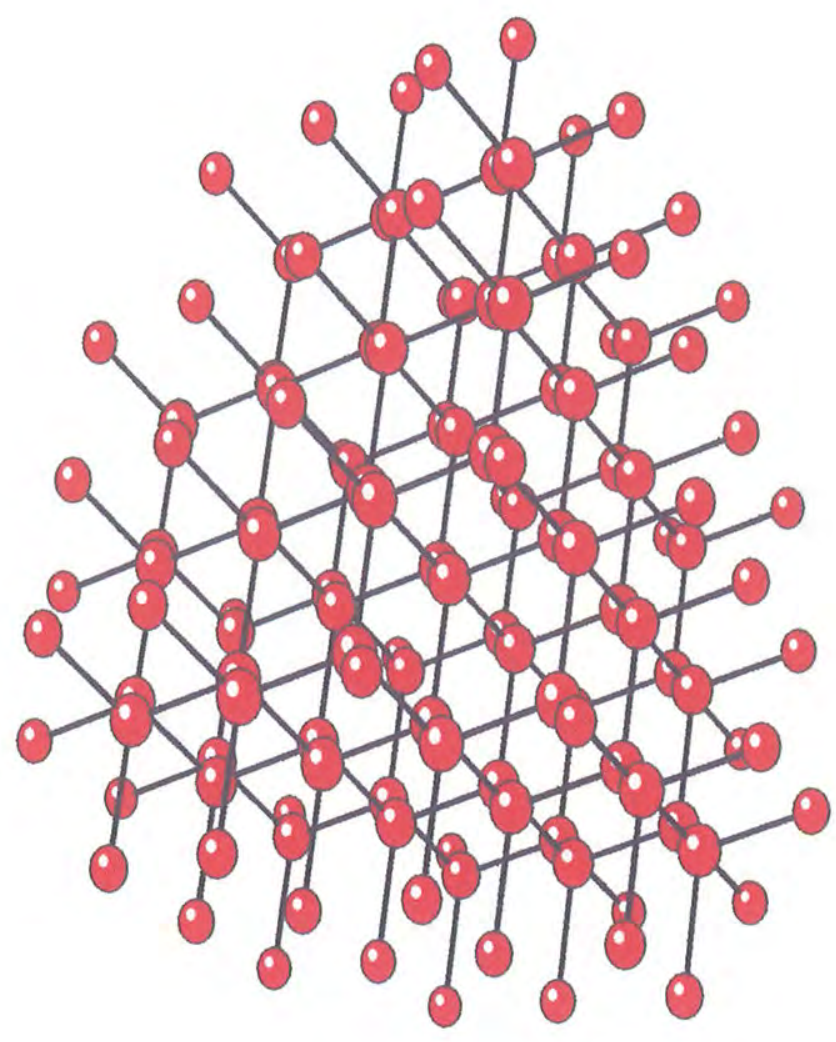

Figura 3.4: Nanocristal de 131 átomos $\left(S i_{71}\right.$ p-Si60) utilizado para representar o Si cristalino. 


\begin{tabular}{|c|c|c|c|}
\hline N. de átomos de Si & CI & orbital virtual & um-elétron \\
\hline 35Si 36pSi & 1.980 & 2.230 & 4.190 \\
\hline 44Si 42pSi & 1.891 & 2.126 & 3.940 \\
\hline 71Si 60pSi & 1.818 & 2.027 & 3.747 \\
\hline
\end{tabular}

Tabela 3.10: Valor do gap (eV) dos nanocristais utilizados para simular o cristal de Si.

O primeiro resultado importante é que a primeira transição ótica, para todos os nanocristais, corresponde a uma transição HOMO $\rightarrow$ LUMO pura. Analisando os MO's correspondentes, e comparando aos resultados para o ZINDO periódico, verificamos que o HOMO tem para todos os aglomerados, características (composição e "fase") do estado do topo da banda de valência em $\Gamma$; a análise do LUMO mostra. equivalência ao estado do fundo da faixa de condução (mínimo em $\mathrm{I}-\mathrm{X}$ ), ou seja, a primeira transição para nanocristais tem características de gap indireto.

Na tabela 3.10 apresentamos o valor do gap (primeira transição ótica) destes nanocristais, em termo do número de átomos de silício no nanocristal para os seguintes casos: (a) aproximação de um-elétron (nesse caso o gap é dado pela. diferença entre o HOMO e o LUMO), (b) com correção de orbital virtual (energias de configurações puras) e (c) fazendo uso do procedimento CI.

A partir do resultado da tabela 3.10 podemos constatar que os efeitos de mistura de configuração, para a primeira transição ótica de nanocristais, diminnem de maneira quase linear com o aumento do número de átomos no nanocristal, e que a correção de orbital virtual já é uma boa correção para o cálculo dos efeitos de correlação para essa primeira transição.

Graficamos na figura 3.5 o valor da primeira transição ótica, em termos do inverso do raio efetivo do nanocristal; fazendo a projeção para o cristal ( on seja, $\frac{1}{l}$ tendendo a zero) o resultado como podemos ver é muito próximo ao gap do Si (con regressão linear simples, obtivemos $\mathrm{Eg}=1.09 \mathrm{eV}$, note que não foi incluido o valor do gap experimental de $\mathrm{Eg}=1.14 \mathrm{eV}$, que melhoraria sensivelmente a qualidade do ajuste).

A partir destes resultados para o gap de um "nanocristal infinito" acr dilamos ter resolvido o problema da inclusão de correlação em $11 \mathrm{~m}$ método HF parı cristais. É claramente importante que os mesmos parâmetros que descrevem o cristal possam ainda descrever bem pequenas moléculas, como silano e disilano. 


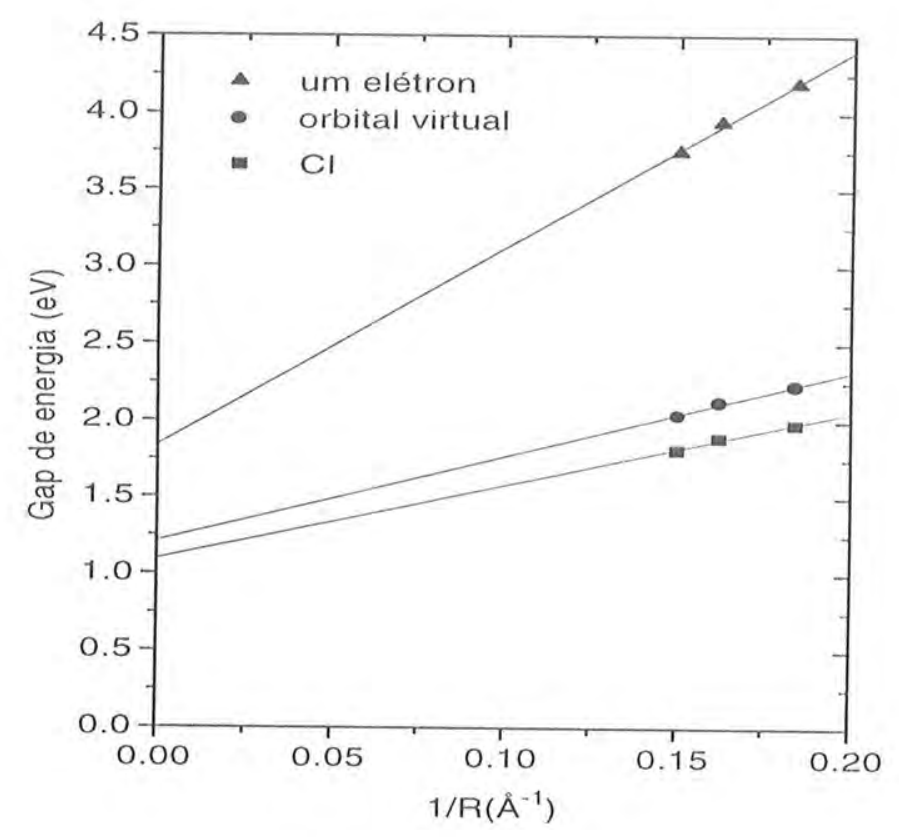

Figura 3.5: Valor da primeira transição ótica para nanocristais de Si em termos de $\frac{1}{R}$ ( R é um comprimento característico, dado pela distância do átomo de Si mais afastado do centro do nanocristal) e a projeção para o cristal infinito $\left(\frac{1}{R}=0\right)$. 


\begin{tabular}{|c|c|c|c|}
\hline $\mathrm{Si}_{2} \mathrm{H}_{4}$ & ZINDO & ZINDO/Cristal & Exp. [68] \\
\hline IP & 13.96 & 13.56 & 12.36 \\
\hline
\end{tabular}

Tabela 3.11: Potenciais de ionizaçâo para o siluno

\begin{tabular}{|c|c|c|c|}
\hline $\mathrm{Si}_{2} \mathrm{H}_{6}$ & ZINDO & ZINDO/Cristal & Exp.[68][67] \\
\hline $1^{\underline{a}} E_{\nu}$ & 8.35 & 7.67 & 7.78 \\
\hline $2^{\underline{a}} E_{\nu}$ & 9.23 & 8.54 & 8.39 \\
\hline \hline $1^{\underline{0}} \mathrm{IP}$ & 11.49 & 11.16 & 10.53 \\
\hline $2^{\underline{\underline{0}}} \mathrm{IP}$ & 12.00 & 12.94 & 12.0 \\
\hline $3^{\underline{\underline{\theta}}} \mathrm{IP}$ & 14.65 & 14.36 & 12.9 \\
\hline
\end{tabular}

Tabela 3.12: Potenciais de ionização (IP) e absorções óticas $\left(E_{\nu^{\prime}}\right)$ do disilano

Para o silano as primeiras transições óticas envolvem principalmente estados de Rydberg, que não estão contidos no nosso cálculo, assim apresentamos apenas () potencial de ionização (tabela 3.11).

Apresentamos na tabela 3.12 os resultados para os potenciais de ionização (IP) e as energias de transição (espectro de absorção ótica), para o disilano, novamente excluindo as transiçõs com alto caráter de estados de Rydberg.

Estes resultados mostram que as moléculas de silano e disilano também estão bem descritas com o método e os devidos parâmetros, passando agora aos parâmetros para o átomo de oxigênio, usamos o cristal de $\alpha$-quartzo e a molécula de disiloxano (cuja geometria estável foi determinada pelo AM1/Cristal). O átomo de () intersticial em Si não tem atividade ótica detectada.

A modificação para os parâmetros do átomo de O seguiram as mesmas estratégias que para o átomo de Si, e os parâmetros finais estão também no apendice B.

Para representar o cristal de quartzo usamos nanocristais com 69 átonos (figura 3.6) e com 102 átomos (figura 3.7).

Na figura 3.8 apresentamos o resultado do gap destes nanocristais, extrapolando para o cristal ("nanocristal infinito"); obtivemos um valor para o gap do $\alpha$-quart.zo muito próximo ao valor experimental (erro de $\sim 5 \%$ ). 


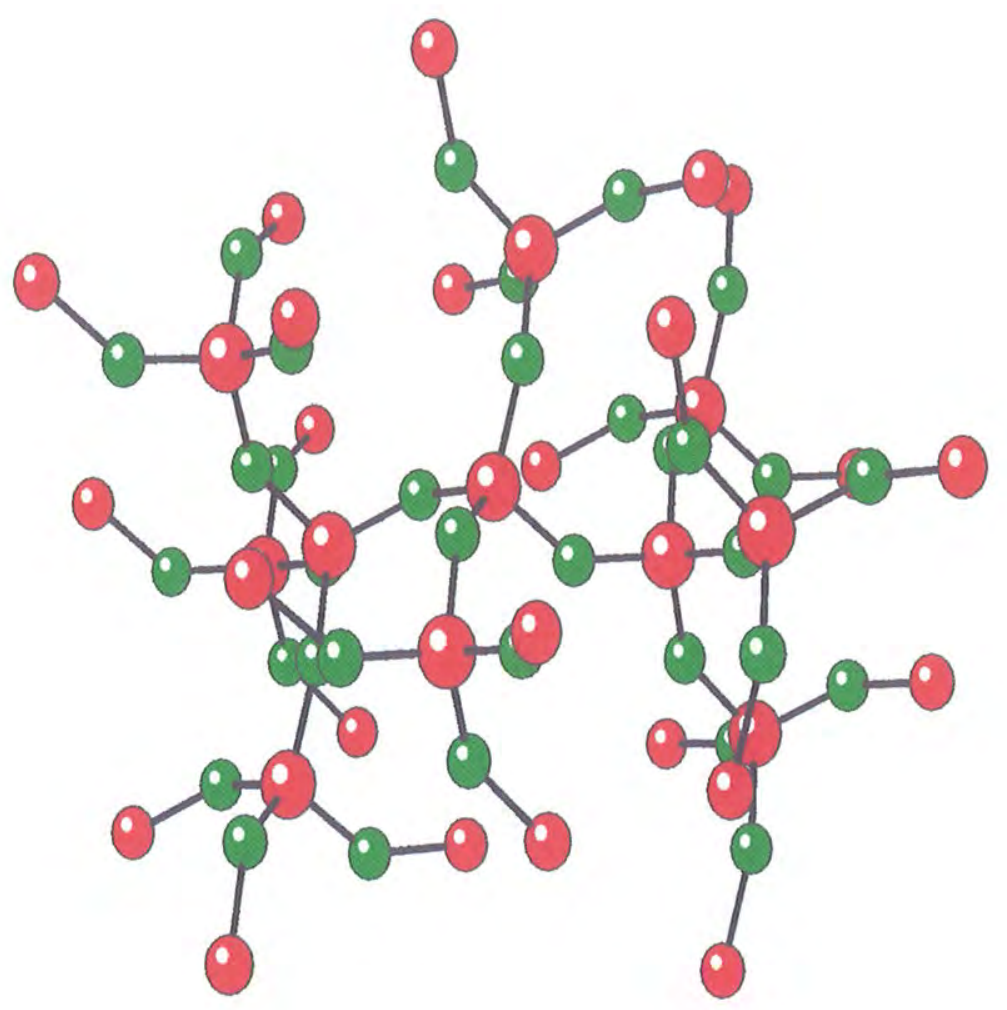

Figura 3.6: Nanocristal de 69 átomos $\left(S i_{11} O_{34} p-S i_{24}\right)$ utilizado para representar o cristal de $\alpha$-quartzo. 


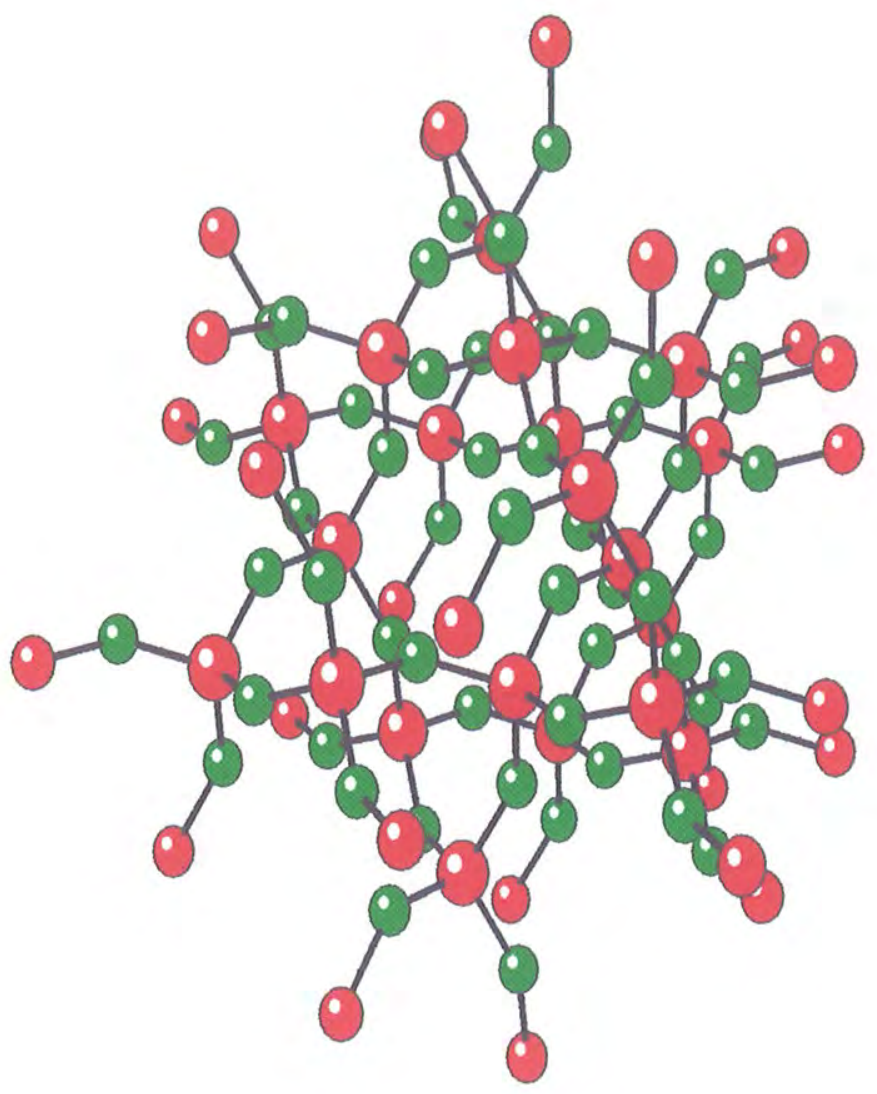

Figura 3.7: Nanocristal de 102 átomos $\left(S i_{20} O_{54} \mathrm{p}-S i_{28}\right)$ utilizado para representar o cristal de $\alpha$-quartzo. 


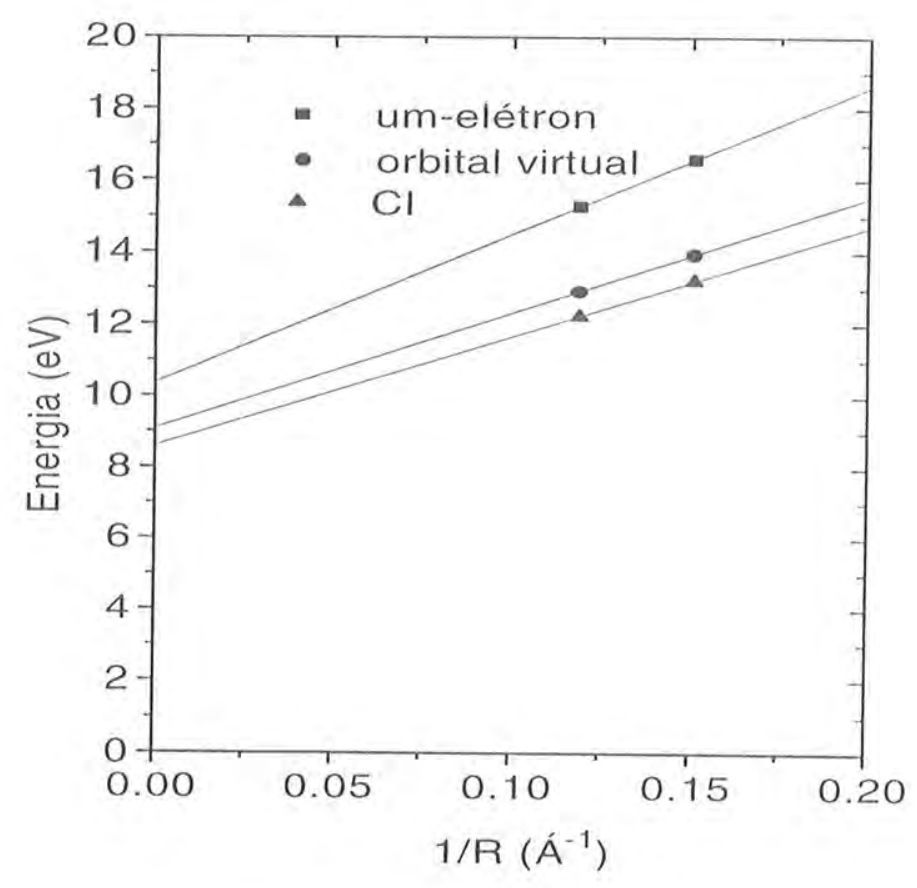

Figura 3.8: Primeira transição ótica dos nanocristais usados para representar o cristal de quartzo, em termos do inverso do raio do nanocristal, e a projeção para o cristal $\left(\frac{1}{R}=0\right)$

Os parâmetros obtidos no "ambiente cristalino" são sempre conferidos nos resultados para pequenas moléculas, calculando os potenciais de ionização e as transiçôes óticas das moléculas de disiloxano e aqui apresentamos tabém o resultado para a. molécula de água (para a água calculamos apenas os potenciais de ionização pois as primeiras transições óticas envolvem estados de Rydberg). Os resultados (ividos estão apresentados nas tabelas 3.13 a 3.14 , junto com os valores experimentais. 


\begin{tabular}{|c|c|c|c|}
\hline $\mathrm{OSi}_{2} \mathrm{H}_{6}$ & ZINDO & ZINDO/Cristal & Exp. [64] \\
\hline 11 IP & 14.76 & 11.39 & 11.19 \\
\hline $2^{-1}$ IP & 14.89 & 11.76 & 11.37 \\
\hline $3^{(1)} \mathrm{IP}$ & 16.96 & 12.83 & 12.42 \\
\hline $4^{(1}$ IP & 20.62 & 13.20 & 12.70 \\
\hline $1^{11} E_{\nu}$ & 6.42 & 7.79 & 7.90 \\
\hline $2^{0} E_{\nu}$ & 7.10 & 8.16 & 8.27 \\
\hline $3^{0} E_{1}$ & 7.86 & 9.68 & 8.92 \\
\hline $4^{\underline{0}} E_{\nu}$ & 9.73 & 10.01 & 9.54 \\
\hline
\end{tabular}

Tabela 3.13: Potenciais de ionizaçäo (IP) e energias de transiçôes óticas ( $E_{\nu}$ ) du molécula de disiloxano.

\begin{tabular}{|c|c|c|c|}
\hline IP & ZINDO & ZINDO/Cristal & Exp.[64] \\
\hline $1^{\text {II }}$ & 12.55 & 14.20 & 12.62 \\
\hline $2^{\text {ㅁ }}$ & 13.88 & 15.28 & 14.75 \\
\hline $3^{\underline{\underline{y}}}$ & 18.65 & 20.33 & 18.54 \\
\hline
\end{tabular}

Tabela 3.14: Potenciais de Ionização (IP) da molécula de $\mathrm{H}_{2} \mathrm{O}$.

Vemos que no caso do disiloxano nossos resultados são indiscutivelmente melhores que os do ZINDO original. Essa grande diferença vem dos parâmetros para o átomo de $\mathrm{Si}$, pois inclusive é impossível começar o cálculo do cristal infinito com os parâmetros originais: há uma inversão do fundo da banda de condução e topo da banda de valência que impede a convergência do cálculo, com qualquer número de vizinhanças.

Novamente o caso da molécula de água é problemático, mas da mesma maneira como foi feito no AM1/Cristal no ZINDO/Cristal decidimos não modificar os parâmetros do átomo de $\mathrm{H}$.

Uma compilação de todos os parâmetros, tanto da aproxiamção AM1/Cristal com ZINDO/Cristal se encontra no apêndice $\mathbf{B}$.

Como teste dos procedimentos propostos e das parametrizações AM1/Cristal e ZINDO/Cristal, escolhemos dois exemplos: para teste a um tempo r levante para aplicação que pretendemos; bem conhecidas na literatura especializida, bem caracterizadas experimentalmente, e bastante diferentes das utilizadas para ajuste de parâmetros. 


\subsection{Centro-A em Silício}

É amplamente conhecido que impurezas de oxigênio em silício produzem um grand. numero de defeitos complexos (veja, por exemplo, a recente revisão de Pajot $\mid 69) \mid$ ). A forma preferencial de incorporação é intersticial entre dois átomos de Si formando uma configuração Si-O-Si, muito similar àquela encontrada em Si $\mathrm{O}_{2}[70,7 \mathrm{I}]$.

Entretanto, em 1961 Watkins e Corbett[72] e Corbett e colaboradores [73] identificaram experimentalmente um nível aceitador em Si a $0.17 \mathrm{eV}$ do fundo da banda de condução, que associaram a um defeito complexo em Si em que uma vacância da rede do Si captura um átomo de $\mathrm{O}$ (formação do par $\mathrm{V}+\mathrm{O}$ ). Este tipo de defeito é costumeiramente conhecido como centro-A em Si.

Esta configuração do par $\mathrm{V}+\mathrm{O}$ foi inferida por experimentos de Ressonancia Paramagnética Eletrônica (EPR)[74]. Os sinais de EPR implican que em amostras de Si crescidas em um ambiente rico em oxigênio há um elétron desemparelhado. cuja origem devia ser explicada. A investigação da influência sobre o nível de l'ernit indicava que esse tipo de defeito era um nível aceitador e foi atribuido à captura do elétron pelo par $\mathrm{V}+\mathrm{O}[74]$.

Resultados posteriores obtidos por Brower também por EPR[75] revelaram que quando amostras de Si ricas em O sofrem efeito de radiação, de energia da ordem do gap do Si $(\sim 1 \mathrm{eV})$ um novo estado de carga com spin inteiro $(S=1)$ aparece, ainda associado ao centro-A.

A análise dos dados de EPR realizada já no trabalho original de Wat.kins e Corbett[72] sugere um modelo microscópico em que o elétron desemparelhado é capturado pela ligação entre dois átomos de Si em torno da vacância (figura 3.9).

Investigações de Caldas e colaboradores[76] com o método de espalhamento múltiplo- $X_{\alpha}$, mostraram que o oxigênio substitucional ao silício (sem relaxação da rede) na posição tetraédrica introduz dois níveis de defeito no gap: 1 m nivel $a_{1}$ ocupado; e um nível $t_{2}$ desocupado e ligeiramente abaixo do fundo da banda de condução do Si, caracterizando o defeito como aceitador. Os autores mostram ainda, que ao capturar $u m$ elétron extra, o nível $t_{2}$ estará parcialmente ocupado, e sendo tridegenerado, forçará o sistema a sofrer uma distorção do tipo Jahn-Teller (JT).

O método de espalhamento múltiplo não permite cálculos de geometria ciitretanto a inferência é que no caso do sistema sofrer uma distorção JT, o ái omo de oxigênio poderá ser forçado para fora do sítio substitucional e formar uma ligação com dois átomos de Si, e os dois átomos de Si restantes da ligação tetraédrica com o O relaxarão para formar uma ligação covalente. A simetria é compatível como 
efeito JT.

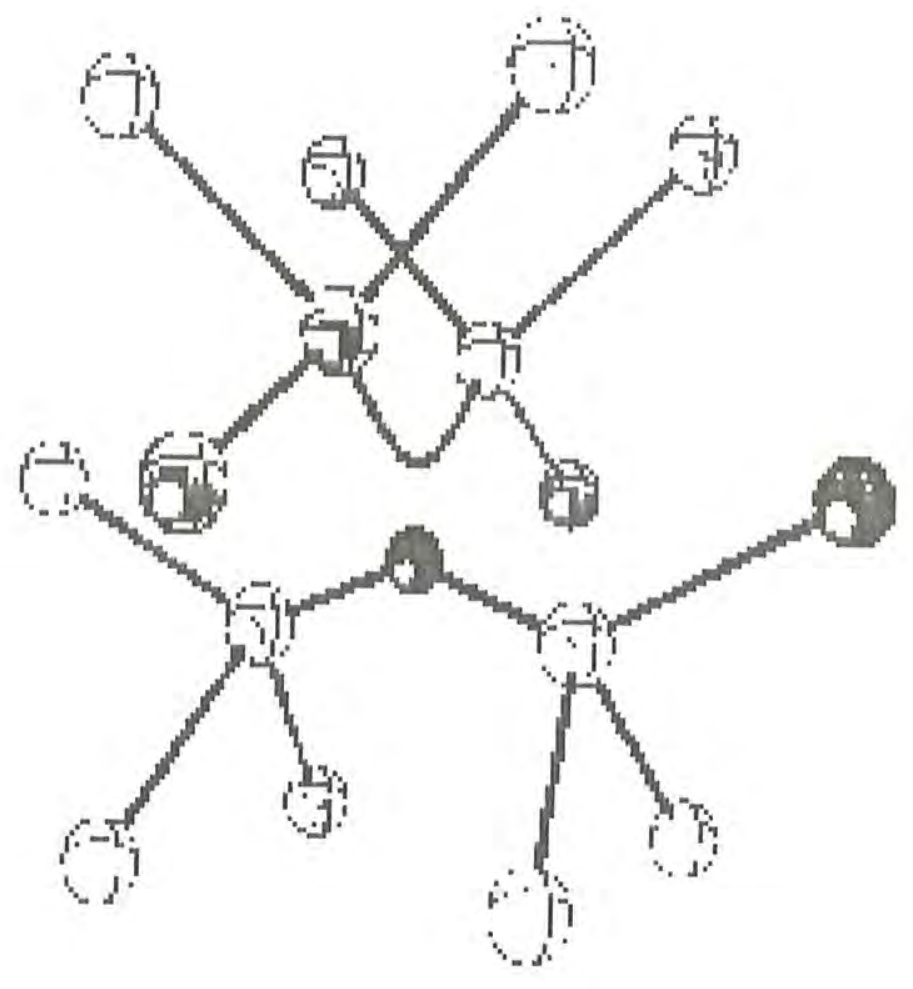

Figura 3.9: Representação esquemática da região do cluster que foi otimizada com a presença do defeito (da Ref.[66]).

Em estudo posterior de DeLeo e colaboradores[77], usando o método semiempírico MNDO concluem que de fato, ao contrário da maior parte das impurezas calcogêneas substitucionais em $\mathrm{Si}$, o O não ocupa o sítio tetraédrico e sim relaxa na direção $<100>$, reduzindo a simetria pontual para $C_{2 v}$ (Note-se que no caso do defeito neutro haveria distorção, devido a um efeito pseudo-Jahn-Teller).

Resultados de Ortega-Blake e colaboradores[78] com um método HF ab initio confirmam o carácter distorcido da impureza substitucional de O em Si. Os cut.ores mostram que o O se desloca de $0.9 \AA$ na direção $<100>$ para formar uma ligação Si-O-Si, com distâncias Si-O de $1.82 \AA$. O outro par de átomos de Si forma una nova ligação covalente, onde é acomodado o elétron extra. 
Como podemos perceber este defeito é bem caracterizado, tanto do ponto de vista experimental como teórico, assim, poderá servir de teste para o nosso método. Vejamos a seguir os resultados obtidos para este defeito.

Para estudar a geometria do centro A usamos o modelo dos nanocristais com 71 átomos, substituindo o átomo central por um átomo de O. Usamos relaxação de primeiros $(\mathrm{O}+4 \mathrm{Si})$ e segundos $(12 \mathrm{Si})$ vizinhos (Note que neste nanocristal já temos terceiros vizinhos pseudo-Si, o que inviabiliza relaxações para vizinhos de mais alta ordem). Uma representação da parte central do aglomerado (17 átomos) está esquematizado na figura 3.9.

A geometria final encontrada apresentou a simetria $C_{2 v}$, (figura 3.10 (b)) com um ganho em energia de $\sim 2 \mathrm{eV}$ em relação á simetria tetraédrica (figura 3.10 (a)).
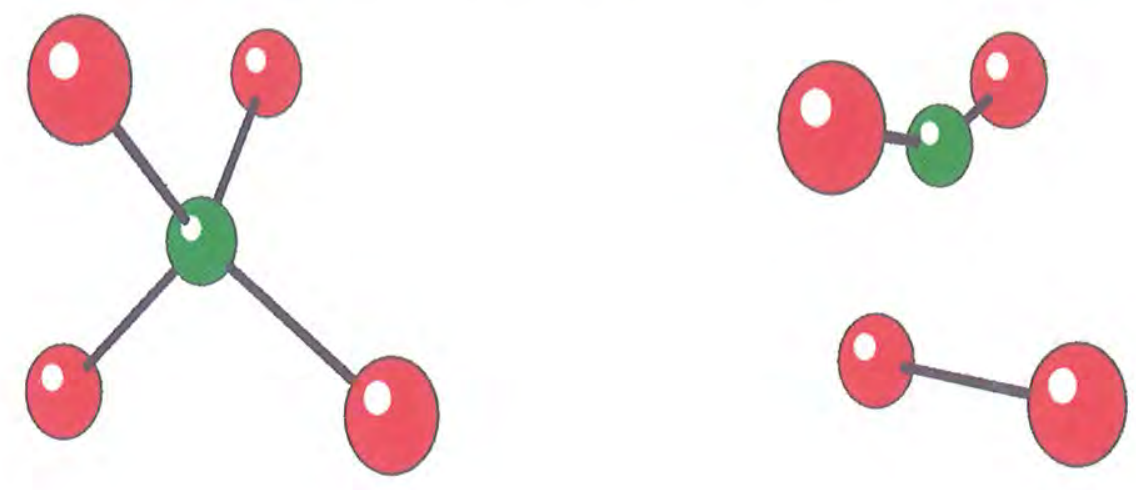

Figura 3.10: representação do oxigênio substitucional em Si: (a) simetria tetraédrica e (b) simetria $C_{2 V}$.

Para investigar uma possível influência do saturador sobre o defeito, utilizamos o nanocristal de 131 átomos (agora todos os terceiros vizinhos são átomos de $\mathrm{Si}$ ), e não detetamos diferença na distribuição de carga da região central, concluindo assim que relaxação de vizinhos de mais alta ordem seria desnecessária.

Comparamos os resultados de geometria obtidos com o nosso método, com a geometria obtida por Ortega-Blake, na tabela 3.15, onde apresentamos os resultados para o deslocamento do átomo de $\mathrm{O}$ e a distância de ligação Si-O. Vemos que mantendo a mesma distância Si-O, nossos resultados indicam menos deslocamento 


\begin{tabular}{|c|c|c|}
\hline método & Dist. (Si-O) & Dist. do O ao centro \\
\hline HF ab initio [78] & 1.82 & 0.90 \\
\hline AM1/Cristal & 1.81 & 0.46 \\
\hline
\end{tabular}

Tabela 3.15: Resultados para a geometria do par $(\mathrm{V}+\mathrm{O})$

do átomo central: isto porque há um movimento acoplado dos átomos de Sii, (juc: se aproximam.

Passamos agora à análise do comportamento elétrico do centro. Com a geometria final calculamos com o ZINDO/Cristal a densidade de estados (DOS) do centro neutro (par $\mathrm{V}+\mathrm{O}$ ), o resultado está apresentado na figura 3.11. Notamos que esses resultados são ainda de partícula independente, e portanto não temos a definição quantitativa do gap. Entretanto, é claro o aparecimento dos níveis de: defeito $a_{1}$ (ocupado por 2 elétrons) e a trinca $b_{1}, b_{2}, a_{1}$ originários do nível $l_{2}$. () nível $b_{1}$ está abaixo do nível determinante do gap de um-elétron do nanocristal, o antigo LUMO.

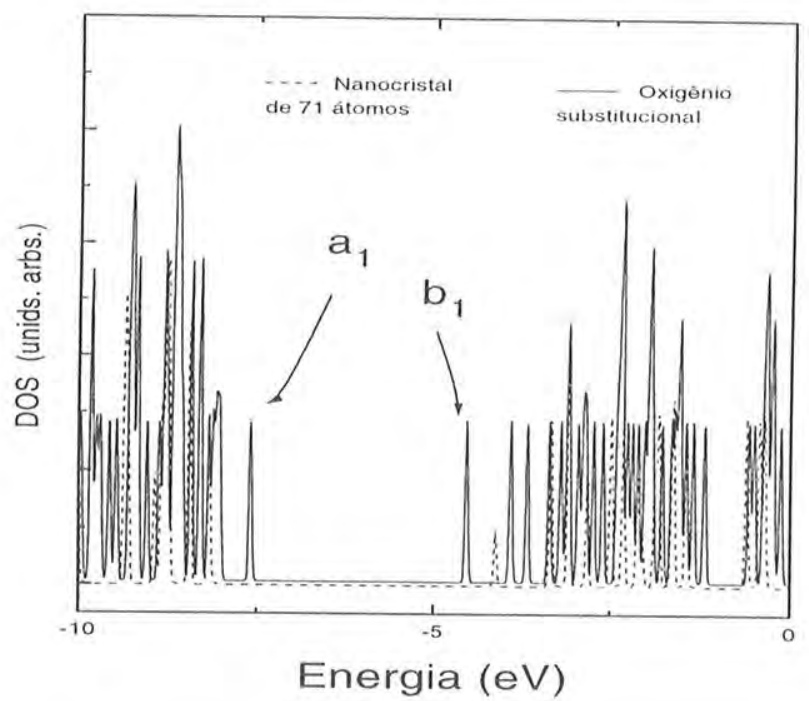

Figura 3.11: Densidade de estados (DOS) do nanocristal de 71 átomos (região próxima ao gap) que simula o centro-A em Si.

Com o objetivo de investigar a origem do sinal detetado por Brower[75], cal- 
culamos usando o ZINDO/Cristal com correção CI a energia total dos primeiros estados singletos e tripletos ${ }^{2}$. A geometria é agnela do mínimo obtida conir a AM1/Cristal. Nosso resultados indicam que o primeiro estado tripleto aparece. a $\sim 0.7 \mathrm{eV}$ acima do estado fundamental (singleto), confirmando a hipótese de Brower.

Para investigarmos o estado aceitador deste defeito, introduzimos $11 m$ elétron extra no sistema, e procedemos a nova otimização da geometria (AMl/Gristal). Analisando a distribuição de carga verifica-se que há acumulo principalmente sol)re os dois átomos de Si vizinhos, porém não ligados ao $\mathrm{O}$, que tiveran suas cargis consideravelmente aumentadas (cada átomo de Si ganhou cerca de 0.3e em relaçâo ao centro neutro). Essa grande concentração é característica de defeitos com níveis profundos e é representada na figura 3.12, onde graficamos a densidade de carga dos orbitais de defeito: $a_{1}$ (ocupado, dois elétrons) e $b_{1}$ (parcialmente ocuparlo, 1 elétron) nos diversos átomos do nanocristal. Esse esquema é obtido projetando a densidade de carga do $\mathrm{MO}$ em questão sobre todos os átomos de uma camada. do nanocristal (mesma distância ao centro), e dividindo pelo número de átomos que compõem a camada; em seguida para visualização, utilizamos funçōes do tipo gaussianas "pesadas" por essa "carga por átomo" na camada. Não há separaçuo em "carga por orbital atômico", ou seja, contribuições $s$ ou $p$.

Costatamos que os estados de defeito $\left(a_{1}\right.$ e $\left.b_{1}\right)$ são fortemente concentrados sobre os dois átomos de Si que formam a fraca ligação covalente, pouca carga sobre os outros 3 átomos que constituem o núcleo do defeito, e praticamente nenhuma carga sobre os demais átomos.

Para uma análise mais fina, mostramos na tabela 3.16 a comparação da localização da função de onda estimada dos dados de ressonância magnética por Watkins e Corbett[72], e a localização obtida aqui para o orbital $b_{1}$ ocupado por 1 elétron. Lembramos que na análise dos dados experimentais entram suposições simplificativas, como por exemplo é feita a restrição de que, sempre, as contribuições $s$ e $p$ de cada átomo ( $\alpha$ e $\beta$ ) são normalizadas a $1\left(\alpha^{2}+\beta^{2}=1\right)$, en cada átomo, o que claramente não é necessário e nem é o caso aqui, onde a situação de normalização é feita para o total das contribuiçôes de todos os átomos. De qualquer maneirra, a análise realmente quantitativa é muito difícil mesmo para cálculos ab initio[79] e assim comparamos a contribuição total de cada átomo. Notamos que o resultado experimental principal é que praticamente $70 \%$ da função de onda de defeito está

\footnotetext{
${ }^{2}$ Neste caso utilizamos excitaçóes simples e duplas pois, de acordo com o teorema de Brilloniu apenas excitaçòes simples nào afetam a energia do estado fundannental
} 


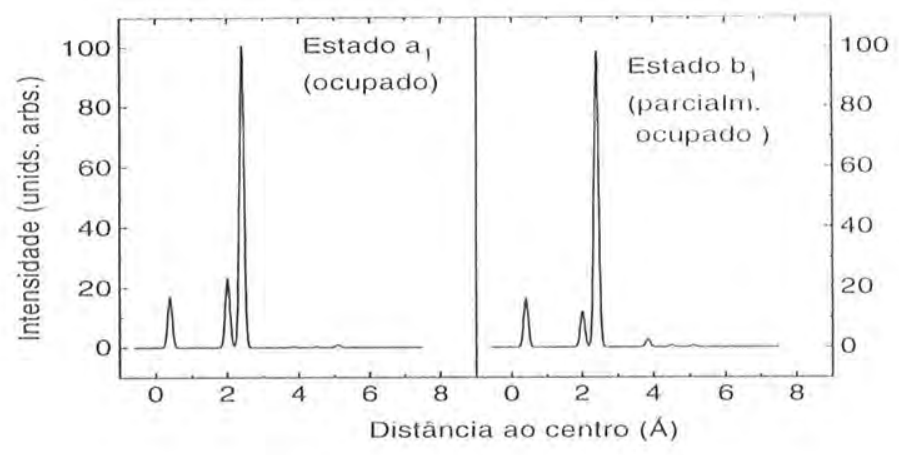

Figura 3.12: Localização dos níveis de defeito do centro-A em Si nas diferentes camadas do cluster utilizado para simular o defeito.

localizada sobre (ou na ligação entre) os dois átomos de Si que se ligam entre si, c muito pouco vai para a outra região do defeito. Nossos resultados mostram uma concordância notável com a análise experimental.

\begin{tabular}{|c|c|c|c|}
\hline Átomo & Classe & Exp.[72] & AM1/Cristal \\
\hline $\mathrm{O}$ & 1 & - & $0.06\left(p_{z}\right)$ \\
\hline $\mathrm{Si}$ & 2 & 0.355 & 0.364 \\
\hline $\mathrm{Si}$ & 2 & 0.049 & 0.029 \\
\hline $\mathrm{Si}$ & 2 & 0.034 & $0.004^{(a)}$ \\
\hline $\mathrm{Si}$ & 4 & 0.022 & 0.020 \\
\hline
\end{tabular}

Tabela 3.16: Comparação entre a localização da função de onda de defeito do centro-A em Si, estimada de dados de EPR, e obtida neste trabalho. A primeira coluna diz o elemento atômico, a segunda a classe de equivalência (quantos átomos equivalentes).

(a) este já é um pseudo-átomo, assim o resultado não é tão confiável.

Em resumo, nossos cálculos reproduzem todas as características do centro-A em Si, com boa precisão. É importante frisar que o ambiente do núcleo de defeito é bastante diferente de todos os sistemas utilizados para ajuste de parâmetros, e envolve situações "traumáticas" com quebra de ligações cristalinas e reconstrução de ligações em simetria mais baixa que a original; com rearranjo de carga considerável, 
inclusive com ionização negativa do nanocristal, sem nenhuma interferência com as condições de contorno (parâmetros dos pseudo átomos) quando dì introduçầ) do defeito, ou sua ionização.

Esses resultados nos permitem passar ao estudo de sistemas controversos, como é o caso das partículas de Si oxi-hidrogenadas que discutiremos nos próximos capítulos. 
Capítulo 4

\section{Propriedades de Nanopartículas de Si Hidrogenadas}




\subsection{Introdução}

Como foi apresentado na capítulo 1, o po-Si é um material complexo, desordenado, extremamente suscetível ao processo de preparação. O que existe de consenso 6 a parte ativa do material ser formada por estruturas de baixa dimensionalidade. mas que mantém a cristalinidade (fios quânticos ou cristalitos), e o debate sobre a dimensionalidade (1D ou OD) tende a reforçar a hipótese de cristalitos, e não d. fios.

No que se segue, adotaremos então o ponto de vista de que as estruturas óticamente ativas podem ser associadas a um diâmetro efetivo, relacionado a regiōes aproximadamente esféricas, com um núcleo cristalino $[80,81,25,27,19]$.

Para que possamos discutir as propriedades óticas, absorção e luminescência. do po-Si é interessante (se não necessário) adotarmos um modelo de referência mais adequado ao estudo teórico, e escolhemos aqui estudar nanopartículas de Si hidrogenadas. Tal sistema já foi realizado experimentalmente (ver artigo de revisão de Kanemitsu[82] e referências ali contidas) na forma de filmes compostos por nanopartículas obtidas por decomposição de gás de silano, seja por plasma de: microondas seja por luz laser. Com esse modelo de referência pode-se estıdar, em particular, a dependência da absorção ótica e das propriedades de lıminescência com o tamanho dos nanocristalitos.

Em geral, as inferências relatadas abaixo, extraidas da análise de po-Si, são confirmadas pelos resultados obtidos para filmes de partículas de Si-H. Voltaremos a esses materiais ao discutirmos os resultados para partículas oxi-hidrogenadas.

Na figura 4.1 apresentamos os resultados de Kanemitsu e colaboradores (83) para a absorção ótica e a fotoluminescência (PL) de três amostras de po-Si com diferentes diâmetros de cristalitos. Os diâmetros são inferidos de mediadas de epectroscopia Raman e microscopia eletrônica de transmissão (TEM). Nota-se o forte deslocamento para o azul do espectro de absorção, quando da diminuição do diâmetro efetivo, indicando claramente efeitos de confinamento quântico. (O) deslocamento para o azul, devido a efeitos de confinamento quântico, do espectro de absorção ótica de nanocristalitos de semicondutores é conhecido[84, 85, 86]).

A figura 4.1 apresenta também o espectro de PL para os mesmos filmes de po-Si com diferentes tamanho de nanocristalitos. O aspecto mais relevante desses resultados é que não se observa nenhuma dependência significativa dos espectros de PL com o tamanho médio dos nanocristalitos. Também Lockwood e colaboradores[87] sustentam que o comprimento de onda do pico de luminescência não apresentia nenhuma correlação com o diâmetro das partículas de Si. Inclusive em filmes de po-Si 


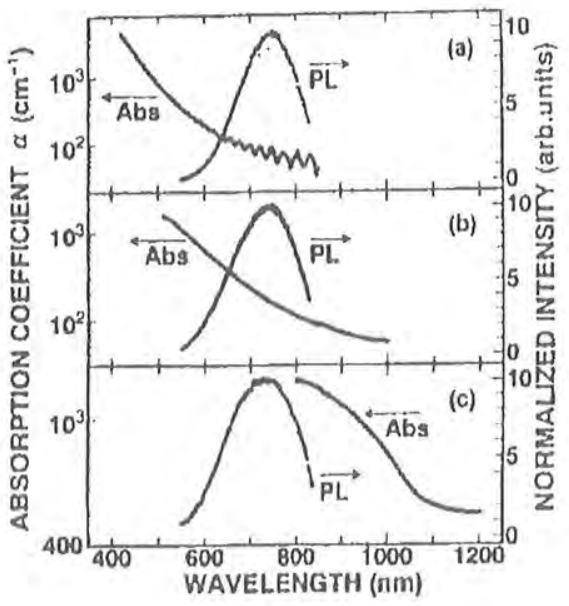

Figura 4.1: Espectros típicos de absorção ótica (Abs) e de fotoluminescência (PI.) de filmes de po-Si a temperatura ambiente. (a) $\mathrm{L} \sim 2 \mathrm{~nm}$, (b) $\mathrm{L} \sim 3.5 \mathrm{~nm}$, e (c) $\mathrm{L} \sim 9 \mathrm{~nm}$. O diâmetro efetivo $(\mathrm{L})$ é determinado a partir de espectroscopias Raman e TEM. Nota-se a cauda exponencial da absorção. Não se observa qualquer dependência significativa com o diâmetro no espectro de PL. (da Ref.[83]).

com cristalitos grandes, aparece uma relação não usual entre espectro de absorção e o de PL: A energia do pico PL é maior que a energia do limiar de absorção (como pode ser visto na figura 4.1 (c)).

Em amostras de po-Si com cristalitos de grande diâmetro, o espectro de fotoexcitação da luminescência (PLE) difere inteiramente do espectro de absorção. A forma do espectro de PLE em po-Si com partículas de diâmetro 9nm (figura 4.I (c)) é similar ao espectro de absorção apresentado pela amostra de cristialitos com diâmetro $\sim 3 \mathrm{~nm}$ (figura 4.1 (b)) da referência[83].

Ora, estudos de TEM[83] indicam que em uma amostra típica de po-Si existem partículas de vários tamanhos. Isto sugere que somente cristalitos com pequeno diâmetro contribuem para a luminescência visível do po-Si.

Este pequeno diâmetro para os cristalitos responsáveis pela forte luminescência do po-Si, foi também sugerido pelas medidas de Schuppler e colaboradores [88]. Os autores propõem que o diâmetro médio dos cristalitos envolvidos na luminescência vermelho-laranja é menor que $15 \AA$.

Outra interpretação para as características apresentadas pela PL, e o desloca- 
mento para o azul do espectro de absorção, é a de que o sítio para a geração de fótons é diferente do sítio onde ocorre a recombinação radiativa dos portadores $|8: 2|$.

Existem numerosos trabalhos teóricos em pequenas partículas de Si (cristalitos) $[89,29,80,27,22,81,28]$ com métodos diversos que vão desde hamiltonianas light binding, até métodos de psendopotenciais semiempíricos. A energia do pico Pl. em amostras de pequeno diâmetro (veja a figura 4.1(a) e (b)) é muito menor que o gup obtido através de cálculos teóricos[81, 27, 25, 80, 90].

A complexidade do problema impede que sejam utilizados métodos ab-initio a não ser para partículas muito pequenas ( 30 átomos). Em geral os estudos não levam em conta a relaxação de geometria, e os cálculos são feitos ou para cristalitos ideais[24, 80] ou para geometrias "estimadas" a partir de dados experimentais para as superfícies hidrogenadas extensas[81], e um cálculo em particular[19| para uma situação criada ad-hoc (um defeito superficial) sem qualquer justificattiva fundamental. Na quase totalidade, não levam em conta o efeito de relaxação para o estado excitado. O único trabalho, que temos conhecimento, que incluiu efeitos de relaxação da estrutura no estado excitado, é o trabalho de Kumar e colaboradores[27]. Os autores usam uma técnica semiempírica (PM3), que é apropriada para a geometria molecular, porém desaconselhável para a ótica. Os autores obtiveram um Stokes shift de $0.58 \mathrm{eV}$ para uma partícula com 10 átomos de Sí. Embora este Stokes shift seja alto não é suficiente para explicar a diferença entre a absorção e a luminescência no po-Si.

Outro efeito muito importante e que deve ser incluido (como vimos nos capítulos precedentes é de relevância fundamental), são os efeitos de correlação. A maior parte dos métodos ignora estes efeitos, já os cálculos dentro da LDA incluem de forma não separável e com os conhecidos problemas para a obtenção do gap.

Assim, nos dispuzemos a fazer um estudo minucioso do espectro de absorçĩo e de emissão ótica de pequenas partículas de Si hidrogenadas. Os resultados obtidos serão apresentados neste capítulo.

Simulamos as nanopartículas por aglomerados de átomos de Si na coordenação tetaédrica, com os dangling bonds da superfície saturados por átomos de hidrogênio. Para clareza da análise dos resultados construimos partículas de alta simetria, porém investigamos simetrias diferentes (ver figuras 4.2 e 4.3). Assim, estudamos partículas em simetria $T_{d}$, centradas em $u$ átomo ( $S i_{5} H_{12}, S i_{17} H_{36}, S i_{29} H_{36}$, $\left.S i_{35} H_{36}, S i_{71} H_{60}\right)$ e centradas no interstício tetraédrico $\left(S i_{10} H_{16}\right)$;partículas em simetria $D_{3 d}$ centradas no meio de uma ligação $\left(S i_{26} H_{30}, S i_{44} H_{42}\right)$. 
Nosso conjunto de ajuste incluiu ligações Si-H somente cm sistemas muito pequenos $\left(\mathrm{SiH}_{4}\right.$ e $\left.\mathrm{SiH}_{6}\right)$ portanto antes de comentar nossos resultados para ats nanopartículas discutimos a superfície de Si hidrogenada. Escolhemos a superlícic $<111>$, que simulamos através de aglomerados especiais: construimos uma lastra ("slab") de $\mathrm{Si}-<111>$ com duas bicamadas, sendo uma das faces da lastra - a superfície- saturada por átomos de H, e a face oposta e as laterais saturadats por pseudoátomos de $\mathrm{Si}$, simulando a ligação com o resto do cristal. Utilizamos dois destes nanocristais de superfície, com $50\left(\mathrm{p}-\mathrm{Si}_{21} \mathrm{Si}_{22} \mathrm{H}_{7}\right)$ e 134 átomos (p$\left.\mathrm{Si}_{45} \mathrm{Si}_{70} \mathrm{H}_{19}\right)$ como representado na figuras 4.4. A otimização de geometria neste caso também é especial, pois impomos condições de simetria de modo a impedir que a superfície fique abaulada (concava on convexa) por efeito da finitude do aglomerado.

Do ponto de vista experimental, essa superfície é muito ben caracterizadia. Higashi e colaboradores [91] em 1990 demonstraram que superfície Si-< III > ideal passivada por $H$, pode ser obtida por tratamento em ácido fluorídrico com elevada concentração de PH e mostra reconstrução 1X1. Desde então $u$ grande número de trabalhos experimentais $[92,93]$ foram efetudos.

A superfície $<111>$ de silício também foi alvo de muitos estudos teóricos nos últimos 20 anos[94, 95, 96], o que nos permite uma boa comparação de resultados.

A geometria de equilíbrio foi obtida para os dois nanocristais, e o espectro vibracional foi levantado para o nanocristal de 50 átomos. Mostramos na tabela 4.1 os valores para a distância, e o modo de estiramento Si-H, junto aos resultados de Nardelli e colaboradores (obtido com a aproximação LDA) e aos valores experimentais.

\begin{tabular}{|c|c|c|}
\hline$H / S i<111>$ & distância $(\AA)$ Si-H & Estiramento $\left(\mathrm{cm}^{-1}\right) \mathrm{Si}-\mathrm{H}$ \\
\hline Exp. $[92]$ & - & 2083 \\
\hline AM1/cristal & 1.455 & 2180 \\
\hline LDA[94] & 1.530 & 2023 \\
\hline
\end{tabular}

Tabela 4.1: Resultados (teóricos e experimentais) para a distância e o modo de estiramento da ligação Si-H para a superfície $<111>$ de Si, passivada por H.

Note que obtivemos um valor para o modo de estiramento ligeiramente acima do valor experimental $(\sim 5 \%)$, porém se recordarmos do processo de parametrização, 


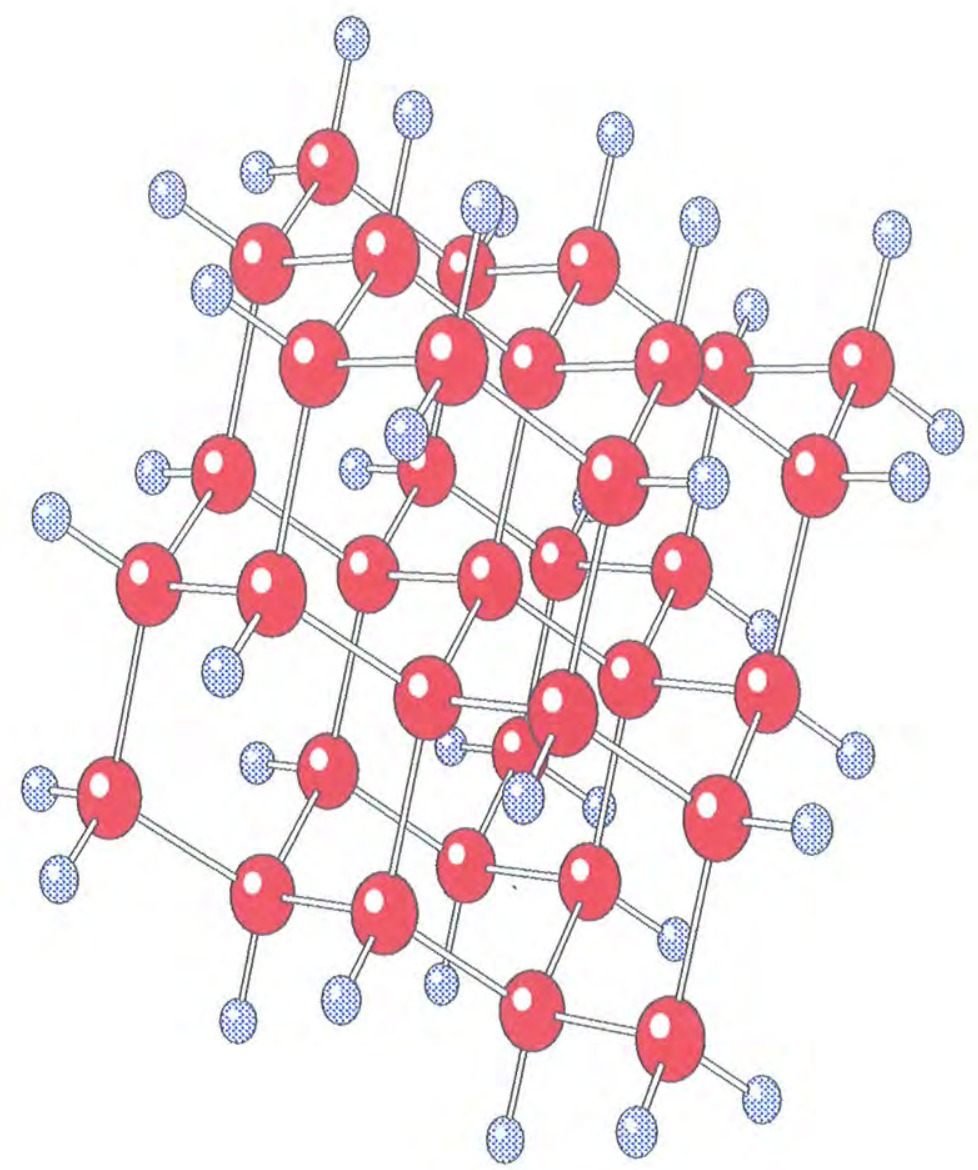

Figura 4.2: Representação da partícula de 71 átomos $\left(S i_{35} H_{36}\right)$. O núcleo (esferas maiores) é composto por átomos de $\mathrm{Si}$ em coordenação tetraédrica, átomos de $\mathrm{H}$ completam as ligações de superfície. 


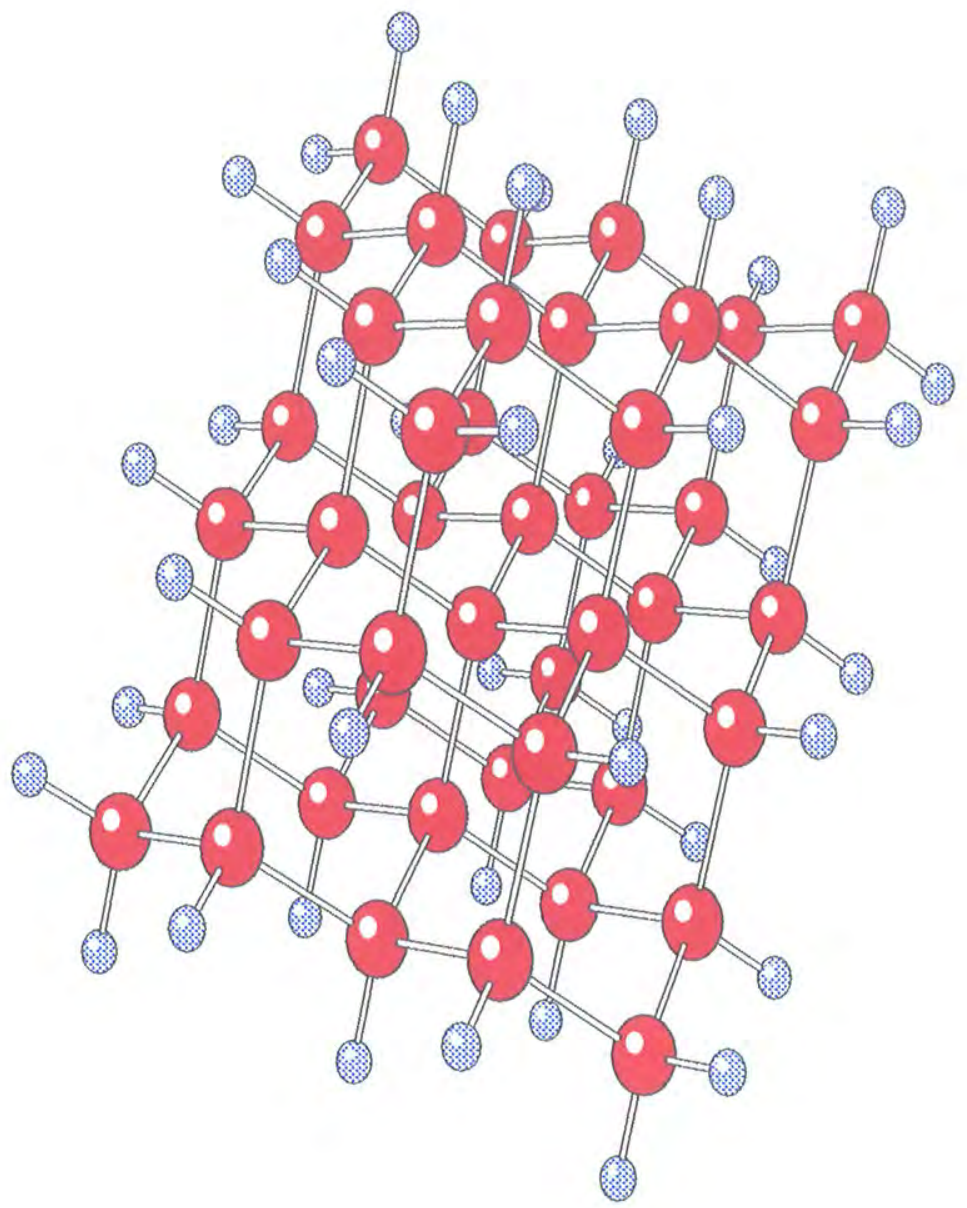

Figura 4.3: Representação da partícula de 86 átomos $\left(S i_{44} H_{42}\right)$. O núcleo (esferas maiores) é composto por átomos de $\mathrm{Si}$ em coordenação tetraédrica, átomos de $\mathrm{H}$ completam as ligações de superfície. 


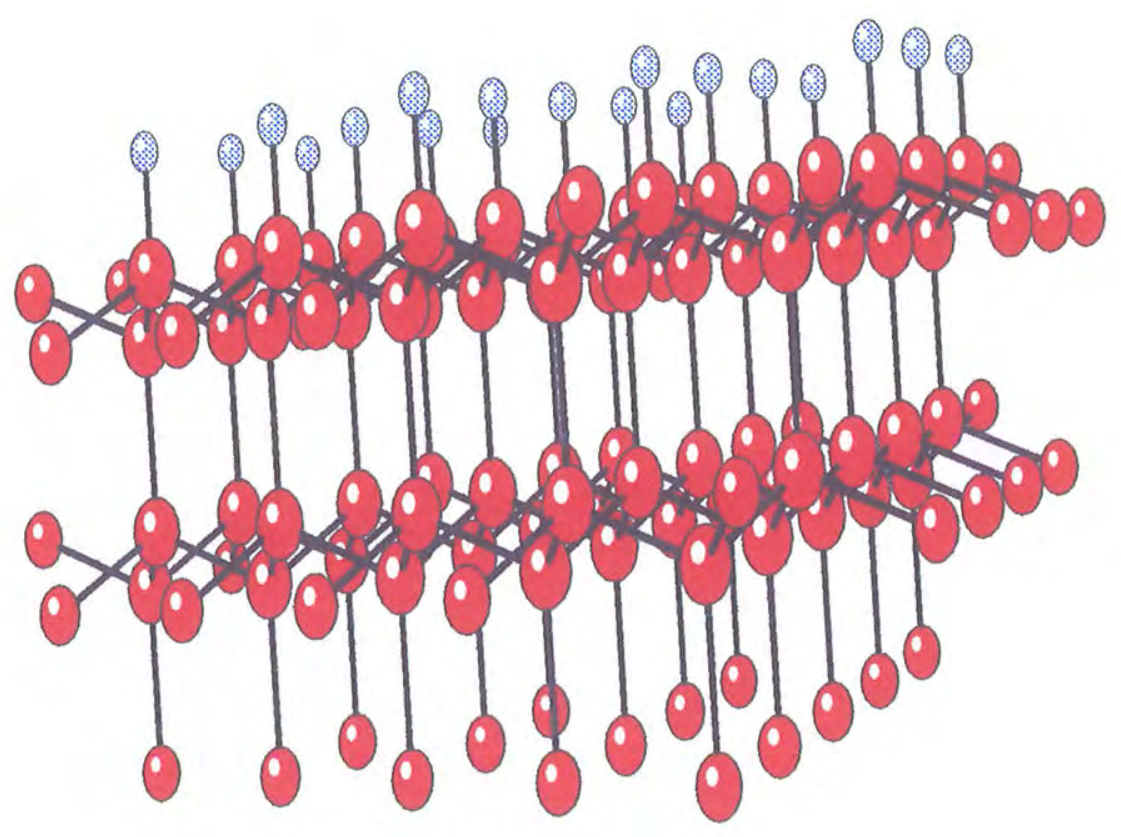

Figura 4.4: Nanocristal utilizado para simular a superfície hidrogenada $<111>$ do $\mathrm{Si}, \mathrm{p}-S i_{45} S i_{70} H_{19}$. Temos duas bicamadas de $\mathrm{Si}$, terminada latralmente e na face inferior por pseudoátomos. A face superficial é saturada por átomos de $\mathrm{H}$. 
este deslocamento já havia ocorrido para as moléculas de silano e disilano, on seja, é carregado de nosso processo de parametrização. Entretanto, a tendencia $\nu_{\text {sup }}<\nu_{\text {silano }}$ é reproduzida a contento.

Passamos agora ao estudo das nanopartículas, que foi realizado com otimização de geometria (AM1/Cristal) permitindo a relaxação de todos os átomos da partícula. Não foi feita nenhuma imposição de simetria neste passo, de forma que as partículas poderiam ter distorcido mas, no estado fundamental, a simetria foi mantida en todos os casos. Verificamos por outro lado que sempre ocorre uma pequena relaxaçao simétrica, não linear, que provavelmente deve desaparecer para partículas de dimensões maiores. Para a partícula $S i_{35} H_{36}$, por exemplo, a primeira camada de 4 átomos contrai ligeiramente $(0.5 \%)$, a segunda expande, e se olharmos a última camada, vemos que a partícula expande ligeiramente seu raio $(\sim 1 \%)$. No geral, consequentemente, a estrutura cristalina é mantida. Desta forma não é surpreendente que partículas relativamente pequenas ( 30 átomos de Si) já reproduzam as frequências de fônons do Si de bulk.

$\mathrm{Na}$ figura 4.5 apresentamos o espectro vibracional, das nanopartículas $S^{\prime} i_{35} / H_{36}$ e $\mathrm{Si}_{44} \mathrm{H}_{42}$ (figura 4.2 e 4.3 , respectivamente).

Vemos em ambos os casos os picos das vibrações Si-H, modo de estiramento a aproximadamente $2.200 \mathrm{~cm}^{-1}$, modo bending (entortamento) entre 570 e $900 \mathrm{~cm} 1$. Vemos ainda na região correspondente às ligações Si-Si que o espectro de fônons já esta basicamente reproduzido, estando a última vibração da banda a 540-544 $\mathrm{cm}^{-1}$ (dependendo da partícula), com $\mathrm{um}$ deslocamento da ordem de $+4 \%$ do fônon ótico a $\Gamma$ (ver capítulo 3). O deslocamento previsto por um modelo de: confinamento quântico puro seria para o vermelho, e atribuimos este deslocamento positivo à relaxação (compressão) ocorrida no núcleo ("core") da partícula que, para partículas desta dimensão, tem peso relativo suficiente. O deslocamento é entretanto muito pequeno mesmo para estas nanopartículas.

Este resultado para o espectro vibracional pode ser relevante em vista da interpretação da réplica de fônons detetada[97] em experimentos de fotoluminescência: Dada a resolução em energia desse tipo de experimentos, a observação de um espaçamento típico de fônons de Si é compatível com uma estrutura do tipo nanopartícula, e de tamanho na região das estudadas aqui (10-20 ̊).

Em resumo, já para partículas de Si hidrogenadas com diâmetros tão pequenos quanto 10-20 $\AA$, as propriedades vibracionais apresentam características cristalinas. Neste sentido, as dimensões características inferidas por Schuppler e colaboradores [88] são compatíveis com as frequências de fônons do tipo bulk observadas por Calcott e colaboradores[97]. 


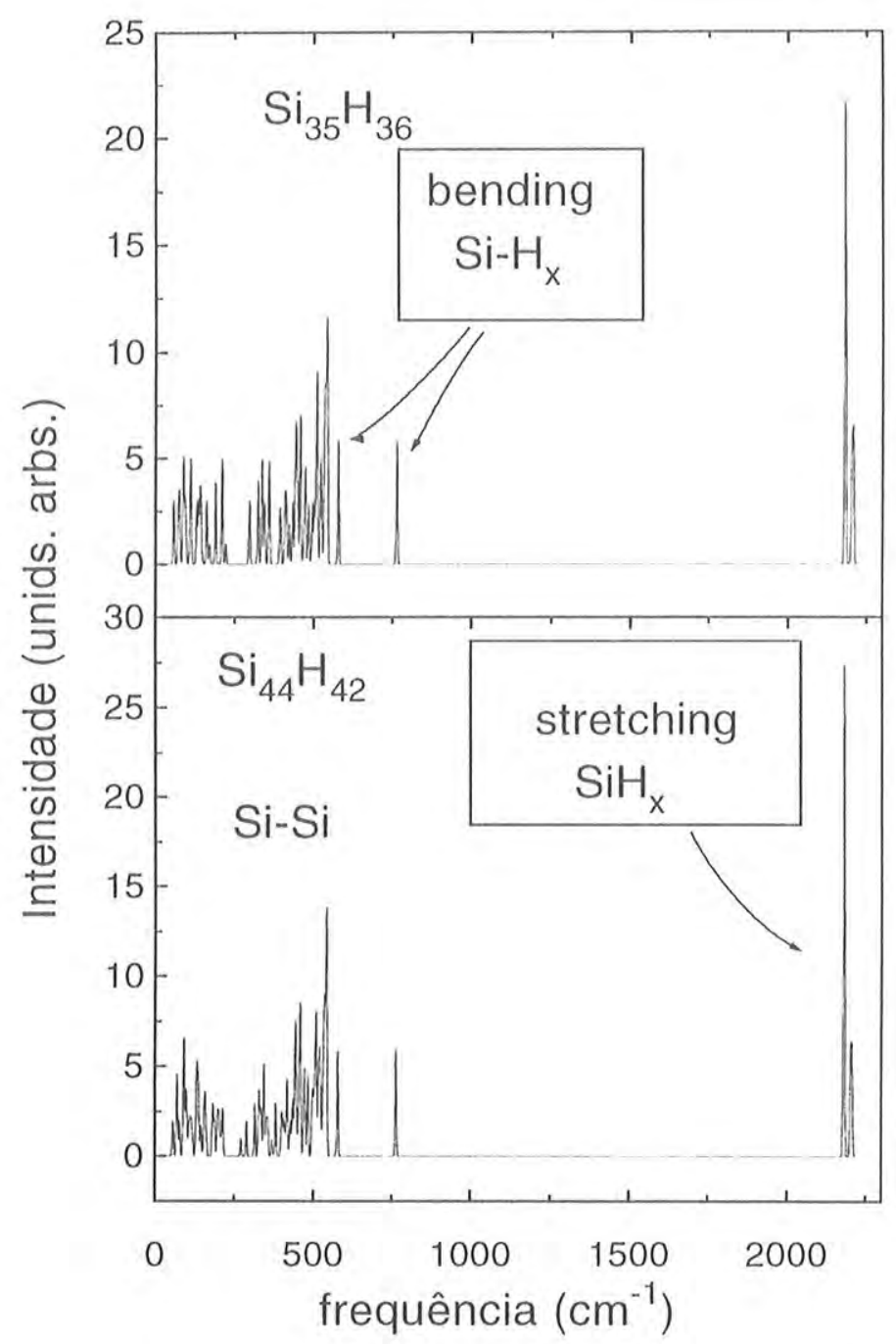

Figura 4.5: Espectro vibracional das nanopartículas $S i_{35} H_{36}$ e $S i_{44} H_{42}$, onde se nota o comparecimento dos modos $\mathrm{Si}-\mathrm{H}$, e a banda correspondente aos modos de Si-Si. 


\subsection{Absorção Ótica de Nanopartículas de Si Hi- drogenadas}

Para as partículas em sua geometria de equilíbrio, calculamos o espectro de alssorção ótica através do ZINDO/Cristal. A correção CI foi feita construindo excitações a partir de estados localizados a cerca de $5 \mathrm{eV}$ abaixo do topo da banda de valência (último estado ocupado, HOMO) e cerca de $3.5 \mathrm{eV}$ acima do fiundo da banda de condução (primeiro estado virtual, LUMO); e não incluímos excitaçòes envolvendo dois elétrons, que tem peso insignificante neste caso.

Na figura 4.6 apresentamos o gap de energia calculado para as partículas de Si hidrogenadas em função do número de átomos de Si presentes. Ciraficamos a diferença de autovalores HOMO $\rightarrow$ LUMO, ou seja, nenhuma correção é incluida; e também incluindo a correção de orbital virtual e finalmente os resultados do cálculo CI.

A partir da figura 4.6 fica claro que, para as partículas menores, a energia de transição ótica associada com efeitos de correlação não é linear com o múmero de átomos de $\mathrm{Si}$, uma vez que esta depende, entre outras coisas, da simetria da partícula envolvida.

Um resultado surpreendente é que as energias de transição obtidas apenas com it correção de orbital virtual são já bastante próximas do resultado final. Isso é importante ao analisarmos os resultados de outros autores, que não incluiram correção CI: uma vez que ela aparentemente não é importante, não seria suficiente para eventuais correções no valor do gap obtido. Note-se também que essa é a primeira. transição efetivamente, ou seja, não existem transições proibidas a energias mais baixas em nenhum caso.

O resultado mais importante da figura 4.6 é a relação entre o tamanho da partícula e a energia do gap. O diâmetro médio das maiores estruturas de Si estudadas aqui é da ordem de 10-20 A, e correspondem a gaps na região $\sim 2.5-3.5$ eV (a partícula $\mathrm{Si}_{44} \mathrm{H}_{42}$ com uma transição em $2.95 \mathrm{eV}$ tem $u$ m diâmetro médio de $\sim 14 \AA$ ). Extrapolação destes valores para diâmetros infinitos (figura 4.7), leva a $u$ gap de $\sim 1.5 \mathrm{eV}$. Isto indica que, além de efeitos de confnamento quântico, a relaxação da estrutura é muito importante na definição do gap destas partículas. Uma vez que efeitos de relaxação no caroço das partículas devem desaparecer após um tamanho crítico, não é razoável extrair dos nossos resultados uma região de diâmetros para partículas que poderiam absorver na região do vermelho-laranja.

Para prosseguir, precisamos mais detalhes sobre a origem de cada pico de ab- 


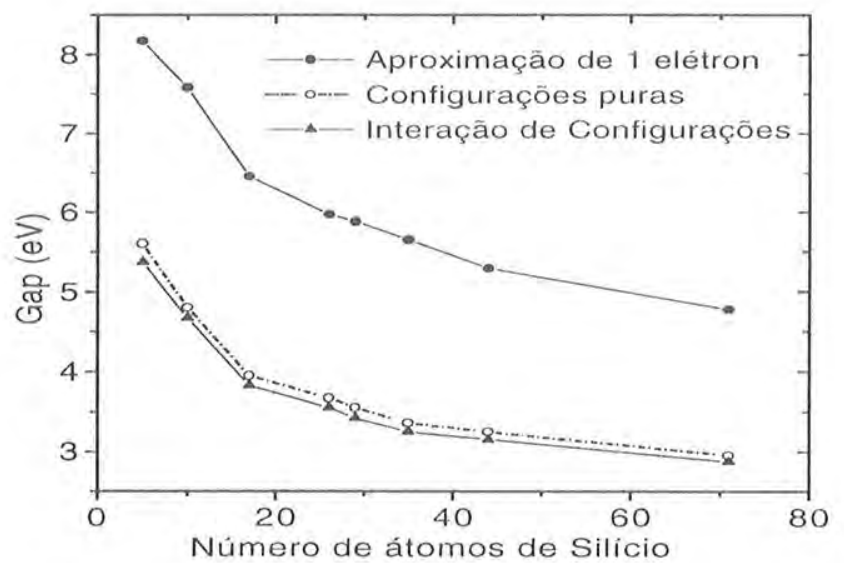

Figura 4.6: Energia calculada para a primeira transição ótica permitida das partículas de Si terminados por $H$, em função do número de átomos de Si (A simetria e a composição das partículas são descritas no texto.) Triângulos: efeitos de correlação são completamente incluidos através de interação de configuraçôes ( ( 7$)$. Circulos abertos: efeitos de correlação são parcialmente incluidos pela correção de orbital virtual, sobre a transição um-elétron mais relevante para aquela transição ótica (para estas partículas é sempre a excitação HOMO $\rightarrow$ LUMO). Circulos cheios: transiçôes de particula independente entre o HOMO e o LUMO dos estados eletrônicos fundamentais (nenhuma correlação é incluida). As linhas são apenas para facilitar a visão. 


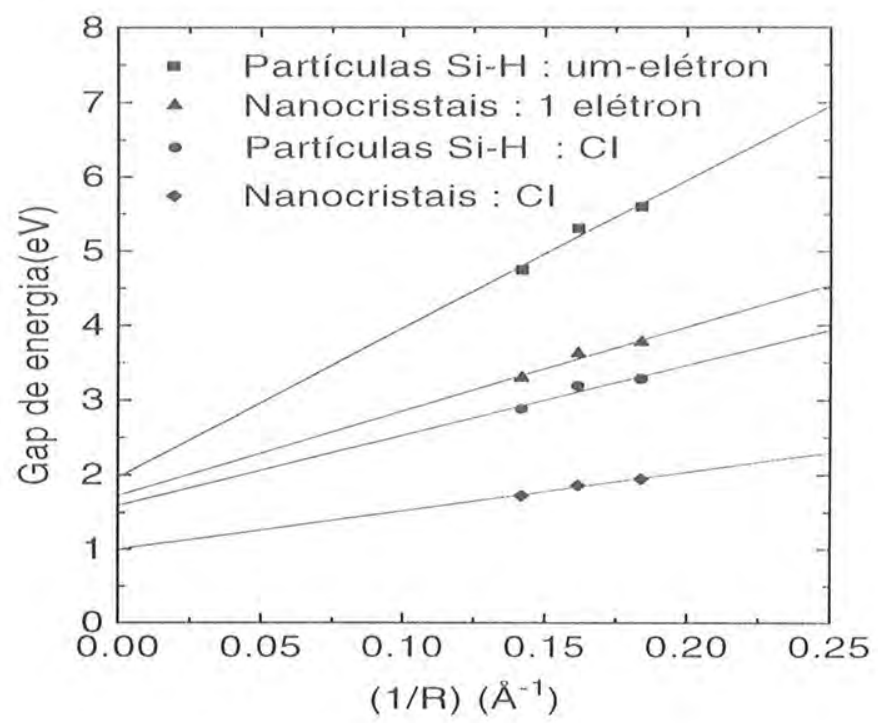

Figura 4.7: Extrapolação do gap de partículas de Si hidrogenadas para partículas de: diâmetro infinito, comparadas aos resultados para nanocristais. Vemos que efcitos de relaxação estrutural são importantes, e provocam um aumento considerável na energia do gap. 
sorção, de cada partícula, e se faz necessária uma análise da composição da funçấ) de onda determinantal responsável por cada um destes picos. Realizamos este 1ritbalho para cada uma das partículas citadas anterormente, porém iremos apresentai detalhes do cálculo apenas para as partículas $S i_{35} H_{36}$ e $S i_{44} H_{42}$; resultados para as outras partículas estudadas são equivalentes.

Na figura 4.8 apresentamos os espectros de absorção ótica para as duas partículas. Desta figura podemos constatar, a presença de três picos ben definidos (assinalados por AI, AII e AII para a partícula menor e PI e PII para a maior).

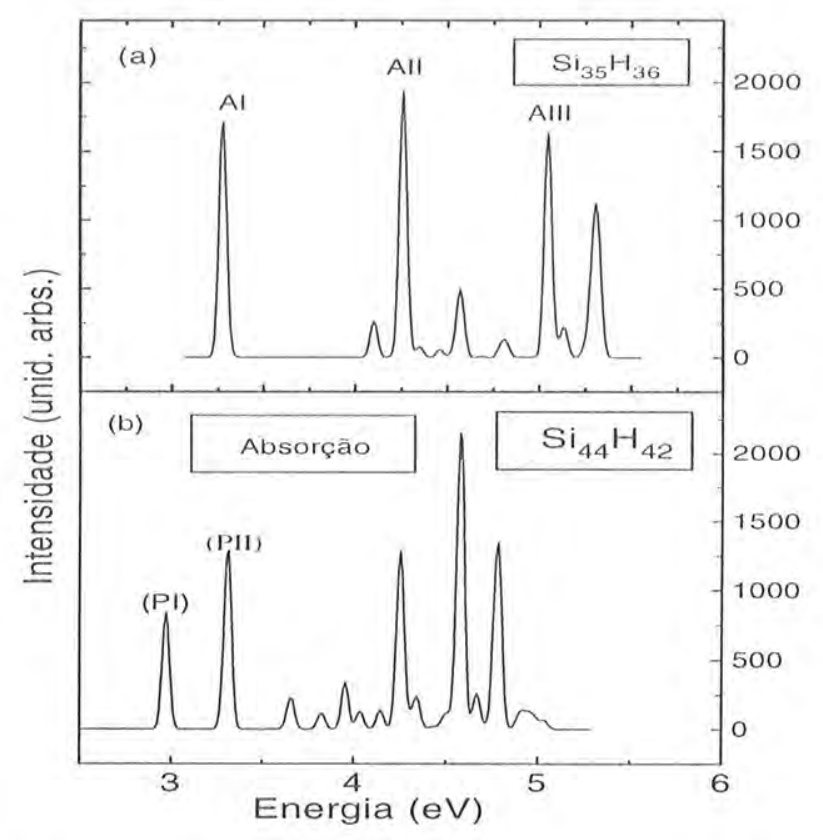

Figura 4.8: Espectro de absorção ótica das partículas $\mathrm{Si}_{35} \mathrm{H}_{36}$ e Si $\mathrm{Si}_{44} \mathrm{H}_{42}$. Nota-se o deslocamento para o azul do limite de absorção com a diminuiçâo da partícula.

Para uma análise da origem destes picos, nas figuras 4.9 e 4.10 projetamos as funções de onda determinantais em termos de estados de "elétrons" (estados ocupados) e "buracos" (estados virtuais). Note que o eixo horizontal representa apenas a ordem em que aparece o autovalor do orbital molecular em questão ( por exemplo, na partícula $S i_{44} H_{42}$ o HOMO é o autovalor 109 e o LUMO o autovalor 110); não reflete a estrutura da Densidade de Estados (DOS) em relação à energia. 
Partículas Si-H

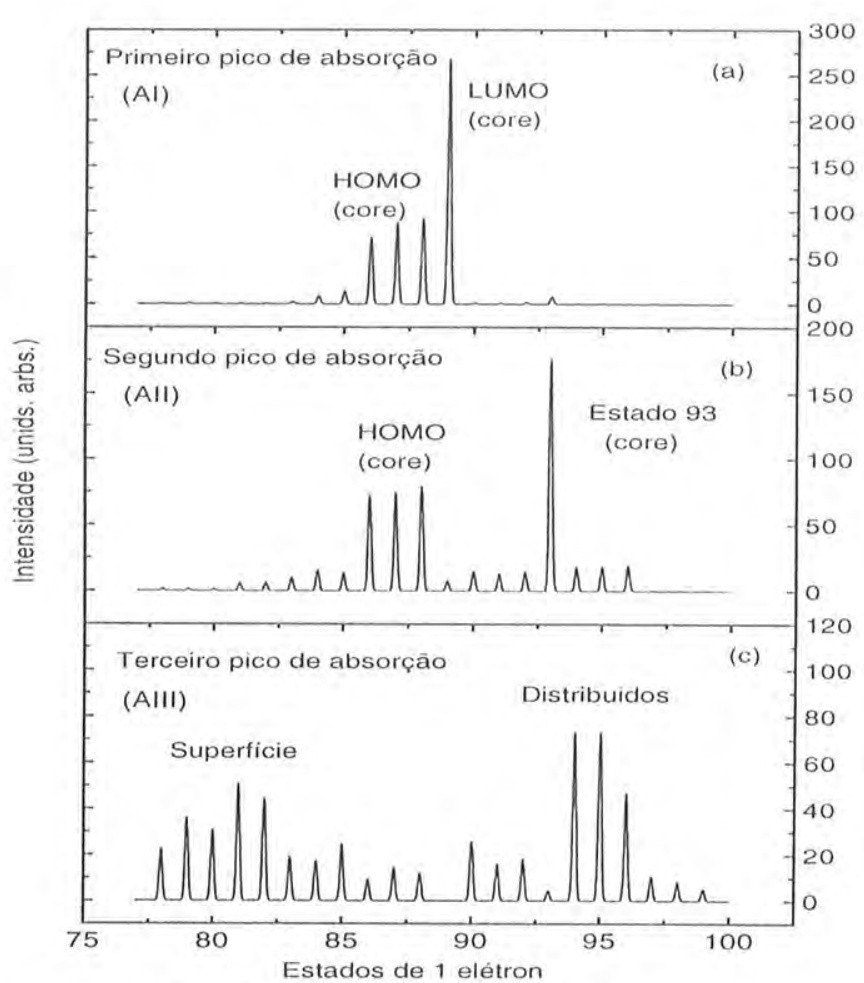

Figura 4.9: Composição das funções de onda determinantais, responsáveis pelos três picos mais intensos de absorção da particula $\mathrm{Si}_{35} \mathrm{H}_{36}$, em termo dos estados de um-elétron. 


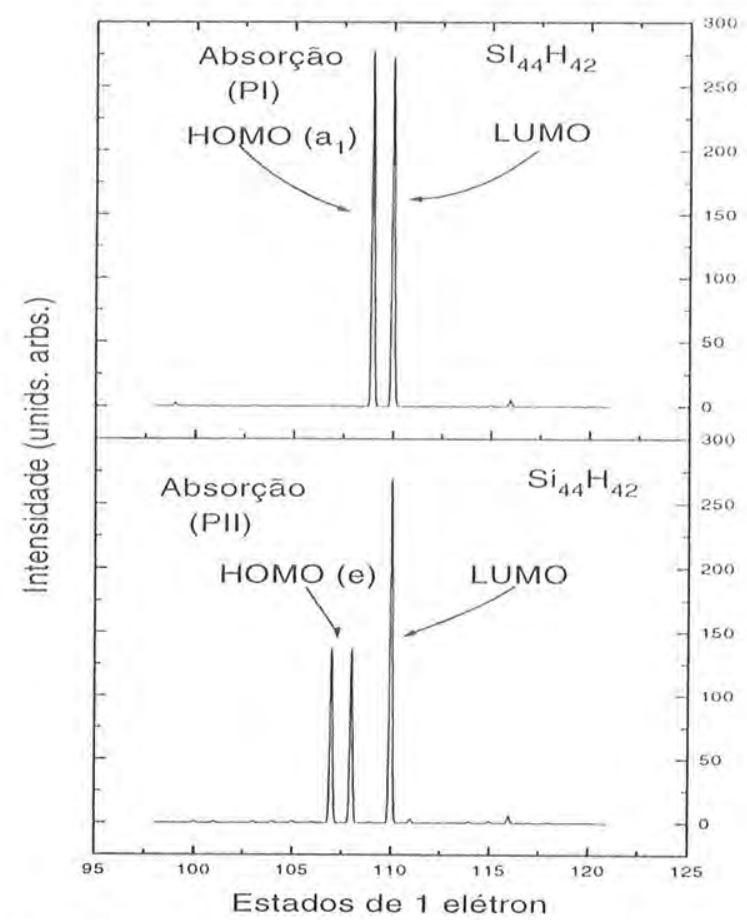

Figura 4.10: Localização das funções de onda determinantais, correspondentes a.os dois primeiros picos de absorção da partícula $\mathrm{Si}_{44} \mathrm{H}_{42}$, em termo dos estados de um-elétron que a compoẽm.

Novamente, o caráter de transição quase pura é mantido nos dois primeiros picos de absorção da partícula $\mathrm{Si}_{44} \mathrm{H}_{42}$ (picos PI e PII na figura 4.10). Deste modo, entende-se porque a correção com a inclusão de efeitos de interação de configurações não é muito importante.

Para o primeiro pico de absorção da partícula $S i_{35} H_{36}$ (pico AI na figura 4.9), a transição ótica envolve uma transição de partícula independente "quase pura" entre o HOMO e o LUMO. Para as próximas transições óticas os efeitos de interação de configurações começam a aparecer, como pode ser visto na figura 4.9.

Para encontrarmos a origem (localização espacial na partícula) das transições óticas, graficamos a distribuição de carga, sobre os átomos-tipo da partícula, dos 
estados de um elétron mais relevantes, para cada transição para a partícula S S $i_{35}{ }_{36}$; e é desta forma que fazemos as atribuições constantes na figura 4.9, localizando os picos AI e AII no "core" e o AIII na superfície. Esta análise é mostrada na figura 4.11. Na figura 4.12 apresentamos a localização do HOMO e do LUMO para a partícula $\mathrm{Si}_{44} \mathrm{H}_{42}$.

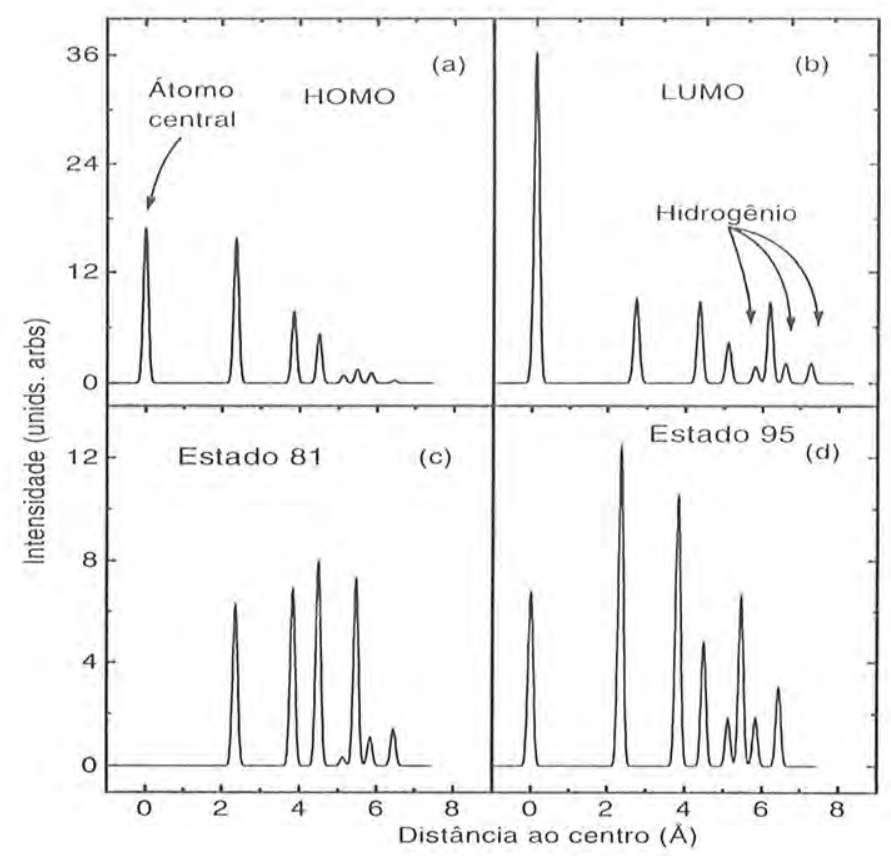

Figura 4.11: Localização espacial dos estados de um-elétron mais relevantes para o espectro de absorção da partícula $\mathrm{Si}_{35} \mathrm{H}_{36}$ : A densidade de probabilidade associad.a a um átomo em uma camada particular é graficada em função da distância da camada ao centro da particula.

Através de um cálculo simples (da soma dos quadrados das componentes orbitais) para as camadas internas da partícula, vemos que estas camadas são responsáveis por $\sim 80 \%$ da densidade orbital do HOMO e do LUMO, o que nos permite concluir que a primeira transição ótica para todas as partículas tem carácter 


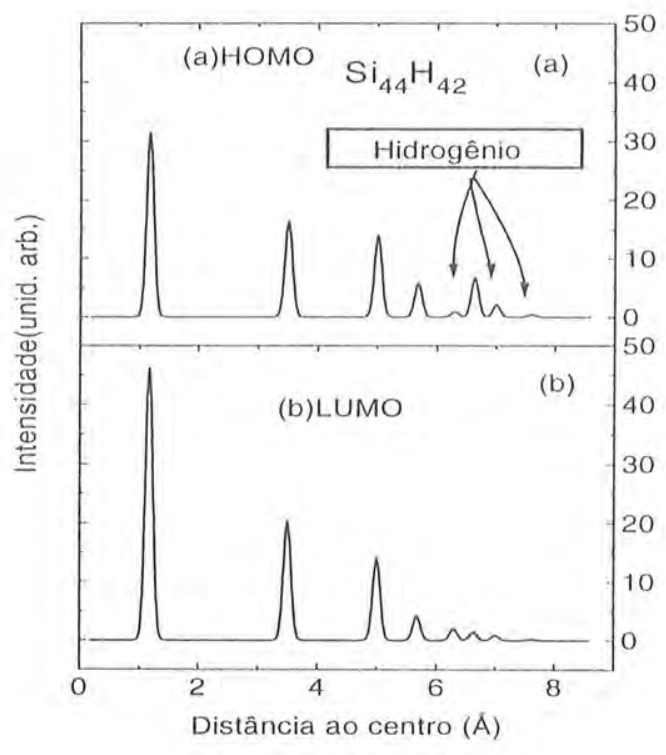

Figura 4.12: Localização espacial do HOMO e LUMO (estados de um elétron) da. particula $\mathrm{Si}_{44} \mathrm{H}_{42}$ em seu estado fundamental (como na figura 4.11).

predominantemente cristalino. Para os próximos picos de absorção, os estados de partícula independente que contribuem para as funções de onda determinantal sâo estados mais distribuidos na partícula, porém localizados em átomos de Si. A contribução dos átomos de $\mathrm{H}$ é muito pequena e isto ocorre para todos os estados de partícula independente próximos ao topo da banda de valência $(\sim 5 \mathrm{eV})$ e ao fundo da banda de condıção $(\sim 4 \mathrm{eV})$.

Nossos resultados indicam então que as absorções óticas abaixo de $5 \mathrm{eV}$ para estas partículas são originárias de $\mathrm{Si}$, sendo que a primeira exibe um comportamento cristalino. Por outro lado, não se espera que a emissão na região do vermelholaranja esteja diretamente associada a esta absorção, uma vez isto implicaria em um Stokes-shift demasiado grande.

Assim, nossa conclusão principal até aqui é que tanto os efeitos de confinamento quântico quanto efeitos de relaxação estrutural contribuem para provocar 
um deslocamento para o azul muito forte na primeira absorção ótica dessas peçuenas partículas, com o resultado final que essa transição se dá na região de $3 \mathrm{eV}$, muito acima da emissão vermelho-laranja. Essa conclusão está en concordância geral com outros resultados teóricos anteriores $[81,25,27,20,80]$, entretanto graças à flexibilidade do nosso procedimento pudemos ganhar uma visäo mais clara dos processos de absorção ótica.

Em particular, temos como dado determinante o fato de que a primeira absorção é, na prática, uma transição de um elétron, ou seja, o primeiro estado excitado é bem representado por uma função determinantal em que um elétron é retirado do HOMO (tridegenerado) e colocado no LUMO (degenerescência simples). Esse dado é importante pois nos permite, a um tempo suspeitar, e a outro calcular uma possível relaxação no estado excitado, que descrevemos a seguir.

\subsection{Espectro de Emissão de Pequenas Partículas de Si Hidrogenadas}

O nosso resultado nos levou então a calcular a melhor geometria para o primeiro estado ecitado, alcançado através da primeira absorção ótica. Com o uso da aproximação AM1/Cristal permitimos a relaxação da partícula no estado excitado, para a sua configuração de mínima energia. Novamente, iremos discutir em detallhes os resultados para apenas uma partícula, $\mathrm{Si}_{44} \mathrm{H}_{42}$, pois os resultados para as demais são similares.

Nossos resultados indicam a ocorrência de uma distorção espontânea, pela qual dois átomos de Si externos, adjacentes cada $\mathrm{mm}$ ligado a apenas $1 \mathrm{~m}$ átomo de H aumentam significativamente a sua distância relativa, enquanto as distancias destes átomos a outros átomos (mais internos) de Si permanece quase inalterada; ao mesmo tempo, um dos átomos de H (ligado a $11 \mathrm{~m}$ dos átomos de Si onde houve a distorção) se move para formar uma "ponte" e reforçar a ligação entre os dois átomos de $\mathrm{Si}$, enfraquecida devido à distorção.

Esta é uma distorção altamente localizada. Na figura 4.13 (b) apresentamos a geometria para o anel de Si envolvendo a distorção, no estado excitado, e para efeitos de comparação apresentamos também na figura 4.13 (a) a geometria deste mesmo anel no estado fundamental.

Para analisarmos a pertubação provocada na região distorcida, apresentamos na tabela 4.2 o indice de ligação (Bond Index) do átomo numerado como 2, na 

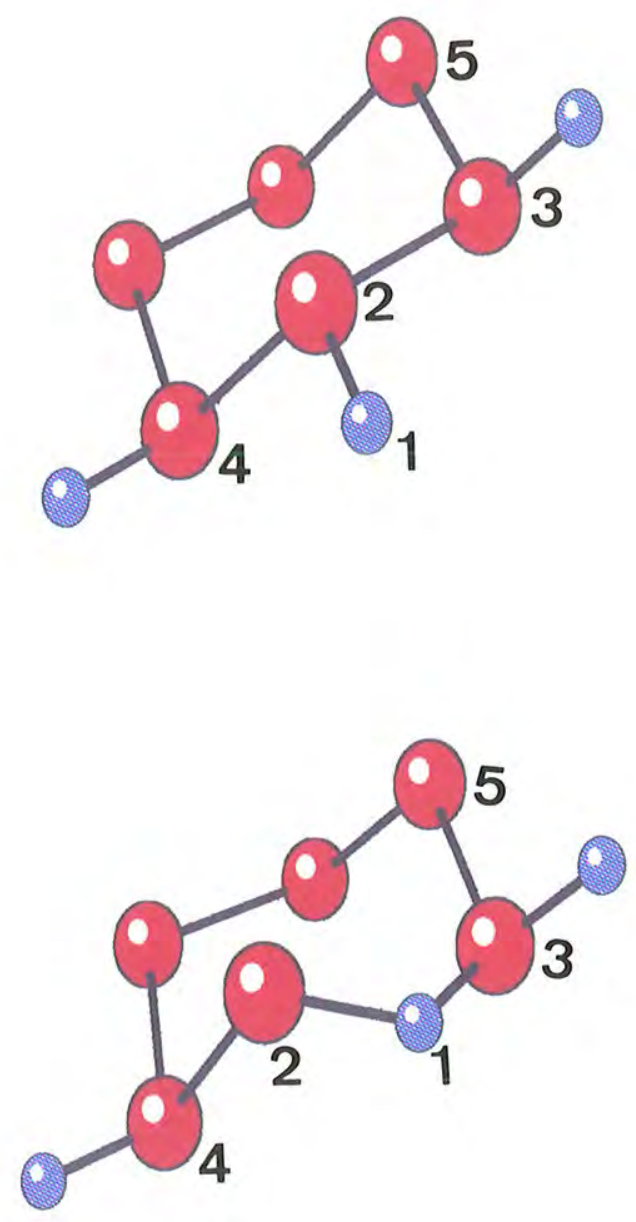

Figura 4.13: (a) Representação de um anel de silício sem distorções (estado fundamental) e (b) anel de silício com a distorção de uma das ligações entre dois átomos de silício (estado excitado). Resultado para a partícula $\mathrm{Si}_{44} \mathrm{H}_{42}$. Note o movimento (bending) de um átomo de hidrogênio (1), e o afastamento dos átomos de Si (2 e 3). As ligações não mostradas são todas a outros átomos de $S i$. 
figura 4.13 (b), com os seus primeiros vizinhos, e com o átomo de hidrogênio que acompanha a distorção (destacado com o número I na figura 4.13 (b), tanto na configuração de estado fundamental como de estado excitado, e as distâncias de ligação.

\begin{tabular}{|c|c||c|c||c|}
\hline & \multicolumn{2}{|c|}{ Estado fundamental } & \multicolumn{2}{c|}{ Estado excitado } \\
\cline { 2 - 5 } Ligação & Indice & distância & Indice & distância \\
\hline$S i_{5}-S i_{3}$ & 0.914 & 2.351 & 0.854 & 2.365 \\
\hline$S i_{3}-S i_{2}$ & 0.919 & 2.367 & 0.398 & 2.634 \\
\hline$S i_{4}-S i_{2}$ & 0.923 & 2.363 & 0.935 & 2.310 \\
\hline$S i_{3}-H_{1}$ & 0.008 & 3.184 & 0.541 & 1.546 \\
\hline$S i_{2} H_{1}$ & 0.956 & 1.476 & 0.392 & 1.673 \\
\hline
\end{tabular}

Tabela 4.2: Indice e distâncias de ligação entre os átomos mais afetados pela formação da ponte Si-H-Si. Numeração de acordo com a figura 4.13.

A partir da tabela 4.2 fica claro que o átomo de H continua ligado ao átomo de Si, mesmo que fracamente, a também que ainda existe ligação direta entre os dois átomos de $\mathrm{Si}$ afetados pela ponte. Este resultado demonstra que a distorção no estado excitado ocorre naturalmente e não é necessário "criar" "un defeito ctprior (remoção de H) como foi proposto por Allan e colaboradores[19].

Não podemos excluir a possibilidade que exista uma pequena barreira à distorção, no caso mais geral, entretanto a degenerescn̂cia do HOMO (que existe desde as partículas menores até o próprio cristal) é propícia à ocorrência de distorção.

Uma vez encontrada a geometria de equilíbrio para a partícula, no estado excitado, calculamos novamente o espectro ótico, usando o ZINDO/Cristal, cujo resultado esta apresentado na figura 4.14 (nesta mesma figura, para efeitos de comparação, apresentamos também o espectro de absorção).

Na figura está o espectro completo das primeiras transições óticas nessa geometria distorcida, e chamaremos a esse espectro, por facilidade, de espectro de emissão. É conveniente lembrar que estamos simulando a relaxação da partícula a partir do primeiro estado excitado, assim na realidade apenas os primeiros picos (dois, EI e EII para esta partícula) são relevantes, uma vez que somente a partir dali uma partícula excitada através da primeira absorção (PI ou PII) poderia decair radioativamente (um terceiro pico EIII pode também estar relacionado ao primeiro estado 
excitado, mas apresenta um deslocamento para o azul e a partícula dificilmente mostrará essa emissão).

Comparando os dois espectros óticos, podemos perceber que houve uma drástica modificação entre o estado excitado e o estado fundamental, principalmente no que se refere à localização em energia da primeira absorção e da primeira enissão.

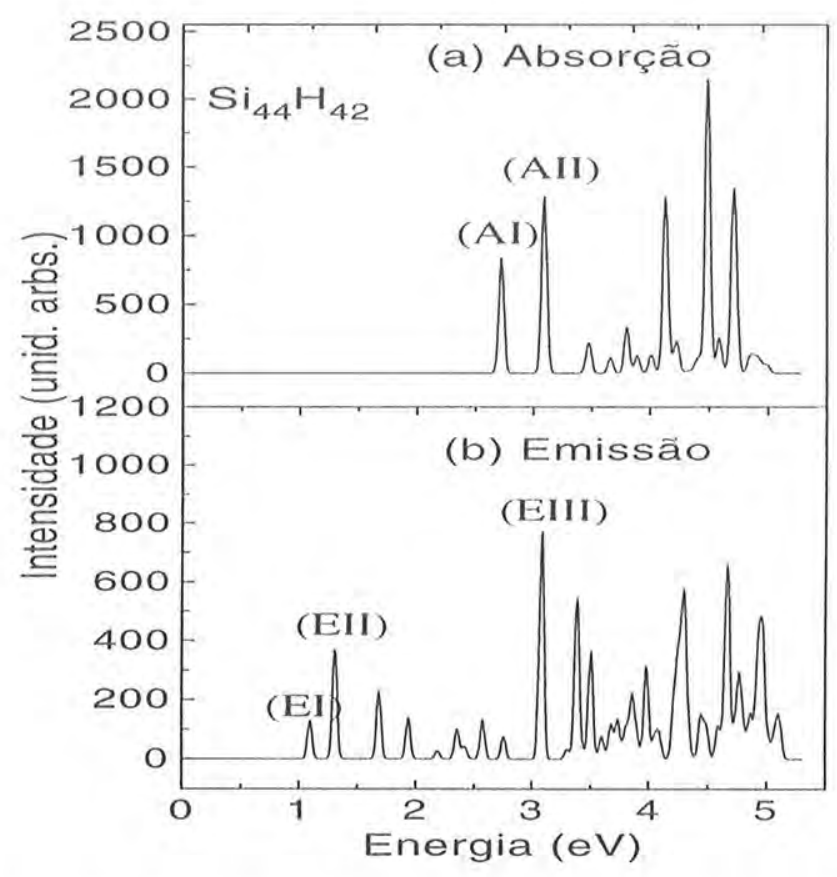

Figura 4.14: Espectros de absorção (a) e emissão ótica (b) da particula $\mathrm{Si}_{44} \mathrm{H}_{42}$.

Para uma análise das transições óticas de estados excitados procedemos da mesma maneira que no caso do estado fundamental. Na figura 4.15 apresentamos a localização da funções de onda determinantais responsáveis pelas duas primeras emissões óticas (assinaladas na 4.14 como EI e EII).

A partir da figura 4.15 constatamos que duas transições mais baixas não são mais transições entre "configurações puras" (como ocorria para a primeira absorção ótica) mas envolvem principalmente uma forte mistura de duas transições de $u m$ elétron $(\mathrm{HOMO} \rightarrow \mathrm{LUMO})$ e $(\mathrm{HOMO} \rightarrow \mathrm{LUMO}+1)$. Assim, se para a primeira ab- 
Partículas Si-H

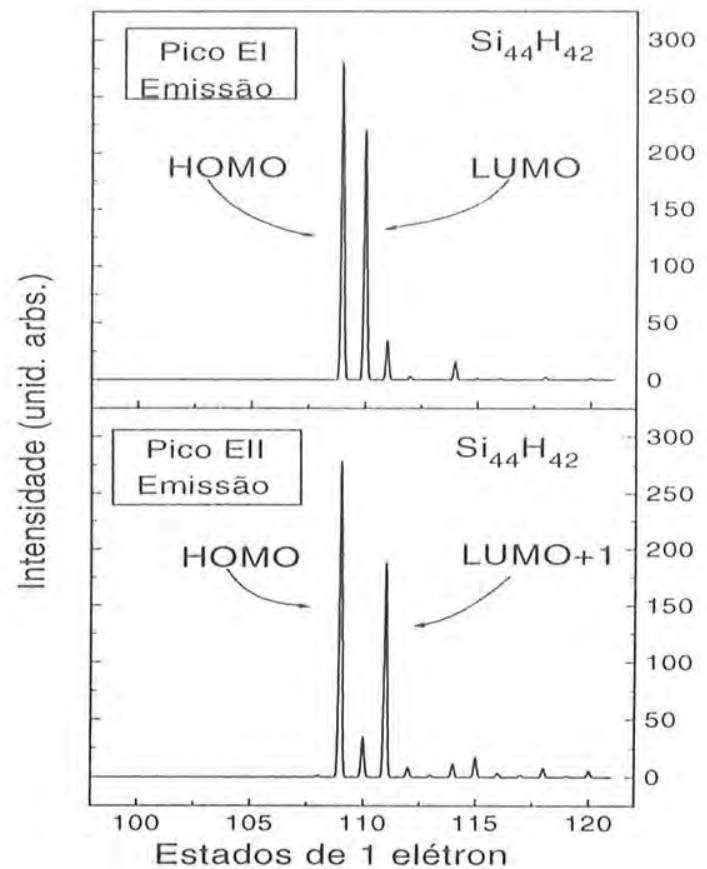

Figura 4.15: Composição das funções de onda determinantais responsáveis pelos dois primeiros picos de emissão da particula $\mathrm{Si}_{44} \mathrm{H}_{42}$ em termos dos estados de um-elétron. 
sorção ótica, os efeitos de interação de configurações não exerciam una forte influência, para obter a energia das duas primeiras emissões óticas este procedimento é de fundamental importância.

A distribuição espacial dos estados de $11 m$ elétron mais relevantes, que compoêm as funções de onda determinantais responsáveis pelos dois primeiros picos de emissão (neste caso o HOMO o LUMO e o LUMO+1), estão apresentados na figura 4.16 .

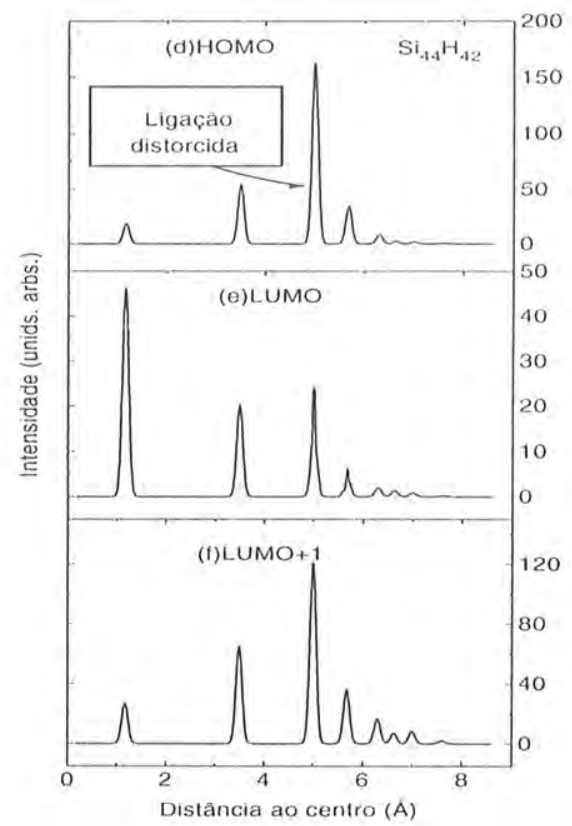

Figura 4.16: Localização espacial dos estados de um elétron mais relevantes para a emissão ótica da partícula $S i_{44} H_{42}$ (como na figura 4.11).

Podemos constatar que, enquanto o LUMO ainda mantém sua localização nos átomos do caroço da partícula, como ocorre no estado fundamental [compare figuras 4.10 (b) e 4.16 (b) ], o HOMO, originalmente tri-degenerado $\left(a_{1}+\right.$ e), se desdobra e. o mais alto estado ocupado está fortemente localizado nos átomos de Si envolvidos na distorção [fig 4.16 (a)]; o segundo orbital virtual, que no estado fundamental se localizava em átomos de Si do caroço da partícula, agora é também localizado 
nos mesmos átomos de Si que tiveram uma de suas ligações distorcidas [compare as figuras 4.10 (c) e 4.16 (c)].

Encontramos um terceiro pico de emissão bastante intenso (assinalado como EIII na figura 4.14) ao redor de $\sim 3.05 \mathrm{eV}$ que deriva de uma transição quase: "pura" reminescente da absorção HOMO-LUMO original; sua energia está แm pouco deslocada para valores mais altos de energia (deslocamento para o azıl) com respeito à absorção, o que ocorre devido a uma interação com as transições de mais baixa energia.

Convém mencionar que uma configuração metaestável para o estado excitado foi encontrada, que corresponde a uma relaxação global da partícula (do tipo modo de respiração); A diferença de energia total entre estas duas configurações excitadas é grande, de $\sim 1 \mathrm{eV}$. Com a partícula nesta configuração metaestável encontramos um Stokes-shift de $\sim 0.2 \mathrm{eV}$.

Resumindo, sem envolver estados extrinsecos[13] encontramos[98] 11ma relaxação estrutural para as partículas em seus estados excitados, que introduz modificações drásticas no espectro ótico. Nessa configuração as transições de mais baixa energia envolvem estados localizados ao redor de átomos de superfície que tiveram uma de suas ligações distorcidas, e isto coexiste com o "caracter cristalino" das ligaçöes de Si no interior da partícula.

Acreditamos que as novas transições, localizadas agora a energias mais baixas, são suficientemente intensas para serem as responsáveis pelo espectro de emissão do po-Si.

Por fim podemos dizer[98] que este mecanismo aqui proposto por nós, é completamente compatível com o modelo de nanocristais para o po-Si. 


\section{Capítulo 5}

\section{Efeitos da Oxidação de Superfície}




\subsection{Introdução: Incorporação de oxigênio em Superfícies de Si}

Un longo debate vem se desenvolvendo em torno da importância da superfície nas propriedades óticas do po-Si. A hipótese inicial $[99,100,11]$ de que a PL seria devida à presença na superfície de espécies estranhas ao cristalito, como polisilanos ou siloxano, já foi descartada e inclusive vimos no capítulo anterior que a luminescência no vermelho/laranja pode ter origem na própria superfície ideal de nanopartículas hidrogenadas. Entretanto, mesmo se não necessária, a presença de: oxigênio é uma constante em amostras expostas ao ar. Além disso, como vimos, a PL é gerada na superfície, assim é importante entender qual a influência do () na superfície das nanopartículas, e é isto o que faremos a seguir.

Do ponto de vista experimental, dada a importância da interface Si/SiO_z para a tecnologia de dispositivos, existe uma literatura ampla sobre a oxidação de superfícies de Si. O interesse natural pelo efeito da oxidação sobre as propriedades óticas do po-Si motivou também ali grande esforço experimental. Do ponto de vistia. teórico, apesar da dificuldade do estudo, também existem (poncos) trabalhos anteriores. Muitos dos estudos anteriores entretanto foram dedicados ou à incorporação na superfície $<111>$ limpa (Veja o trabalho de Oshiro e colaboradores[101] e as referências ali contidas) ou a complexos mais semelhantes ao siloxano e siloxeno mais propriamente ditos [102, 37] e o estudo em particular de Mazzone[103] foi feito para estudar diretamente a influência do oxigênio em "clusters" de silício hidrogenados, mas ali tratando-se de clusters de Si puro, que não mantém a cordenação tetraédrica.

Iniciamos nosso estudo pela superfície de $\mathrm{Si}<111>$ hidrogenada, que tem sido usada como paradigma para estudar o po-Si[82], inclusive por sua semelhança, quando totalmente oxidada, ao siloxano[100]. Uma característica conhecida[82] é que a influência do oxigênio depende do sítio de incorporação. Mostramos na figura 5.1 esquemas da incorporação de oxigênio na $\mathrm{H}$-Si $<111>$. Nota-se que no caso intersticial podem-se formar "ilhas" em torno de um átomo de Si de superfície, hipótese esta levantada por Borghesi e colaboradores[104] para explicar o processo inicial de oxidação e sua desordem.

Nossa simulação consiste em introduzir um ou mais átomos de oxigênio nos nanocristais utilizados para simular a superfície $\mathrm{H}-\mathrm{Si}<111>$ : contendo 50 (p$\left.S i_{21} S i_{22} H_{7}\right)$ e 134 átomos $\left(\mathrm{p}-S i_{45} S i_{70} H_{19}\right)$. Estes nanocristais já foram descritos no capítulo anterior. 

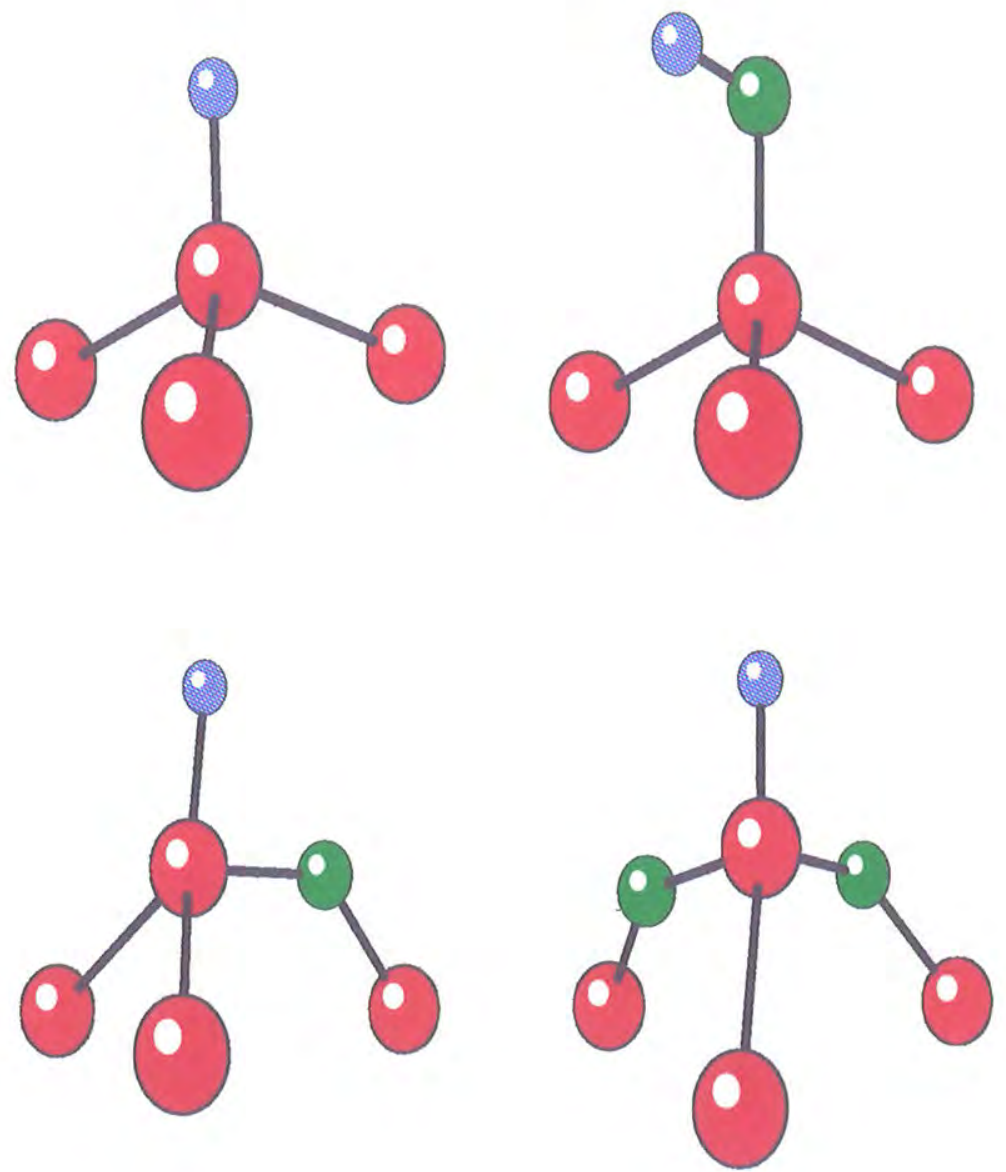

Figura 5.1: Representação da incorporação de oxigênio na superfície $<111>$ de $\mathrm{Si}$ passivada por $\mathrm{H}$ : em cima, à direita, terminação $\mathrm{Si}-\mathrm{H}$, superfície limpa, à esquerda, oxigênio como hidroxila, Si-OH, em baixo, oxigênio subsuperficial Si-O-Si isolado, à direita, ilha com 2 Si-O-Si. 
Introduzimos átomos de oxigênio nos sítios intersticiais entre o átomo de si central da superfície e os seus primeiros vizinhos (localizados na primeira camadi interna à superfície). Alternativamente, introduzimos $11 m$ átomo de oxigênio na. ligação Si-H central, formando assim uma ligação do tipo Si-OH (hidroxila). () cálculo de energia total (utilizando o nanocristal de 134 átomos e otimizando a superfície e as duas primeiras camadas) mostrou que a formação da ligação Si-()।I é desfavorecida em relação à incorporação sub-superficial na forma Si-O-Si, com diferença de energia total de $\sim 0.39 \mathrm{eV}$. Esse resultado está em confronto com resultados de Oshiro e colaboradores[101] para a superfície $S i<111>$ não saturadi por H. À parte a diferença de superfícies, os resultados de Oshiro e colaboradores foram obtidos utilizando a aproximação MNDO original, que, sustentamos, não pode reproduzir corretamente ambientes de Si em coordenação tetraédrica (os próprios autores consideram o resultado duvidoso; a diferença de energia encontrada por eles é de $\sim 0.3 \mathrm{eV}$ ). Nossos resultados indicam claramente a preferência pelo sítio sub-superficial, e assim incluiremos essa configuração quando estudarmos as nanopartículas.

Essa preferência pela configuração intersticial Si-O-Si foi também observada por Pedersen e colaboradores[102] no estudo dos sistemas siloxenicos/siloxanicos. Mostramos na figura 5.2 duas das estruturas estudadas pelos autores, que investigamos também através do nosso método. Ambas as estruturas tem estequiometria $\mathrm{Si}_{2} \mathrm{OH}_{4}$, e a mudança é apenas estrutural.

O cálculo de Pedersen e colaboradores é realizado dentro do formalismo L.DA com pseudopotencial de troca-correlação de tipo Ceperley-Alder, usando expansão das funções de onda em gaussianas, e é feito para sistemas finitos. A otimização de geometria é feita pelas forças de Hellman-Feynman, e os autores incluem também correções de gradiente generalizadas ao termo de correlação. Comparamos na tabela 5.1 os resultados por eles obtidos, referentes à diferença de energía total entre as duas estruturas, com os resultados obtidos neste trabalho através do AM1/Cristal. Vemos que nossos resultados concordam muito bem, com a diferença entre nossos valores e os valores LDA+GGA de apenas $0.06 \mathrm{eV}$ por átomo de oxigênio incorporado.

Além disso, calculamos as frequências de vibração para os defeitos de superfície, que mostramos na tabela 5.2 juntamente com os resultados experimentais. Incluimos já resultados obtidos para a oxidação de superfície das nanopartículas que serão discutidas adiante. Os resultados são para o modo de estiramento Si-H na presença de oxigênio.

Vemos que comparando os nossos resultados aos resultados experimentais de 


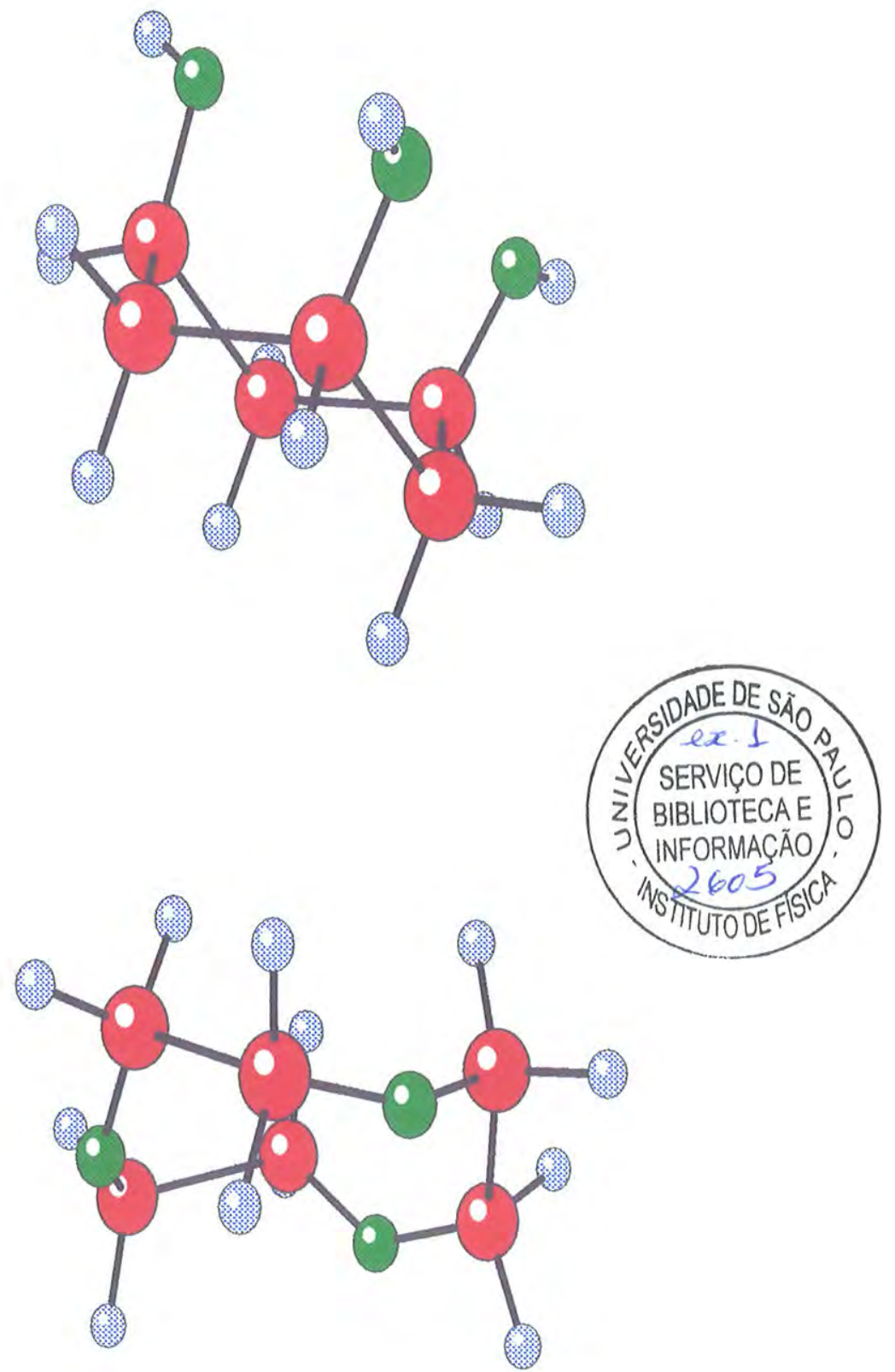

Figura 5.2: Representação das estruturas (siloxenica e siloxanica) estudadas por Pedersen e colaboradores[102] e pelo nosso trabalho. As esferas menores representam átomos de hidrogênio, as intermediárias átomos de oxigênio, e as maiores átomos de silício. 


\begin{tabular}{|c|c|c|c|}
\hline Método & LDA & LDA+GGA & AM1/Cristal \\
\hline$\Delta \mathrm{E} / \mathrm{O}(\mathrm{eV})$ & 0.40 & 0.44 & 0.50 \\
\hline
\end{tabular}

Tabela 5.1: Estabilidade da estrutura H-Si-O-Si-H (oxigênio no esqueleto) em relação à estrutura hidroxilada $\mathrm{H}-\mathrm{Si}-\mathrm{Si}-\mathrm{OH}$, para as moléculas $\mathrm{Si}_{6} \mathrm{O}_{3} \mathrm{H}_{12}$ (ver figura 5.2 anterior) obtidos por diferentes métodos: LDA e LDA+GGA [102] c AM1/Cristal deste trabalho. A estabilidade é media em ganho energético (em eV) por átomo de oxigênio

\begin{tabular}{|c|c|c|c|}
\hline \multicolumn{2}{|c|}{ Atribuição do Modo } & Exp. $\left(\mathrm{cm}^{-1}\right)[105,104]$ & Este Trabalho \\
\hline $\mathrm{S}$ & $\mathrm{Si}_{3}-\mathrm{SiH}$ & 2087 & 2180 \\
\hline $\mathrm{P}$ & $\mathrm{Si}_{3}-\mathrm{SiH}$ & 2087 & 2182 \\
\hline $\mathrm{S}$ & $\mathrm{Si}_{2} \mathrm{O}-\mathrm{SiH}$ & 2110 & 2192 \\
\hline $\mathrm{P}$ & $\mathrm{Si}_{2} \mathrm{O}-\mathrm{SiH}$ & 2136 & 2248 \\
\hline $\mathrm{S}$ & $\mathrm{SiO}_{2}-\mathrm{SiH}$ & 2220 & 2247 \\
\hline $\mathrm{S}$ & $\mathrm{O}_{3}-\mathrm{SiH}$ & 2270 & 2309 \\
\hline $\mathrm{P}$ & $\mathrm{Si}_{2} \mathrm{H}-\mathrm{SiH}$ & 2116 & 2205 \\
\hline
\end{tabular}

Tabela 5.2: Resultados experimentais (de acordo com a atribuição dos autores) da frequência de vibração de compostos moleculares envolvendo Si, H e O na superfície de $\mathrm{Si}<111>$ hidrogenada $(\mathrm{S})$ e de amostras de po-Si (P) em comparação com os resultados obtidos neste trabalho utilizando o $\mathrm{AM} 1 /$ Cristal (ver texto).

Borghesi e colaboradores [104] encontramos 11 ma ótima concordância para o deslocamento para energias mais altas quando da incorporação de oxigênio.

Para investigarmos a possível formação de ilhas de oxigênio, utilizamos o nanocristal de 134 átomos e para as configurações $\mathrm{Si}_{2} \mathrm{O}-\mathrm{SiH}_{\text {, }} \mathrm{SiO}_{2}-\mathrm{SiH}$ e $\mathrm{O}_{3}-\mathrm{SiH}$, otimizamos a geometria ao redor da região central da superfície (primeiros e segundos vizinhos dos átomos de oxigênio).

Para obtermos o ganho de energia pela formação de ilhas calculamıs a diferença de energia entre nanocristais diferentes, mas mantendo o número total de constituintes. Por exemplo para encontrarmos o ganho de energia para a formação de uma ilha com dois átomos de $\mathrm{O}\left(\mathrm{SiO}_{2}-\mathrm{SiH}\right)$ comparamos a energia total do 


\begin{tabular}{|c|c||c|c|}
\hline $\begin{array}{c}\text { Átomos } \\
\text { de } \mathrm{O}(\mathrm{n})\end{array}$ & $\begin{array}{c}\text { Ganho de Energia } \\
\left(E_{n}-E_{0}\right)(\mathrm{eV})\end{array}$ & $\begin{array}{c}\text { Formação } \\
\text { de ilhas }\end{array}$ & $\begin{array}{c}\text { Ganho de: } \\
\text { Energia }(\mathrm{eV})\end{array}$ \\
\hline 1 & 319.77 & - & - \\
\hline 2 & 640.78 & $\left(E_{2}+E_{0}-2 E_{1}\right)$ & 1.25 \\
\hline 3 & 962.93 & $\left(E 3+2 E_{0}\right)-\left(E_{1}+E_{2}+E_{0}\right)$ & 2.39 \\
\hline 3 & 962.93 & $\left(E_{3}+2 E_{0}\right)-3 E_{1}$ & 3.64 \\
\hline
\end{tabular}

Tabela 5.3: Energia de incorporação de átomos de O subsuperficiais formando ilhas em torno de um átomo de Si de superfície.

nanocristal com a ilha, somada à energia total do nanocristal sem a presença de (), com a energia total de dois nanocristais contendo $11 \mathrm{~m}$ átomo de O cada. Simulamos desta forma a diferença de energia para a incorporação de dois átomos de oxigênio em duas situações distintas: formando uma ilha de dois átomos, ou como defeitos isolados. Os resultados para o ganho de energia devido a formação de illıas estão apresentados na tabela 5.3.

Os resultados da tabela 5.3 mostram que há uma clara tendência nas energias totais do defeito para a formação de "clusters" de átomos de O, o que nos permite: dizer que os estágios iniciais da oxidação da superfície $\langle 111>$ de Si procedem por formação de ilhas.

Este resultado tem uma relevância própria, independentemente de sua aplicação ao estudo de po-Si, pois indica a origem da excepcional rugosidade da interface $\mathrm{Si} / \mathrm{SiO}_{2}$.

Para este trabalho em particular, nos levou a incluir entre as partículas oxidadas configurações envolvendo também mais de $u$ m átomo de oxigênio em vizinhança próxima.

No capítulo anterior apresentamos o estudo de absorção e emissão ótica de pequenas partículas de Si hidrogenadas. Neste capítulo iremos repetir este mesmo estudo para partículas de Si oxi-hidrogenadas, ou seja, com O e H presentes na superfície.

Apresentamos os resultados somente para as configurações obtidas a partir da oxidação da partícula $S i_{35} H_{36}$. Resultados para as demais são similares.

Introduzimos assim átomos de $\mathrm{O}$ formando as diferentes ligações químicas com os átomos de Si e H comentadas acima: ligações do tipo Si-OH, O intersticial isolado e formando ilhas (moléculas) de $\mathrm{SiO}_{2}$. Além disso investigamos também a influência 
da corrosão (etching) da partícula por oxigênio atômico, pela substituição de um grupo $\mathrm{SiH}_{2}$ de superfície por um único átomo de (). Chamamos essa configuraçáo de O substitucional.

\subsection{Absorção Ótica de Nanopartículas Fraca- mente Oxidadas}

Nosso estudo da oxidação das nanopartículas se restringiu à algumas configuraçōes de oxidação de superfície. Em particular, procuramos manter intacto o "core" da partícula, oxidando preferencialmente os sítios mais externos. Não chegamos em nenhum caso a alguma configuração onde se pudesse afirmar que temos uma camada de $\mathrm{SiO}_{2}$ na superfície. Lembramos que para essa partícula $\mathrm{Si}_{35} \mathrm{H}_{36}$, dos 35 átomos de Si apenas os 5 átomos centrais não tem nenhuma ligação com átomos de hidrogênio; na próxima camada ( a terceira com 12 átomos) cada átomo já tem um átomo de $\mathrm{H}$ vizinho, assim como a seguinte (quarta camada com ontros 12 átomos), e na camada mais externa, de seis átomos de $\mathrm{Si}$, cada $u$ se liga a 2 átomos de H. A oxidação foi estudada, em praticamente todos os casos, na quinta ou entre a quarta e a quinta camadas, com um máximo de 12 átomos de oxigênio (muito longe portanto da possível incorporação). Devido ao pequeno tamanho da partícula, a incorporação em grau elevado poderia mascarar os resultados (o "core" efetivo ficaria muito reduzido) e optamos por analisar o efeito quase individual do oxigênio sobre a absorção e emissão ótica dos sistemas.

Dado o grande número de estudos sobre a incorporação de oxigênio na forma de grupos hidroxila, iniciamos a discusão por este tipo de oxidação. Existem resultados teóricos anteriores sobre as propriedades óticas decorrentes da hidroxilação de superfícies [82] e fios[106] de Si, e também para as estruturas siloxenicas discutidas acima, finitas [102] $\left(\mathrm{Si}_{6} \mathrm{H}_{12}\right.$ versus $\left.\mathrm{Si}_{6} \mathrm{O}_{3} \mathrm{H}_{12}\right)$ e infinitas [102, 107] (bicamadas com estequiometria $\mathrm{Si}_{2} \mathrm{H}_{2}$ versus $\mathrm{Si}_{2} \mathrm{OH}_{2}$ ou $\mathrm{Si}_{2} \mathrm{O}_{2} \mathrm{H}_{2}$ ).

O resultado comum a todos os estudos é que a hidroxilação provoca un fechamento do gap, com um efeito maior sobre o fundo da faixa de condução. Comparamos na tabela 5.4 os resultados para as estruturas siloxenicas de Pedersen e colaboradores [102], Van de Walle e Northup[107], e os obtidos neste trabalho. Os resultados de Van de Walle e Northup são para o gap de quasipartícula com correção de autoenergia $(\mathrm{GW})$, já os resultados de Pedersen e colaboradores são para a diferença LDA de autovalores $\mathrm{HOMO} \rightarrow \mathrm{LUMO}$, que também inclui correlação isotrópica. Os 


\begin{tabular}{|c|c|c|c|}
\hline Estrutura & LDA+GW[107] & LDA simples[102] & ZINDO/Cristial \\
\hline H-Si-Si-H (infinita) & 2.75 & - & \\
\hline H-Si-Si-OH (infinita) & $1.7 \pm 0.3^{a}$ & 1.2 & \\
\hline H-Si-Si-H & - & 5.80 & 5.66 \\
$\left(\mathrm{Si}_{6} \mathrm{H}_{12}\right)$ & - & & $5.44^{b}$ \\
\hline $\mathrm{H}-\mathrm{Si}-\mathrm{Si}-\mathrm{OH}$ & - & 4.25 & 4.90 \\
$\left(\mathrm{Si}_{6} \mathrm{H}_{6}(\mathrm{OH})_{6}\right)$ & - & & $4.59^{b}$ \\
\hline
\end{tabular}

Tabela 5.4: Gap de energia (em eV) obtido para estruturas siloxenicas (ver figura da seção anterior) por diferentes métodos teóricos; Notar o fechamento do gap causado pela hidroxilação previsto por todos os modelos.

(a) correção GW estimada a partir do resultado para a bicamada Si-H.

(b)transição proibida.

nossos resultados são para o cálculo CI, sendo os valores entre parênteses para a primeira transição ótica, que é proibida (não tem força de oscilador). Apesar da diferença entre os métodos, fica evidente o efeito de fechamento do gap, que a primeira vista poderíamos esperar também no caso das partículas.

Mostramos na figura 5.3 a geometria da partícula com 12 grupos $\mathrm{OH}$ e podemos primeiramente perceber que não ocorreu grandes distorções do "core" quase cristalino. O espectro de absorção ótica para as configurações com 1, 2 e 12 grupos hidroxila esta apresentado na figura 5.4.

Vemos que com oxidação em apenas $u m$ sítio ( 1 e 2 grupos $\mathrm{OH}$ ) a primeira absorção praticamente não é afetada, a menos de uma perda pequena de intensidade (força de oscilador). A mesma tendência é seguida para 4 ou 6 grupos $O H$, con uma quebra mais notável de simetria implicando em maior alargamento do pico de absorção. A presença dos grupos $\mathrm{OH}$ tem ação mais forte sobre o pico AlI, que também deriva da região de caroço, mas se alarga muito mais com a presença de grupos superfíciais, perdendo com isso intensidade no máximo a ponto de quase não ser visto com 2 grupos $\mathrm{OH}$. A simetria da partícula pode restaurar esse pico, como vemos quando da incorporação de 12 grupos hidroxila.

Para a partícula com 12 grupos $\mathrm{OH}$ pela primeira vez a primeira absorção é uma transição proibida, e temos um pequeno deslocamento para o vermelho. Essa perda de força de oscilador não é decorrente de simetria, uma vez que a transição proibida é também do tipo geral $\mathrm{T} \rightarrow \mathrm{A}$, é primariamente uma transição de um- 
elétron HOMO $\rightarrow$ LUMO, como vemos na figura 5.5. Vemos entretanto (figura 5.6) que o HOMO nesse caso é "puxado" para os átomos de Si superficiais, pela oxidação, enquanto o LUMO continua tendo um caráter de "core".

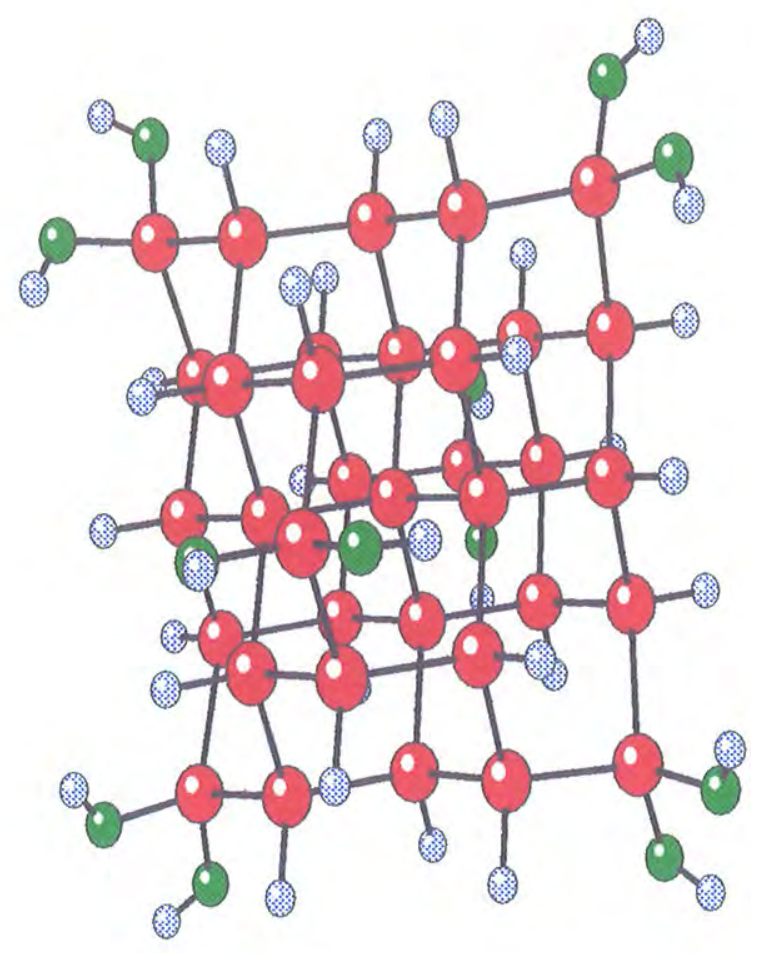

Figura 5.3: Representação gráfica da partícula $S i_{35} H_{36}$ com incorporação de 12 grupos hidroxila superficiais. 


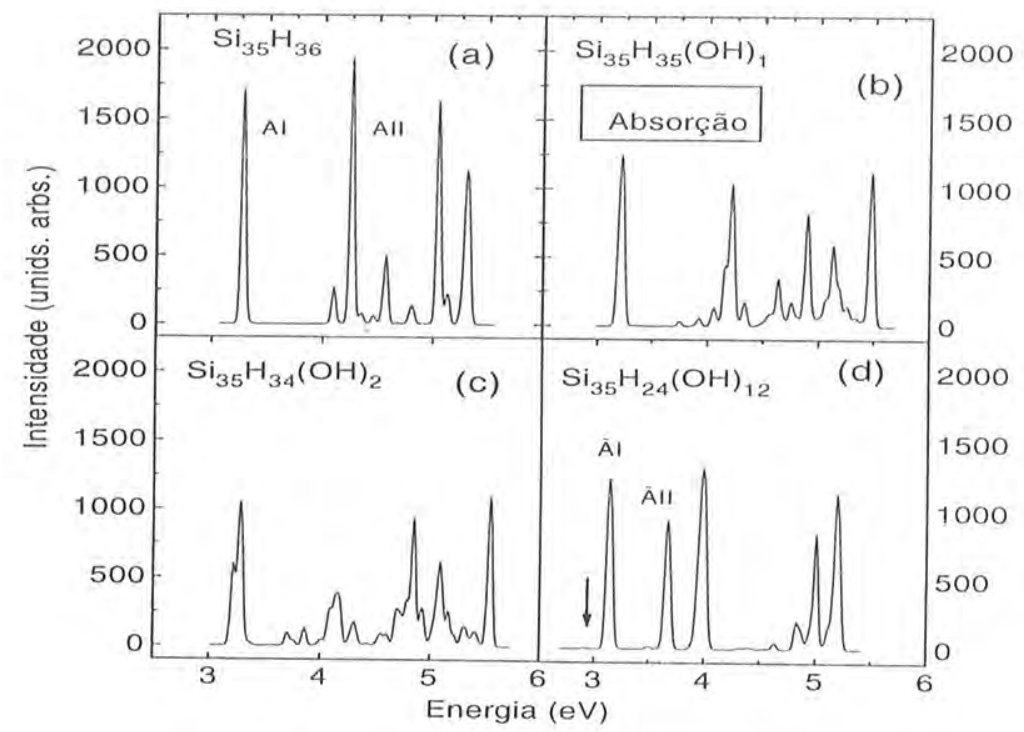

Figura 5.4: Efeito sobre a absorção ótica da hidroxilação dos átomos de Si mas externos à partícula: em (a) repetimos para comparação a absorşào da parlícula apenas hidrogenada, em (b) com um grupo hidroxila, em (c) com dois grupos ligados a um mesmo átomo de Si, e em (d) temos a configuração da figura anterior (1:? grupos hidroxilas). A flecha indica a energia da primeira transiçăo proibida. 


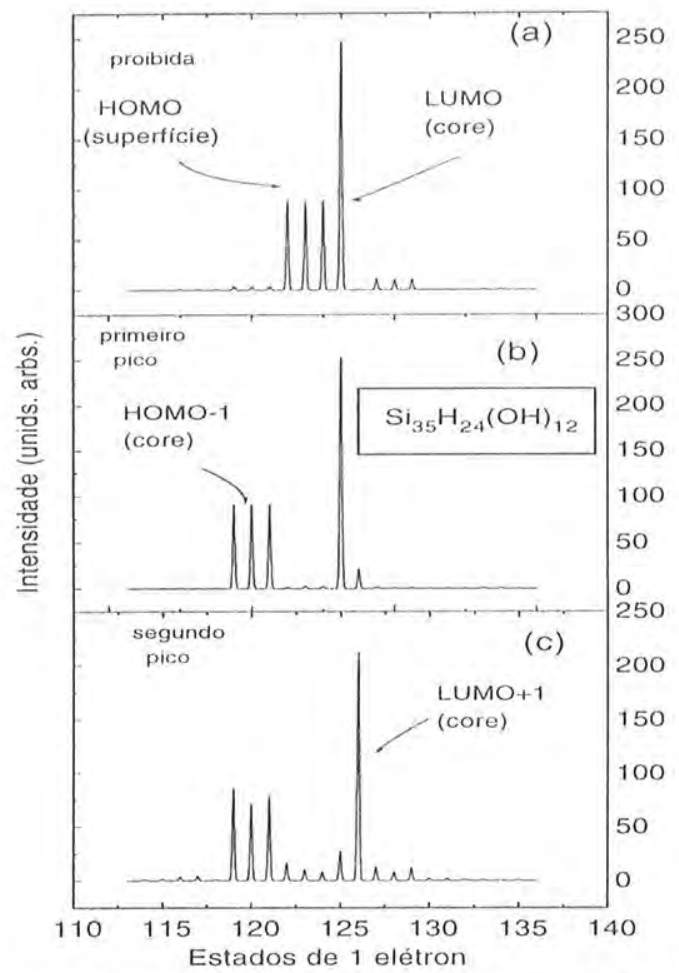

Figura 5.5: Composição das funções de onda determinantais correspondentes à primeira absorção ótica da partícula $\mathrm{Si}_{35} \mathrm{H}_{24}(\mathrm{OH})_{12}$ com 12 grupos hidroxila na superfície (camada mais externa), em termos de estados de um-elétron. 


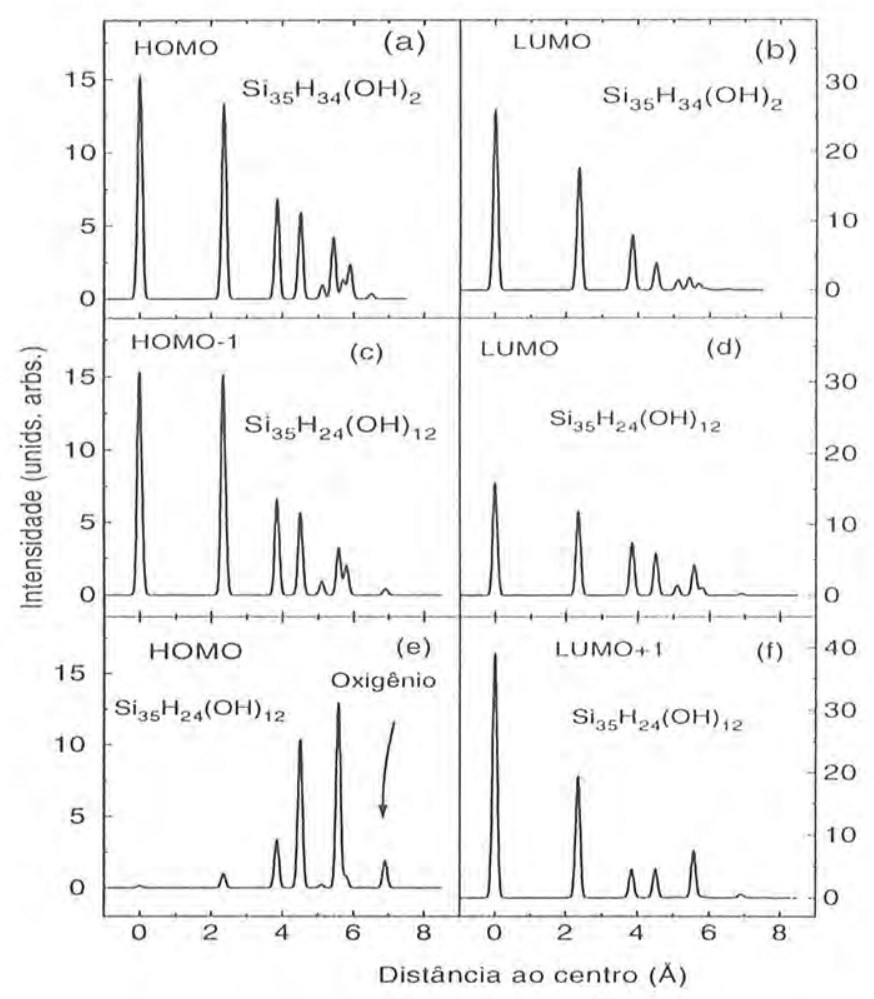

Figura 5.6: Localização espacial dos estados de um-elétron mais relevantes para o espectro de absorçâo das nanopartículas com grupos hidroxila na superfície.

Vamos reencontrar a absorção AII, no caso da partícula com $12 \mathrm{OH}$, logo acima. da primeira transição, com um forte deslocamento para o vermelho (pico ÂII). Esse pico mantém um caráter de transição quase pura (HOMO-1) $\rightarrow(\mathrm{LUMO}+1)$, e o deslocamento de energia ocorre já a nível de partícula independente, por um efeito claro da presença dos grupos superficiais, mas indireto (não temos contribuição de átomos de $\mathrm{O}$ a estes estados, como vemos na figura 5.6). O estado LUMO+1 vem diretamente de um estado que estava a energias muito mais altas (antigo estado 93 na partícula sem a presença dos grupos $\mathrm{OH}$ ) mas desce relativamente aos outros no caso da oxidação.

O estado mais afetado pela incorporação de grupos OH superficiais é o HOMO, 

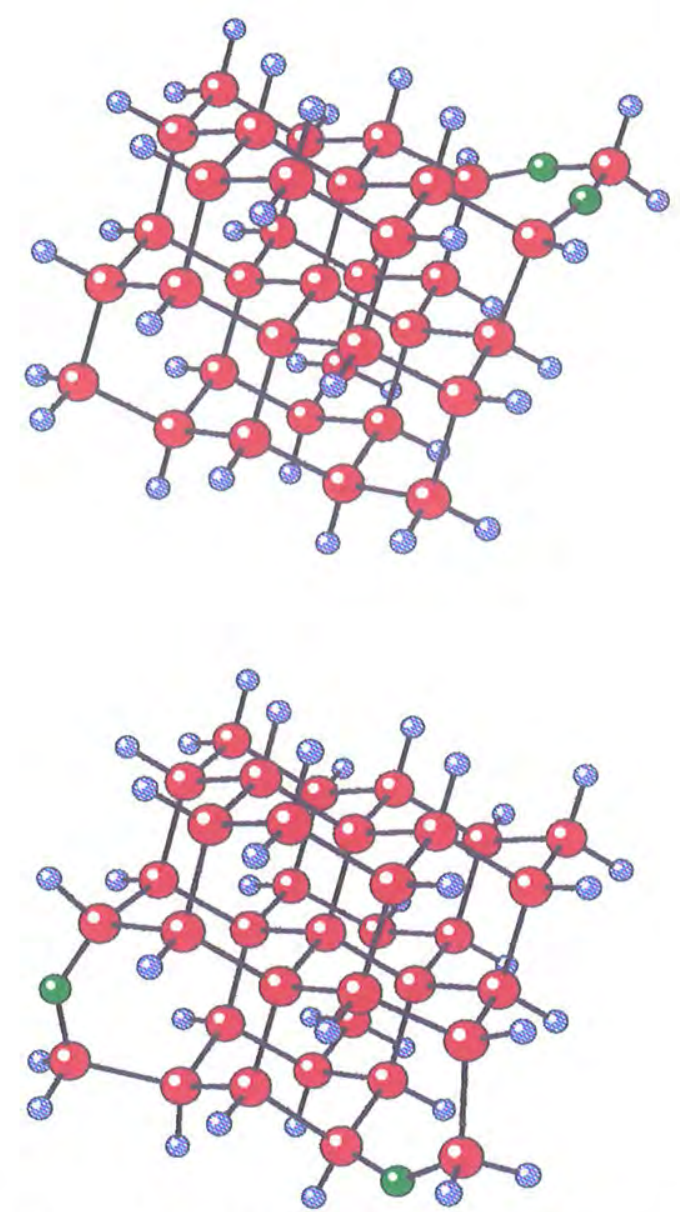

Figura 5.7: Representação gráfica das partícula $S i_{35} H_{36}$ com incorporação de 2 átomos de $\mathrm{O}$ subsuperficiais, separados e formando uma "molécula" de $\mathrm{SiO}_{2}$.

mas em energias temos um deslocamento substancial tanto do HOMO quanto do LUMO (maior) e LUMO+1. O gap de um elétron fecha em torno de $\sim 0.3 \mathrm{eV}$, com maior influência em energia do fundo da "faixa de condução". Entretanto, após inclusão de correlação, vemos que o efeito geral é muito pequeno.

Passemos agora ao caso de incorporação subsuperficial, que vimos ser o mais provável no caso real. Mostramos na figura 5.7 a geometria de duas nanopartículas com átomos de $\mathrm{O}$ subsuperficial em duas configurações distintas: isoladas $\left(2 O_{\text {int }}\right)$ e ligadas a um mesmo átomo de $\mathrm{Si}$ superficial $\left(\mathrm{SiO}_{2}\right)$. Estudamos também casos com maior grau de oxidação (até 12 átomos incorporados subsuperficialmente à camada mais externa). 


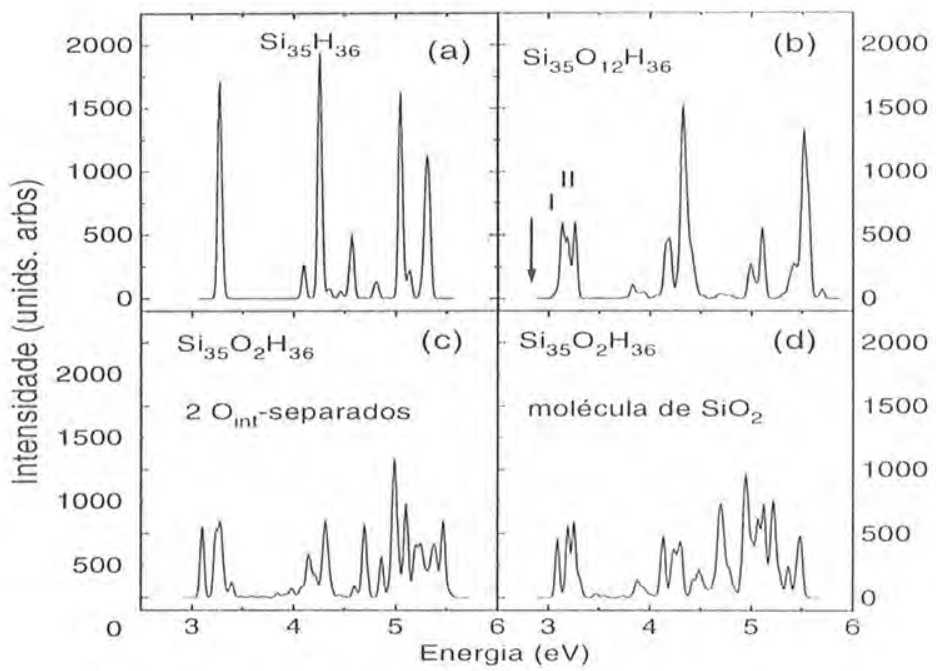

Figura 5.8: Efeito sobre a absorção ótica da incorporaçâo de oxigênio subsuperficiul à camada mais externa da partícula: em (a) repetimos para comparaçào a absorçao da partícula limpa, em (b) com saturação da última camada, em (c) e (d) com dois átomos de O separados na superfície e ligados ao mesmo átomo de Si, como mostra a figura anterior.

Mostramos na figura 5.8 o espectro de absorção para as estruturas com 2 e 12 átomos de oxigênio. Notamos o alargamento abrupto e perda de intensidade do primeiro pico, entretanto sem alteração significativa do limiar de absorção. 


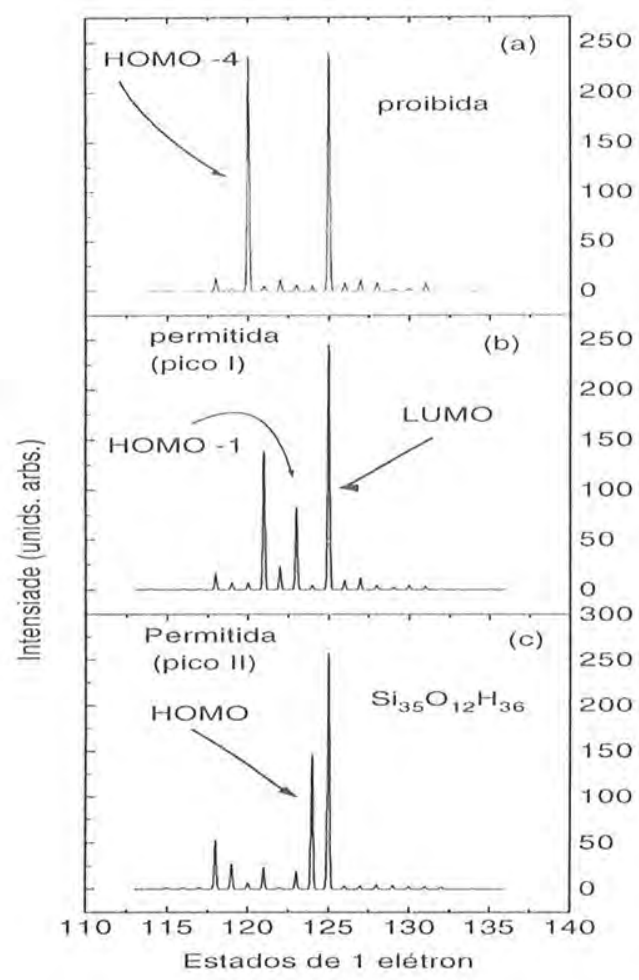

Figura 5.9: Composição das funções de onda determinantais correspondentes ì absorçâo ótica da partícula $\mathrm{Si}_{29}\left(\mathrm{SiO}_{2}\right)_{6} \mathrm{H}_{36} \mathrm{com} 6$ compostos $\mathrm{SiO}_{2}$ em termos de estados de um elétron.

Na figura 5.9 graficamos a composição das funções de onda determinantais responsáveis pelos primeiros picos de absorção ótica da partícula com 12 átomos de O subsuperficiais. Novamente a primeira transição é HOMO $\rightarrow$ LUMO, apenas há um deslocamento do antigo HOMO, que neste caso não perde o caráter cristalino como podemos ver na figura 5.10 . 


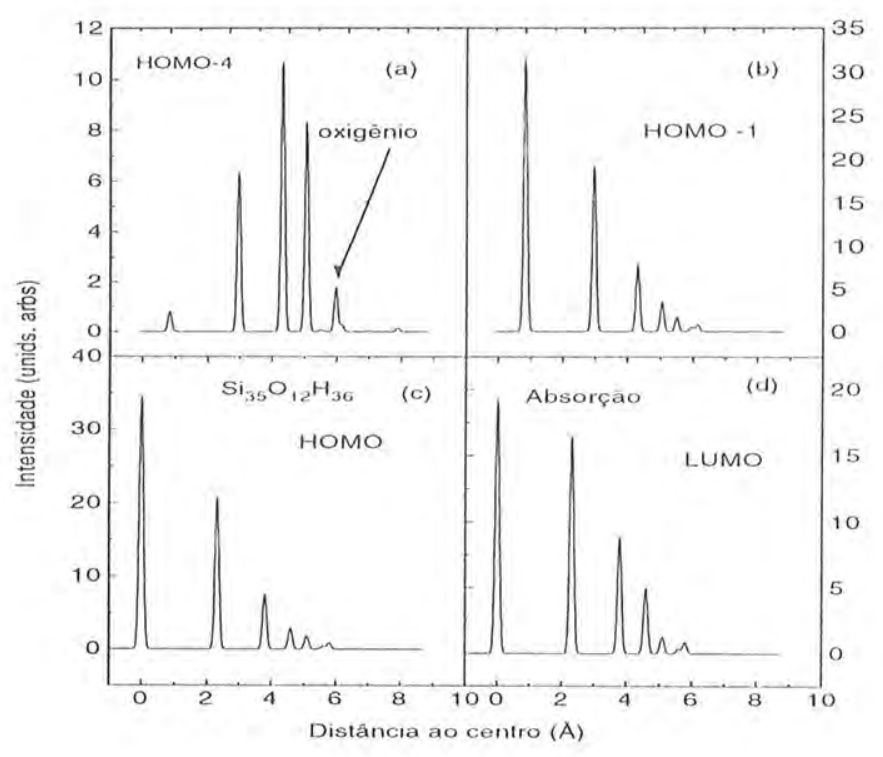

Figura 5.10: Localização espacial dos estados de um-elétron mais relevanles pura o espectro de absorção ótica da nanopartícula $\mathrm{Si}_{29}\left(\mathrm{SiO}_{2}\right)_{6} \mathrm{H}_{36}$.

Os estados HOMO-1 e HOMO são ainda caracteristicos de "core", assim como o LUMO, e a primeira banda (picos I e II) é derivada dessas transições [(HOMO1) $+\mathrm{HOMO} \rightarrow$ LUMO] com mistura de configurações mais acentuada, mas sem envolver os estados de superfície como HOMO-4. Entretanto, cabe notar que temos de novo uma transição proibida, envolvendo um estado que é puxado para a superfície, que só se mostra claramente com a simetria restaurada pela incorporação de 12 átomos subsuperficiais.

Nossa próxima simulação, de corrosão superficial (ver representação na figura 5.11), produz resultados muito semelhantes como visto na figura 5.12. O maior efeito é ainda de desdobrar e diminuir a intensidade do primeiro pico de absorção, e afetar drasticamente o pico AII. De novo nesse caso, com a restauração de simetria causada pela corrosão completa da última camada da partícula, aparece uma transição proibida pouco abaixo de $3 \mathrm{eV}$.

Aqui a dimensão efetiva da partícula sofreu uma pequena redução, e o HOMO 

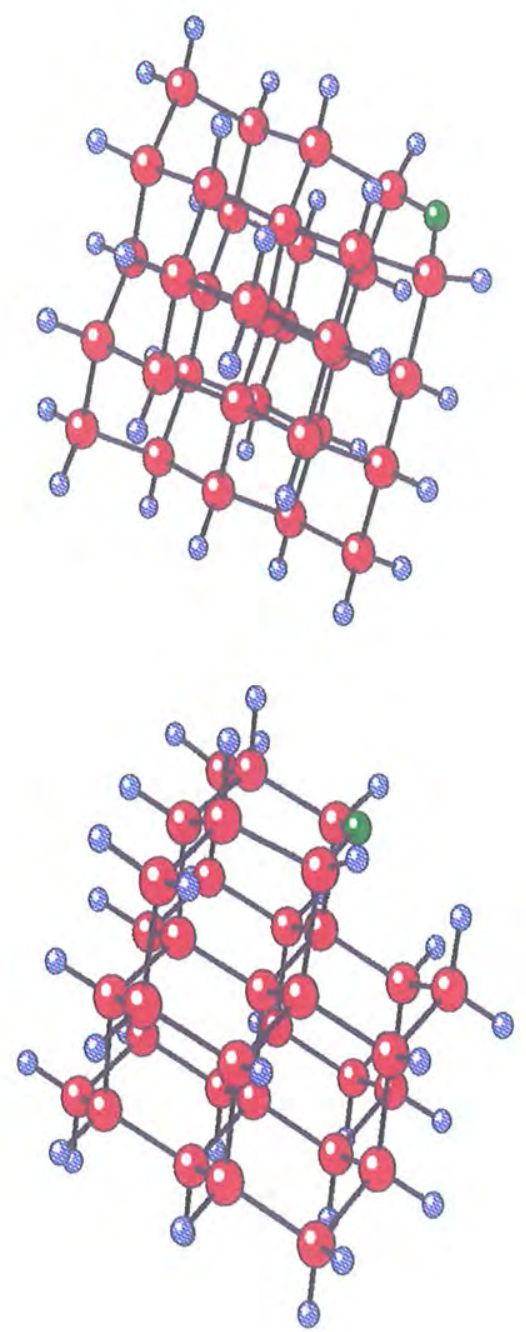

Figura 5.11: Representação gráfica das partículas $S i_{35} H_{36}$ com corrosão por oxigênio: (a) oxigênio corroendo a última camada da superfície e (b) oxigênio corroendo a camada anterior a superfície. 


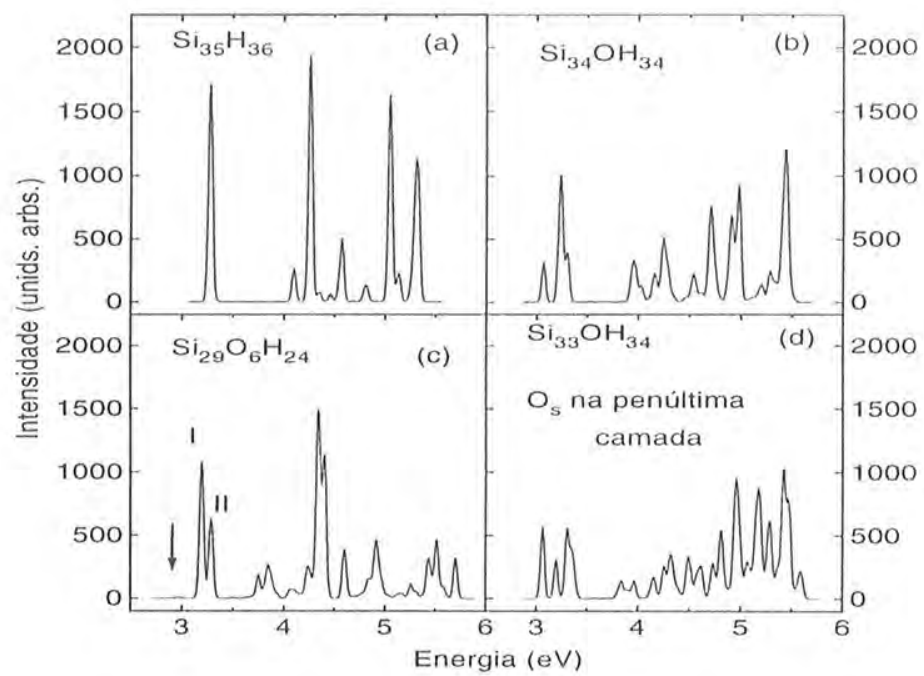

Figura 5.12: Efeito sobre a absorção ótica da corrosão de grupos $\mathrm{SiH}_{2}$ por oxigênio na camada mais externa da particula, em (b) $e$ (c). A flecha indica a energiu da primeira transição proibida. Em (a) repetimos para comparação a absorção da partícula limpa. Em (d) a corrosão é mais profunda (ver a figura anterior) causando uma quebra acentuada de simetria. 


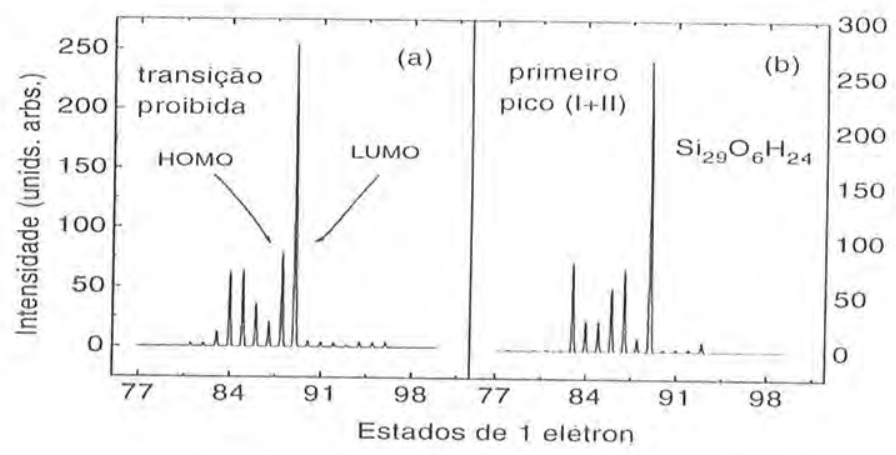

Figura 5.13: Composição das funções de onda determinantais, correspondentes aos primeiros picos do espectro de absorçâo da partícula com corrosão de 6 grupos sill. de superfície, em termos de estados de um-elétron.

sofre mudança de caráter (ver figura 5.14). Desta vez tanto a primeira banda quanto a transição proibida tem uma característica de mistura de configuraçōes (ver figura 5.13), sendo claro que a transição que tem contribuição de HOMO é a proibida.

Comparando os três tipos de oxidação, para as partículas com 12 átomos de $\mathrm{O}$ incorporados (12 OH, 5.4(d), $6\left(\mathrm{SiO}_{2}\right) 5.8$ (b)) e com corrosão dos 6 átomos de Si externos (figura 5.12 (c)), vemos que o maior efeito quanto ao gap é causado pelo O subsuperficial, e é ainda bastante pequeno. 


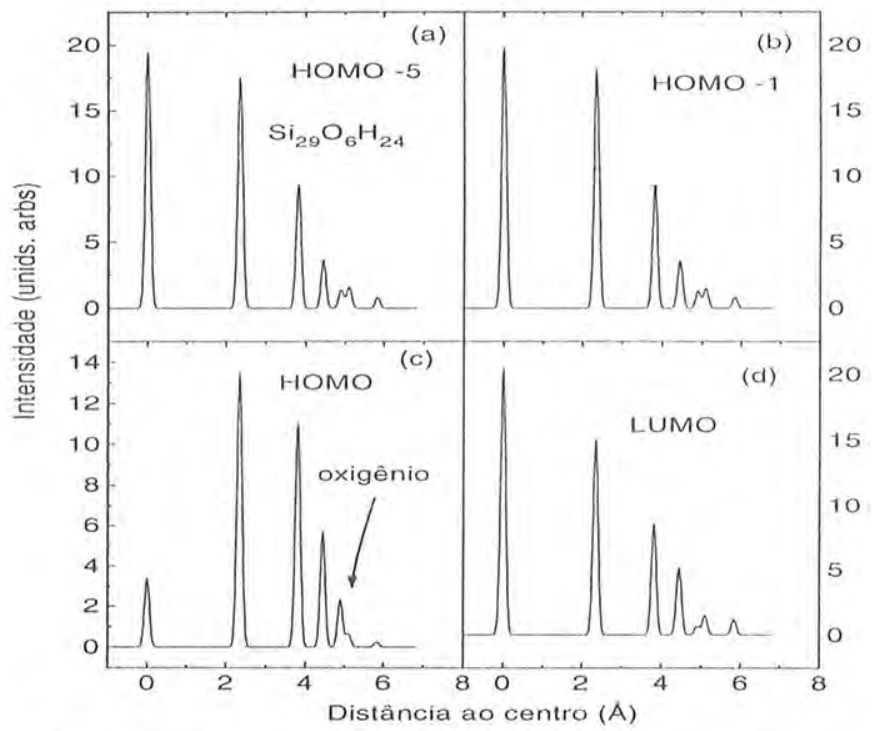

Figura 5.14: Localização espacial dos estados de um-elétron mais relevantes para o espectro de absorção da partícula com corrosão por 6 átomos de $O$.

É realmente notável a pouca sensibilidade que encontramos para a absorção ótica dessa partícula à oxidação da superfície, ao menos no que diz respeito à primeira absorção. Inclusive quando a corrosão atinge uma região $u m$ pouco mais central (ver figura 5.11 (b) com o espectro de absorção na figura 5.12 (d)) além do efeito de reduzir drásticamente toda a intensidade de absorção na região super-limiar, temos o deslocamento e redução do primeiro pico. Entretanto, em nenhum caso é detectado o deslocamento para o azul da primeira transição: ao contrário, existe um pequeno deslocamento para o vermelho.

Podemos atribuir isto ao fato de termos em todos os casos (com uma única exceção) pertubado apenas as camadas mais externas, deixando assim o "core" da partícula (região quase cristalina) praticamente intacto. Como a absorção se dá no "core", essas pertubações não afetam essa propriedade. 


\subsection{Emissão Luminescente de Partículas de Si- H fracamente oxidadas}

Da mesma forma que para as partículas limpas, estudamos as propriedades de decaimento radioativo dessas partículas oxidadas. Uma vez que a alta simetria das partículas completamente oxidadas coloca uma transição proibida abaixo do limiar de absorção, e considerando ainda que é interessante conhecer o comportamento para situações de simetria mais baixa e onde o papel do oxigênio possa ser individualizado, estudamos apenas as partículas com ataque a $11 m$ sítio de Si: partícula com dois grupos hidroxila $\left(\mathrm{Si}_{35} \mathrm{H}_{34}(\mathrm{OH})_{2}\right)$ ligados a $11 \mathrm{~m}$ mesmo átomo de $\mathrm{Si}$; partícula com um átomo de $\mathrm{O}$ subsuperficial $\left(S i_{35} \mathrm{OH}_{36}\right)$; e corrosão de um "canto" $\mathrm{SiH}_{2}\left(\mathrm{Si}_{34} \mathrm{OH}_{34}\right)$.

Em todos esses casos, a primeira transição é permitida e tem caráter de transição "quase pura" (HOMO $\rightarrow$ LUMO). Lembramos que quase sempre existe pertubação do HOMO, mas o LUMO permanece inalterado. Simulamos agora essa transição excitônica, e calculamos com o AM1/Cristal as propriedades estruturais do estado excitado, com relaxação completa de todos os átomos da partícula.

Mostramos nas figuras 5.15 e 5.16 a geometria de estado excitado obtida para. essas nanopartículas oxidadas, comparadas à partícula limpa. Podemos notar dois pontos importantes. Em primeiro lugar, a configuração de ponte Si-H-Si continua a ser espontaneamente criada no estado fotoexcitado; em segundo lugar, o defeito fotocriado é atraido pela distorção já existente próxima ao sítio de oxidação. O॥ seja, a ponte é criada envolvendo um átomo de Si primeiro vizinho a $11 m$ átomo de O, no "canto" corroido (partícula $S i_{34} O H_{34}$ ), ou segundo vizinho ao átomo de () no caso das outras duas partículas.

Confirma-se assim nossa previsão de que a "rugosidade" da superfície atrai ou propicia esse defeito fotocriado.

Analisamos agora o efeito sobre a energia da luminescência esperada, picos I e II na figura 5.17. Dada a semelhança geral do impacto da fotoexcitação, não é de estranhar o fato de que os espectros sejam quase idênticos entre si, incluindo o caso da partícula limpa. Lembramos novamente que a parte alta do espectro não é causadora de luminescência, já que a partícula distorce sob o efeito da excitação na primeira linha do espectro de absorção. 

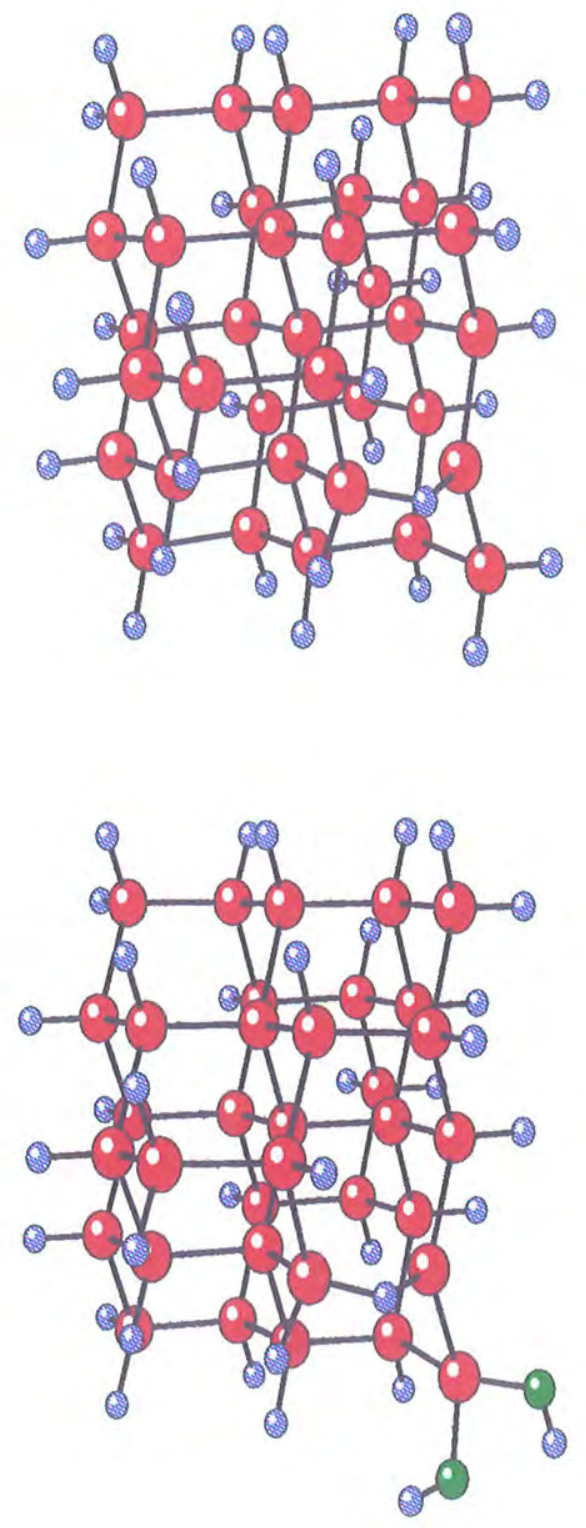

Figura 5.15: Representação gráfica das partículas $S i_{35} H_{36}$ no estado excitado: (a) limpa e (b) com dois grupos hidroxila. Notar o defeito fotocriado, a ponte $\mathrm{Si}-\mathrm{H}-\mathrm{Si}$, no canto inferior direito das figuras. 

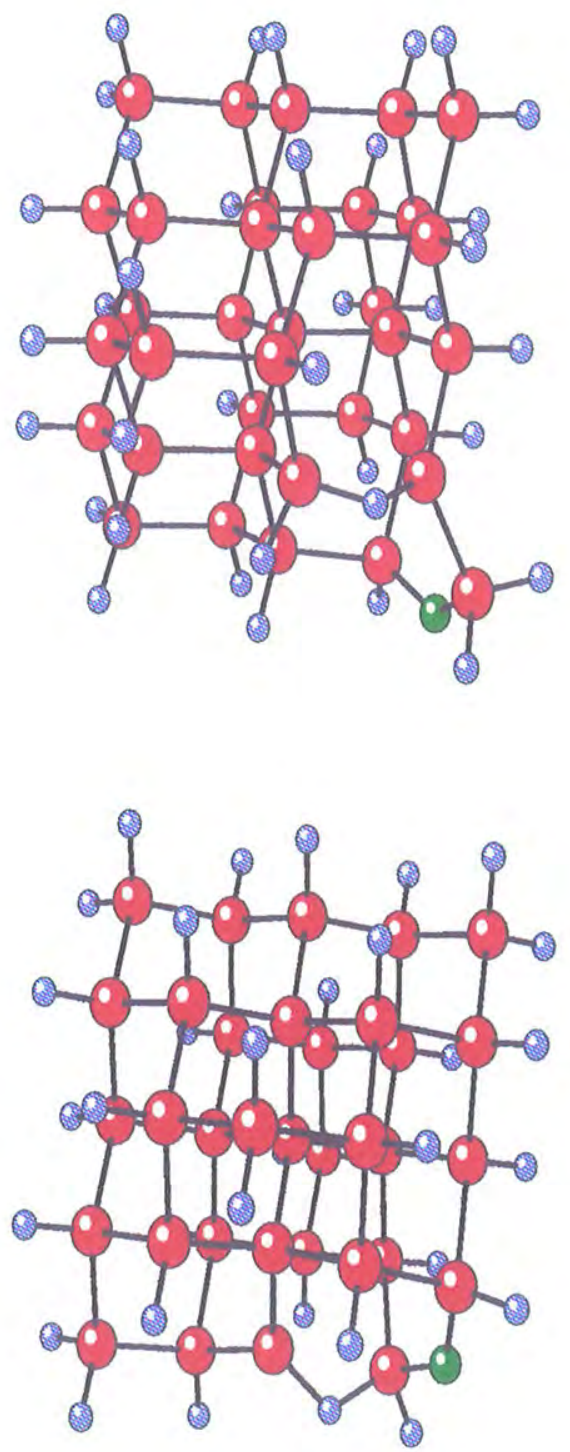

Figura 5.16: Representação gráfica das partículas $S i_{35} H_{36}$ no estado excitado: (a) com um átomo de $\mathrm{O}$ subsuprficial e (b) com corrosão de um grupo $\mathrm{SiH}_{2}$ de superfície. Noter o defeito fotocriado, a ponte $\mathrm{Si}-\mathrm{H}-\mathrm{Si}$, no canto inferior direito das figuras. 


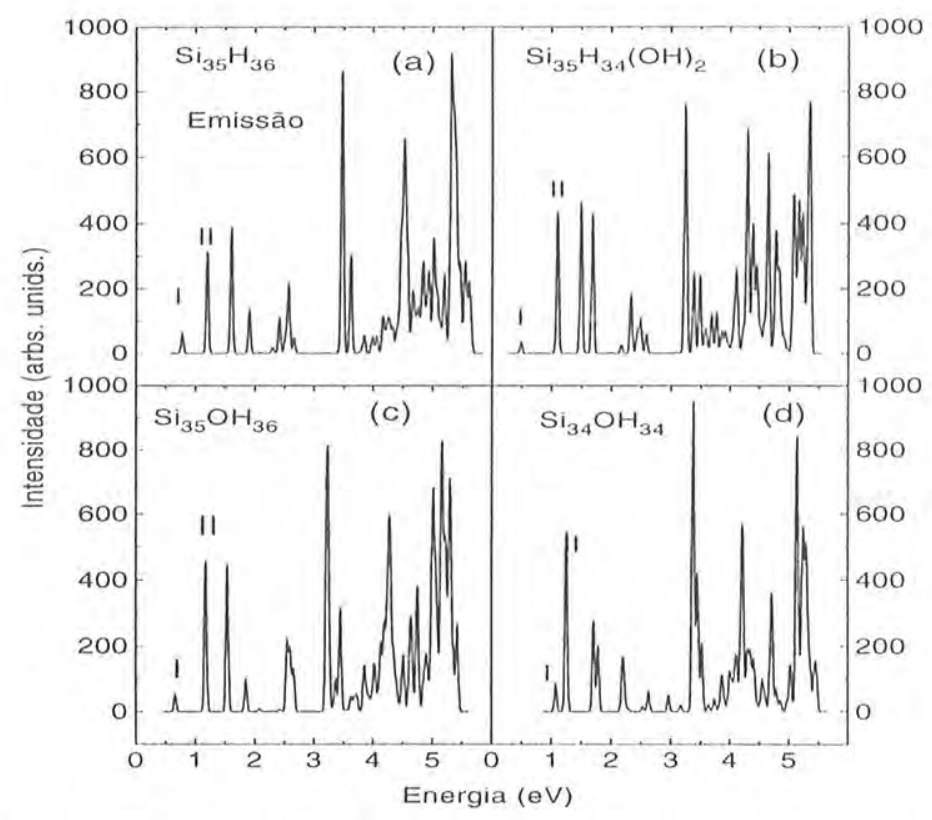

Figura 5.17: Espectro de emissão (região baixa) das nanopartículas de Si hidrogenadas:(a) limpa; (b) com incorporação de dois grupos hidroxila; (c) com 111 átomo de O subsuperficial e (d) substitucional, corrosão de um grupo $\mathrm{SiH}_{2}$ de superfície. Veja as duas figuras anteriores para a geometria do estado excitado.

A semelhança entre os espectros deriva da extrema localização da transição sobre os átomos da ponte Si-H-Si. Mostramos primeiramente na figura 5.18 a composição da transição para as três partículas, e incluimos os resultados para a partícula limpa. Registramos novamente a interação de configurações entre LUMO e LUMO+1. Ao analisarmos esses estados, na figura 5.19, constatamos novamente a concentração, sobre os átomos átomos do defeito, do HOMO e do LUMO+1. 

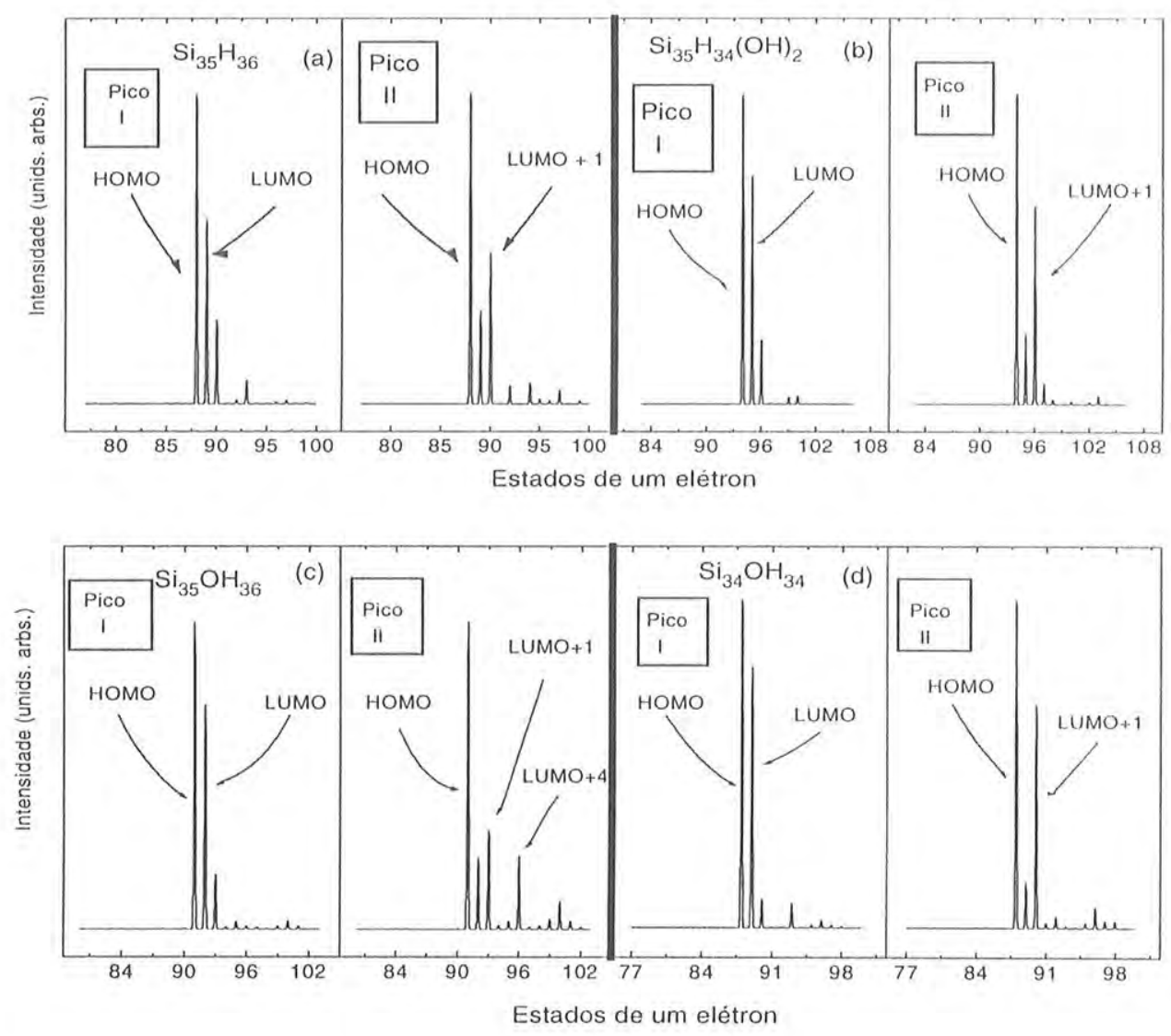

Figura 5.18: Composição das funções de onda determinantais responsáveis pelos dois primeiros picos de emissão da nanopartícula em termos de estados de um elétron: (a) partícula $\mathrm{Si}_{35} \mathrm{H}_{36}$ limpa; (b) com dois grupos hidroxila de superfície; (c) com um átomo de $\mathrm{O}$ subsuperficial e (d) com corrosão de um grupo $\mathrm{SiH}_{2}$ de superfície por um átomo de $\mathrm{O}$. 


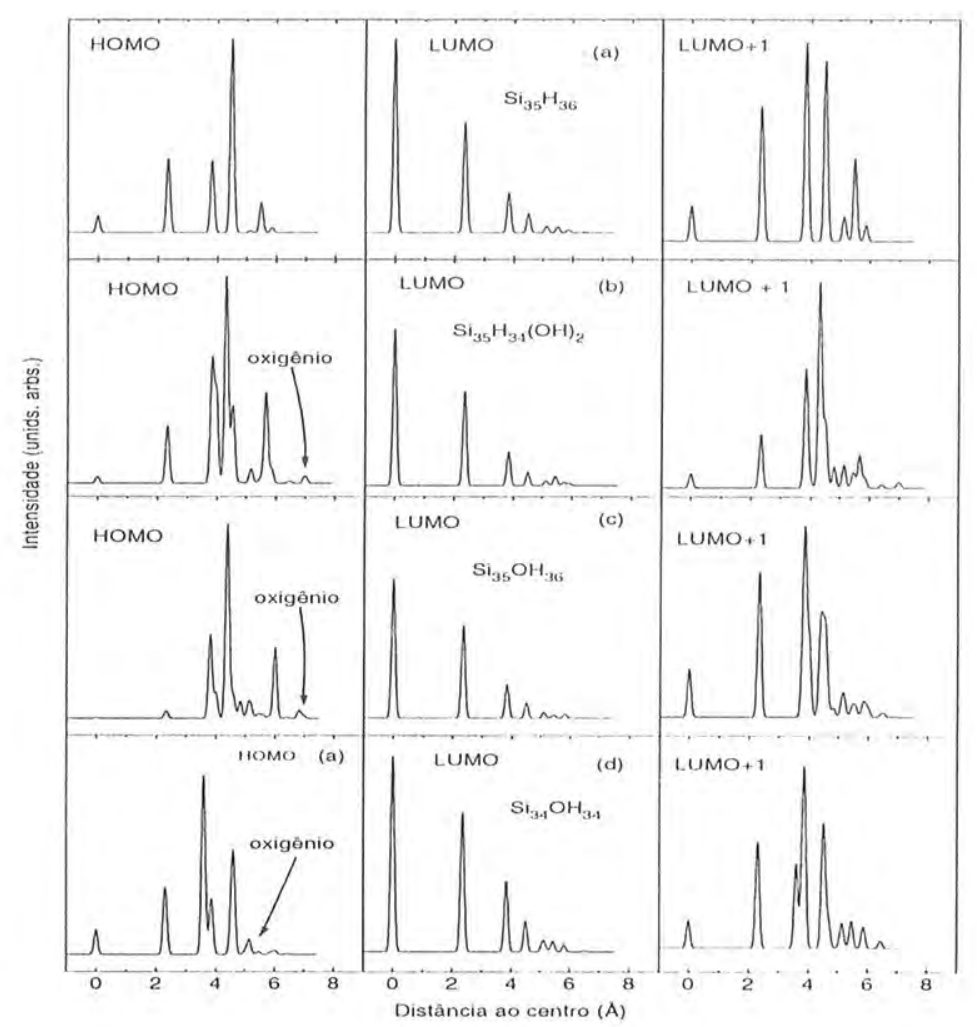

Figura 5.19: Localização espacial dos estados de um elétron mais relevantes para a emissão ótica da partícula. Em (a) partícula $S i_{35} H_{36}$ limpa; (b) com dois grupos hidroxila de superfície; (c) com um átomo de O subsuperficial e (d) com corrosão de um grupo $\mathrm{SiH}_{2}$ de superfície por um átomo de $\mathrm{O}$. 
Resumindo nossos resultados para a luminescência de partículas fracamente oxidadas, vemos que o defeito superficial de ponte Si-H-Si continua sendo fotocriado, em sítios próximos ao átomo de oxigênio incorporado, e mantém as características principais exibidas no caso da partícula limpa.

A análise do espectro de emissão nos indica principalmente que a energia da luminescência é fracamente afetada pela presença de átomos de O na superfícic. Podemos discernir um pequeno deslocamento para o vermelho no caso da incorporação de grupos hidroxila, e um deslocamento para o azul mais considerável ( $0.3 \mathrm{eV})$ no caso da corrosão.

Podemos especular a partir destes resultados que o maior efeito da oxidação é a supressão de sítios para a fotocriação de defeitos, uma vez que a presença do átomo de $\mathrm{O}$ entre os átomos de $\mathrm{Si}$ claramente proibe a formação da ponte. Com a supressão dos sítios, a intensidade da luminescência vermelho-laranja necessariamente diminui. 


\section{Capítulo 6 Conclusões}


Apresentamos neste trabalho um procedimento para o estudo de propriedades estruturais e óticas de sistemas semicondutores complexos, tais commo defeitos pontuais, no volume ou em superfícies e interlaces, reconstruçoes e assim por diante. Este procedimento de destina principalmente a sistemas onde mma ampla gama do configuracões diferentes deva ser estudada, e por consequência o uso de métodos ab initio está fora de questão. Para tal, fomos buscar métodos de simulaşão entre as técnicas semiempíricas da Química Quântica, que têm demonstrado enormo sucesso na descrição das propriedades moleculares.

A simples "apropriação" destas técnicas para aplicação em sistemas semicondıtores tem tido sucesso apenas moderado, mas este trabalho mostrou que isto se deve ao fato de que as parametrizações originais das técnicas consideradas não inclıen, com peso relevante, os sistemas de coordenação tetraédrica. Assim, nosso procedimento envolve uma versão das técnicas AM1 e ZINDO com periodicidade de Bloch (que é usada apenas para permitir uma parametrização fiel ao caso cristalino), e um modelo de aglomerados ou nanocristais; além disso, envolveu a reparametrização completa de ambas as técnicas para os átomos de Si e O.

É importante ressaltar que este procedimento permite estudar a gometria dos sistemas através de otimização baseada em cálculo da energia total, levando em conta o rearranjo de carga eletrônica por usarmos uma técnica quântica e autoconsistente. Além disso, ao trabalharmos no formalismo de Hartree-Fock-Roothaan, podemos incorporar também efeitos de correlação eletrônica ao estudar a ótica das sistemas (através da correção de Interação de Configurações).

Com este procedimento, estudamos as propriedades estruturais e óticas de nanopartículas de Si hidrogenadas, e com oxidação da superfície.

Essas estruturas foram escolhidas por serem um modelo passível de estudo teórico, com realização na prática, e que tem bastante semelhança com o material silício poroso (po-Si).

Nosso estudo das propriedades estruturais de nanopartículas com desde 29 $\left(S i_{29} H_{36}\right)$ até 71 átomos de $\mathrm{Si}\left(S i_{71} H_{60}\right)$ revela que há relaxação simétrica não linear das diferentes camadas da partícula, mas com expansão final total muito pequena. É mantido um alto grau de cristalinidade, com reflexo no espectro vibracional, que espelha muito de perto o espectro de fônons do cristal de Si, além de mostrar as frequências características da ligação Si-H.

Nossos resultados para a absorção ótica dessas partículas (que têm diâmetro médio em torno de 10-15 $\AA$ ) confirma estudos teóricos anteriores colocando a primeira transição a energias $(\sim 3 \mathrm{eV})$ muito mais altas que a energia observada para o pico de fotoluminescência em po-Si (região vermelho/laranja). Entretanto, 
os valores estão em concordância boa com os dados experimentais para a curva de absorção seja de po-Si, seja de nanopartículas de Si, e mostran claramente efeitos de confinamento quântico (deslocamento para o azul conforme diminui o diâmetro efetivo da partícula).

Nosso estudo, uma vez que permite estudar em detalhes as transições óticas, revelam que a primeira transição tem um carácter "excitônico" no sentido de ser uma transição de um-elétron quase pura. A partir deste dado, pudemos estudar a emissão ou luminescência das partículas ao calcular a geometria ótinı para o estado excitado, e as propriedades óticas nessa nova geometria.

Nossos resultados para partículas perfeitamente saturadas por $\mathrm{H}$ indicanl a ocorrência de uma distorção muito forte e localizada no estado excitado, em que um átomo de hidrogênio desloca-se formando uma "ponte" entre dois átomos de Si de superfície, distorcendo um anel de Si. Nessa geometria, a energia de decaimmeto é muito menor, com um Stokes-shift da ordem de $2 \mathrm{eV}$. Uma outra configuraçấ metaestável, com apenas relaxação simétrica, também é encontrada.

Prosseguindo nossa investigaão para a oxidação da superfície, temos resultados que indicam em primeiro lugar que as propriedades óticas são muito pouco influenciadas pela presença de O na superfície das partículas. Se a absorção sofre algumas vezes mudanças mais profunda, os resultados para a emissão mostram uma curiosa indiferença à oxidação, nestes níveis em que ela foi estudada (sempre parcial).

Um resultado relevante é que a distorção no estado excitado ocorre próximo ao sítio de incorporação de oxigênio, onde a estrutura já tem alguma distorção. Entretanto, fazemos notar que com um maior grau de oxidação da superfície os sítios onde o defeito pode ser fotocriado seriam atacados, impedindo sua criação. Isso tem consequências sobre a intensidade da fotoluminescência.

Nossos resultados permitem assim fazer $1 \mathrm{~m}$ modelo para as propriedades óticas do po-Si. Mostramos na figura $6.1 \mathrm{um}$ esquema-resumo de nossos resultados. A absorção (A) ocorre no "core" da partícula, a energias cujo limiar depende do diâmetro efetivo da partícula e mostra efeitos de confinamento quântico. A emissão pode ocorrer ou na região vermelho/laranja $(\mathrm{PL}(\mathrm{R}))$ ou na região verde $(\mathrm{PL}(\mathrm{V}))$.

A emissão na região verde também tem carácter cristalino (é práticamente idêntica à absorção) e deriva de uma relaxação simétrica da partícula. Tem alta intensidade, mas é desfavorecida em energia, perdendo para a emissão PL(R). Esta emissão é práticamente fixa em energia, não depende do diâmetro da partícula, tem intensidade menor (maior vida média no estado excitado), e práticamente não é afetada pelo estado de oxidação da superfície. Entretanto a oxidação diminui o número de sítios onde a relaxação pode ocorrer, diminuindo assim, em uma amostra 


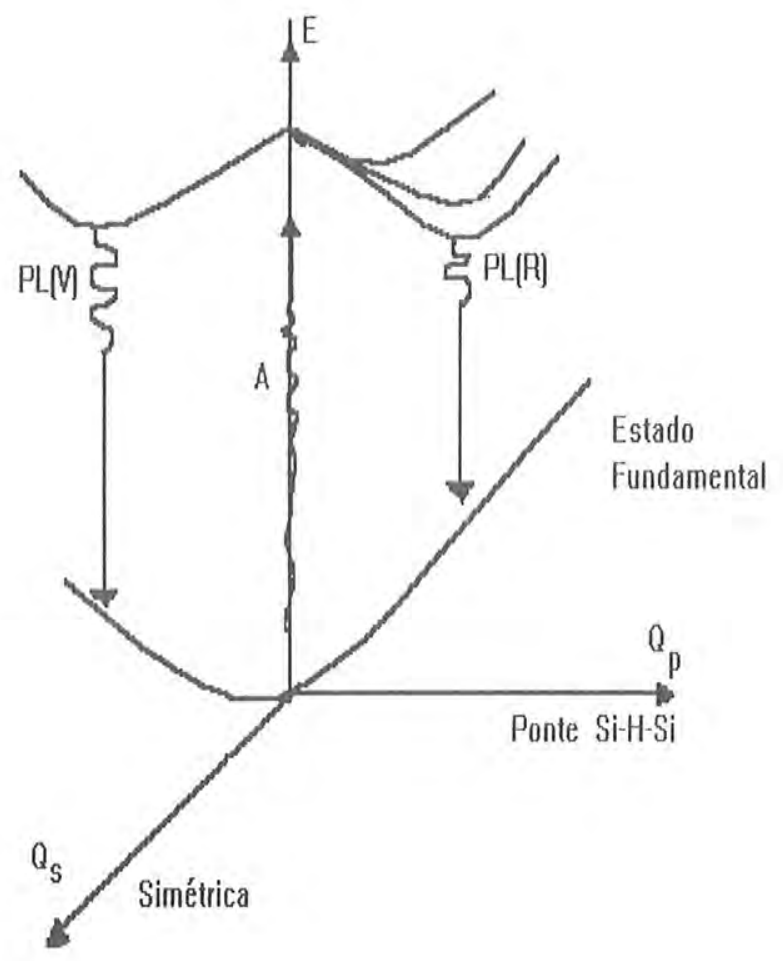

Figura 6.1: Esquema de transições óticas nas nanopartículas de silício hidrogenadas estudadas, segundo os resultados deste trabalho.

macroscópica, a intensidade total da $\mathrm{PL}(\mathrm{R})$.

O conjunto de nossos resultados nos permite concluir que os sítios ativos no silício poroso são regiões que podem ser consideradas como cristalitos esféricos; que a absorção ocorre no "core" cristalino do material, enquanto a luminescência está associada a defeitos criados na superfície por efeito da luz; e que a oxidação causaria um "enrijecimento" da superfície que diminui o número de sítios de luminescência, mas nào afeta a energia do pico.

Esses processos foram revelados pela primeira vez por este trabalho, e devem ter importância também em outros sistemas envolvendo superfícies rugosas, interfaces e outros ambientes "macios". 
Apêndice A

Matrizes de Fock para somas de Bloch: $\mathrm{Si}$ e $\mathrm{SiO}_{2}$ 
Neste apêndice iremos apresentar em detalhes como obter a matriz de Fock cristalina. Iremos apresentar para duas simetrias pontuais diferentes: simetria $T_{d}$, cristal de Si (célula unitária com 2 átomos e com 8 átomos, simetria tetraédrica); e simetria $D_{3 h}$, cristal de quartzo (célula unitária de 9 átomos com simetria $D_{3 h}$ ).

\section{A.1 Simetria tetraédrica com dois átomos na célula unitária e interação apenas entre pri- meiros vizinhos}

Para uma estrutura tetraédrica com dois átonos na base e interação apenas entre primeiros vizinhos, cada átomo "vê" um átomo localizado na própria célula unitária e outros três átomos localizados em células contíguas.

O elemento da matriz de Fock cristalina para o caso $A=B$, ou seja, átomos equivalentes (mesma subrede, ou mesma posição na célula), será

$$
\begin{aligned}
\mathbf{F}_{\mu \nu}^{A, A}(\mathbf{K}, \mathbf{r})= & \frac{1}{N_{c}} \sum_{I \neq J} e^{i \mathbf{K} \cdot\left(\mathbf{R}_{J}-\mathbf{R}_{I}\right)}<\phi_{\mu}^{A}\left(\mathrm{r}-\left(\mathbf{R}_{I}+\mathrm{d}_{A}\right)\right)|\mathbf{H}| \phi_{\mu^{\prime}}^{B}\left(\mathrm{r}-\left(\mathbf{R}_{I}+\right.\right. \\
& \left.\left.\mathrm{d}_{B}\right)\right)>+\frac{1}{N_{c}} \sum_{J} e^{i \mathrm{~K} .0}<\phi_{\mu}^{A}\left(\mathrm{r}-\mathrm{d}_{A}\right)|\mathrm{H}| \phi_{\nu}^{A}\left(\mathrm{r}-\mathrm{d}_{A}\right)>
\end{aligned}
$$

Lembrando que átomos equivalentes localizados em células diferentes nunca serão primeiros vizinhos resulta que

$$
\mathrm{F}_{\mu \nu}^{A \cdot A}(\mathrm{~K}, \mathrm{r})=\left(\frac{N_{c}}{N_{c}}<\phi_{\mu}^{A}\left(\mathrm{r}-\mathrm{d}_{A}\right)|\mathrm{H}| \phi_{\mu^{\prime}}^{A}\left(\mathrm{r}-\mathrm{d}_{A}\right)>.\right.
$$

Como podemos notar este elemento da matriz de Fock cristalina é idêntico ao elemento correspondente da matriz de Fock "molecular", ou seja

$$
\mathbf{F}_{\mu \nu}^{A, A}(\mathrm{~K}, \mathrm{r})=F_{\mu \nu}^{A . A}
$$

Os elementos da matriz de Fock cristalina para átomos que não sejam equivalentes, $A \neq B$, serão

$$
\mathbf{F}_{\mu \nu}^{A, B}(\mathbf{K}, \mathbf{r})=\frac{1}{N_{c}} \sum_{I \neq J} e^{i \mathbf{K} \cdot\left(\mathbf{R}_{J}-\mathbf{R}_{I}\right)}<\phi_{\mu}^{A}\left(\mathrm{r}-\left(\mathbf{R}_{I}+\mathrm{d}_{A}\right)\right)|\mathbf{H}| \phi_{\nu}^{B}\left(\mathbf{r}-\left(\mathbf{R}_{J}+\right.\right.
$$




$$
\left.\left.\mathrm{d}_{B}\right)\right)>+\frac{1}{N_{c}} \sum_{, I} e^{i \mathrm{~K} .0}<\phi_{\mu}^{A}\left(\mathrm{r}-\mathrm{d}_{A}\right)|\mathrm{H}| \phi_{u^{\prime}}^{B}\left(\mathrm{r}-\mathrm{d}_{B}\right)>
$$

Lembrando que nesta estrutura cada átomo "vê" como primeiro vizinho $11 m$ outro átomo localizado em $\mathbf{R}_{\mathbf{J}}=\mathbf{R}_{\mathbf{I}}$ (na própria célula) e outros três átomos localizados em células contíguas ligadas pelos vetores de translação primitivos $\mathrm{a}_{\mathrm{p}}$, C uma vez que

$$
<\phi_{\mu}^{A}\left(\mathrm{r}-\mathrm{d}_{A}\right)|\mathbf{H}| \phi_{\nu}^{B}\left(\mathrm{r}-\mathrm{d}_{\mathrm{B}}\right)>=F_{\mu \mu^{\prime}}^{A . B}
$$

encontramos que

$$
\mathbf{F}_{\mu \nu^{\prime}}^{A \cdot B}(\mathbf{K}, \mathrm{r})=\left[1+\sum_{\mu=1}^{3} e^{i \mathrm{~K} \cdot \mathbf{a}^{\prime \prime}} R_{p}\right] F_{\mu \nu^{\prime}}^{A \cdot B}
$$

onde $\mathbf{a}_{\mathbf{p}}$ são as translações primitivas da rede de Bravais e $R_{p}$ são rotações próprias do grupo pontual que pertence o cristal, que levam uma interação entre (os dois) átomos na célula à interação entre um átomo na célula e outro na célula contígua. Para o caso de uma simetria tetraédrica em que o átomo 1 está localizado na origen e o átomo 2 está distânciado de $\mathrm{d}=\sqrt{3} \frac{\mathrm{a}}{4}$ ao longa da diagonal positiva ( onde $a$ é o parâmetro de rede da célula cúbica convencional), temos que os vetores de translação $a_{p}$ são dados por

$$
\begin{aligned}
& \mathrm{a}_{1}=\left( \pm \frac{\mathrm{a}}{2}, 0, \pm \frac{\mathrm{a}}{2}\right) \\
& \mathrm{a}_{2}=\left( \pm \frac{\mathrm{a}}{2}, \pm \frac{\mathrm{a}}{2}, 0\right) \\
& \mathrm{a}_{3}=\left(0, \pm \frac{\mathrm{a}}{2}, \pm \frac{\mathrm{a}}{2}\right)
\end{aligned}
$$

e as rotações neste caso são as $C_{2}$ do grupo $T_{d}$.

Vejamos agora como podemos construir a matriz de Fock cristalina para o caso de interação entre vizinhos de mais alta ordem. 


\begin{tabular}{|c|c|c|c|}
\hline tipo de & \multicolumn{3}{|c|}{ coordenadas $(a)$} \\
\cline { 2 - 4 } átomo & $\mathrm{x}$ & $\mathrm{y}$ & $\mathrm{Z}$ \\
\hline 1 & 0 & 0 & 0 \\
\hline 2 & $\frac{1}{4}$ & $\frac{1}{4}$ & $\frac{1}{4}$ \\
\hline 3 & $\frac{1}{2}$ & 0 & $\frac{1}{2}$ \\
\hline 4 & $\frac{1}{4}$ & $\frac{1}{2}$ & $\frac{1}{2}$ \\
\hline 5 & 0 & $\frac{1}{0}$ & 0 \\
\hline 6 & $\frac{1}{2}$ & $\frac{1}{2}$ & $\frac{1}{4}$ \\
\hline 7 & $\frac{3}{4}$ & $\frac{3}{4}$ & $\frac{3}{4}$ \\
\hline 8 & $\frac{3}{4}$ & $\frac{1}{4}$ & $\frac{3}{4}$ \\
\hline 9 & $\frac{1}{4}$ & $\frac{3}{4}$ & $\frac{1}{4}$ \\
\hline 10 & $-\frac{1}{4}$ & $\frac{1}{4}$ & $-\frac{1}{4}$ \\
\hline 11 & $-\frac{1}{4}$ & $\frac{1}{4}$ & $-\frac{1}{4}$ \\
\hline 12 & $\frac{1}{4}$ & $-\frac{1}{4}$ & $\frac{1}{4}$ \\
\hline 13 & $\frac{3}{4}$ & $-\frac{1}{4}$ & $\frac{3}{4}$ \\
\hline 14 & 1 & 1 & 0 \\
\hline 15 & $\frac{1}{2}$ & 1 & $\frac{1}{2}$ \\
\hline 16 & 1 & $\frac{1}{2}$ & $\frac{1}{2}$ \\
\hline
\end{tabular}

Tabela A.1: Posições adotadas para a estrutura baseada na rede cúbica simple's de aresta a, com 8 átomos na base. Os primeiros 8 átomos pertencem à célula unitária, os demais estão em células contíguas (ver texto).

\section{A.2 Simetria tetraédrica com oito átomos na base e interação de até segundos vizinhos}

Para obtermos uma estrutura tetraédrica com oito átomos na base podemos colocar a origem do nosso sistema de coordenadas em um dos vértices do cubo (ver fígura A.1). Com isso os átomos de interesse para a obtenção da matriz de Fock cristalina estão localizados nas posições listadas na tabela A.1 ( $a$ é a aresta do cubo).

Os oito primeiros átomos são os átomos que estão contidos dentro da célula unitária tomada com origem,os átomos externos á célula unitária e de interesse nesse são : átomo 9, primeiro vizinho do átomo 6 e segundo vizinho do átomo 3; átomo 10, segundo vizinho dos átomos 6 e 7; átomo 11, segundo vizinho dos 


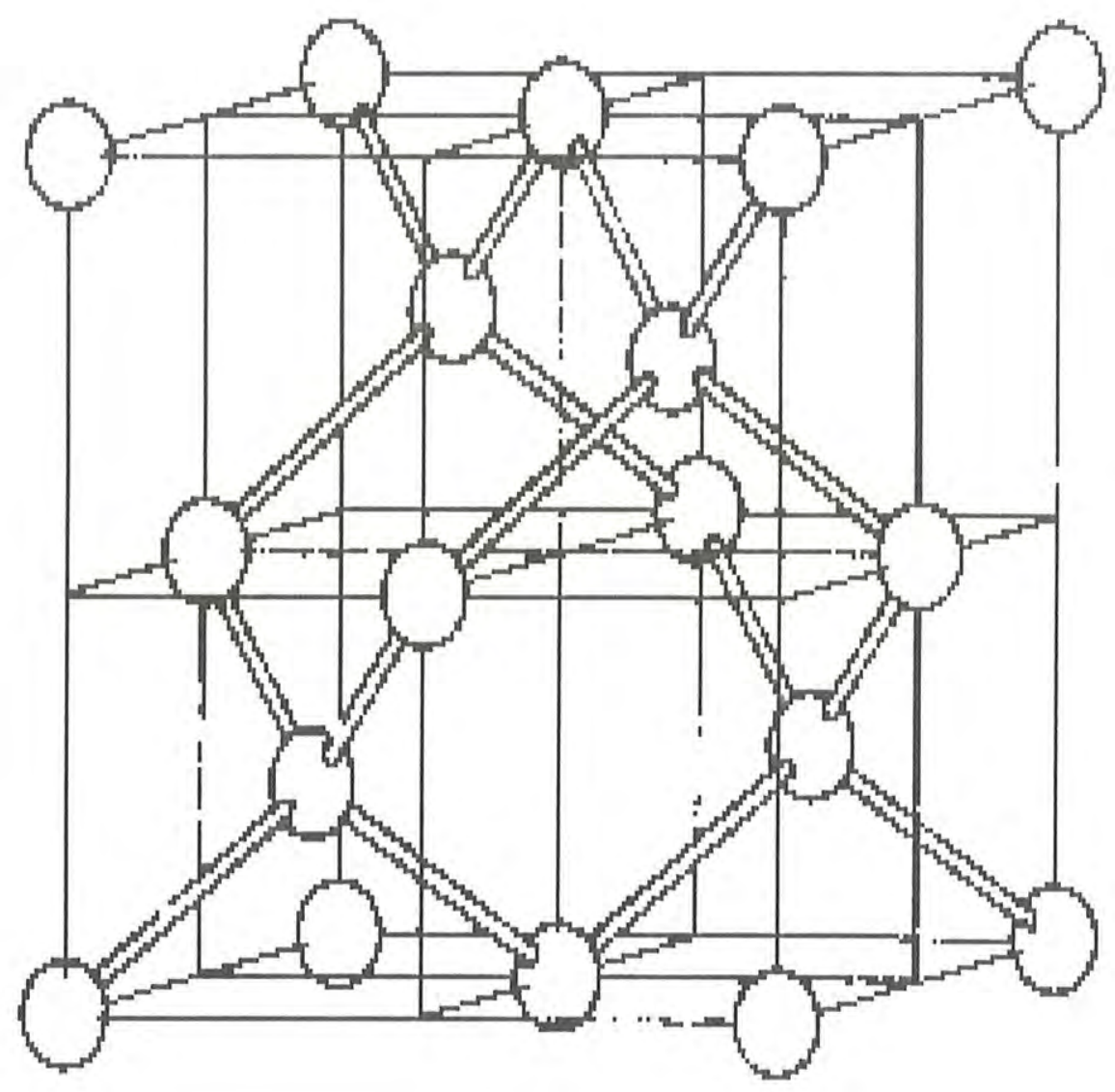

Figura A.1: Representação da estrutura cristalina do diamante. 
átomos 1 e 4; atomo 12, primeiro vizinho do átomo 6 e segundo vizinho do átomo 3; átomo 13, primeiro vizinho do átomo 1 e segundo vizinho do átomo 2; átomo 14, primeiro vizinho do átomo 3 e segundo vizinho dos átomos 2 e 6 .

Essa é a célula unitária de uma rede cúbica simples, pois é fácil verificar que se usarmos os vetores de translação da rede cúbica simples podemos preencher todo o espaço.

Uma vez especificadas as posições dos átomos e a geometria da célula unitária correspondente, podemos construir a matriz de Fock cristalina, na aproximação de interações de até segundos vizinhos.

Inicialmente consideremos o caso de átomos idênticos, $A=B$, lembrando que agora temos 8 átomos inequivalentes na célula, e uma vez que átomos equivalentes localizados em células diferentes nunca serão primeiros ou segundos vizinhos, temos

$$
\mathrm{F}_{\mu \nu}^{A \cdot A}(\mathrm{~K}, \mathrm{r})=\left(\frac{N_{c}}{N_{c}}<\phi_{\mu}^{A}\left(\mathrm{r}-\mathrm{d}_{A}\right)|\mathrm{H}| \phi_{\nu}^{A}\left(\mathrm{r}-\mathrm{d}_{A}\right)>,\right.
$$

ou seja, novamente

$$
\mathbf{F}_{\mu \nu}^{A \cdot A}(\mathbf{K}, \mathbf{r})=F_{\mu \nu}^{A . A}
$$

A partir de agora passamos a considerar o caso de átomos não idênticos, $A \neq B$, e uma vez que a matriz de Fock cristalina deve ser hermiteana podemos considerar apenas os casos em que $A$ é menor que $B$.

O átomo 1 "vê" como seus primeiros vizinhos o átomo 2 localizado dentro da célula tomada como referência, e outros três átomos, que estão localizados externamente a célula ( que são equivalentes aos átomos 6,7 e 8 por um vetor de translação da rede); como segundos vizinhos o átomo 1 "vê" três átomos (átomos 2,3 e 4) localizados na própria célula unitária e outros 9 átomos (externos a célula, que são equivalentes aos átomo 2, 3 e 4).Com isso teremos:

$$
\begin{aligned}
& \mathbf{F}_{\mu \nu}^{1,2}(\mathrm{~K}, \mathrm{r})=<\phi_{\mu}^{1}\left(\mathrm{r}-\mathrm{d}_{1}\right)|\mathrm{H}| \phi_{\nu}^{2}\left(\mathrm{r}-\mathrm{d}_{2}\right)>=F_{\mu \nu}^{1.2} ; \\
& \mathbf{F}_{\mu \nu}^{1,3}(\mathbf{K}, \mathbf{r})=\left[1+\sum_{p=1}^{3} e^{i \mathbf{K} \cdot \mathbf{a}_{\mu^{\prime}}} R_{p}\right] F_{\mu \nu^{\prime}}^{1,3} ; \\
& \mathbf{F}_{\mu \nu}^{1,6}(\mathbf{K}, \mathbf{r})=e^{i \mathbf{K} \cdot \mathbf{a}_{1,6}}<\phi_{\mu}^{1}\left(\mathbf{r}-\mathrm{d}_{1}\right)|\mathrm{H}| \phi_{\nu}^{6}\left(\mathbf{r}-\mathrm{d}_{6}\right)>=R_{1.6} F_{\mu \nu}^{1.6} .
\end{aligned}
$$

Outras interações envolvendo o átomo 1 (1-4, 1-5, 1-7 e 1-8) são obtidas de maneira análoga. 
Procedendo da mesma forma para as interações que envolvem o átomo 2, temos que esse possui todos os seus primeiros vizinhos (átomos 1,3,4 e 5) internos a célula. e seus segundos vizinhos são os átomos 6,7 e 8 internos a célula e outros 9 átomos externos a célula e diferindo dos átomos 6,7 e 8 por 11 m vetor de translação da rede. Desta forma os elementos da matriz de Fock cristalina que envolve o átono 2 serão:

$$
\begin{gathered}
\mathbf{F}_{\mu \nu}^{2.3}(\mathbf{K}, \mathrm{r})=<\phi_{\mu}^{2}\left(\mathrm{r}-\mathrm{d}_{2}\right)|\mathrm{H}| \phi_{\nu}^{3}\left(\mathrm{r}-\mathrm{d}_{3}\right)>=F_{\mu \mu^{\prime \prime}}^{2.3} \\
\mathbf{F}_{\mu \nu}^{2.6}(\mathbf{K}, \mathbf{r})=\left[1+\sum_{\nu=1}^{3} e^{i \mathbf{K} \cdot \mathbf{a}_{l^{\prime}}} R_{\nu^{\prime}}\right] F_{\mu \mu^{\prime}}^{2.6}
\end{gathered}
$$

O átomo 3 possui os primeiros vizinhos os átomos 2 e 6 internos a célula e: outros dois átomos externos (equivalentes aos átomos 6 e 8) e segundos vizinhos os átomos 1,4 e 5 internos a célula e outros 9 átomos externos a célula (equivalentes aos átomos 1, 4 e 5), portanto:

$$
\begin{aligned}
& \mathbf{F}_{\mu \nu^{\prime}}^{3.4}(\mathbf{K}, \mathbf{r})=\left[1+\sum_{p=1}^{3} e^{i \mathbf{K} \cdot \mathbf{a}_{\nu^{\prime}}} R_{p}\right] F_{\mu \nu^{\prime \prime}}^{3.4} \\
& \mathbf{F}_{\mu \mu^{\prime}}^{3.6}(\mathrm{~K}, \mathrm{r})=<\phi_{\mu}^{3}\left(\mathrm{r}-\mathrm{d}_{3}\right)|\mathrm{H}| \phi_{\nu^{\prime}}^{6}\left(\mathrm{r}-\mathrm{d}_{6}\right)>=F_{\mu \mu^{\prime \prime}}^{3.6} \\
& \mathbf{F}_{\mu \nu}^{3.7}(\mathbf{K}, \mathbf{r})=e^{i \mathbf{K} \cdot \mathbf{a}_{3,7}}<\phi_{\mu}^{1}\left(\mathbf{r}-\mathbf{d}_{3}\right)|\mathbf{H}| \phi_{\nu}^{6}\left(\mathbf{r}-\left(\mathbf{a}_{3.7}+\mathrm{d}_{7}\right)>=R_{1.7} F_{\mu \mu^{3.6}}^{3 .}\right.
\end{aligned}
$$

Os átomos 4 e 5 da mesma forma que o átomo 3 estão localizados nas faces do cubo e com isso os elementos da matriz de Fock cristalina envolvendo esses átomos podem ser obtidos da mesma forma que são obtidos para o átmo 3. Resta o átomo 6 que possui como primeiros vizinhos o átomo 3 localizado interno a célula e outros três átomos externos a célula equivalenes aos átomos 1,7 e 8 respectivamente, como segundos vizinhos esse possui os átomos 2,7 e 8 internos a célula e mais 9 outros átomos externos a célula e equivalentes aos átomos 2,7 e 8, com isso temos

$$
\mathbf{F}_{\mu \nu}^{6,7}(\mathbf{K}, \mathbf{r})=\left[1+\sum_{p=1}^{3} e^{i \mathbf{K} \cdot \mathbf{a}_{\nu^{\prime \prime}}} R_{p}\right] F_{\mu \nu}^{6,7}
$$


Interações envolvendo os átomos 7 e 8 podem ser obtidas da mesma forma que as interações envolvendo o átomo 6.

Os vetores de translação $\left(\mathrm{a}_{\mathrm{p}}\right)$ são os vetores da rede cúbica simples e as rotações $\left(R_{p}\right)$ continuam sendo as $C_{2}$ do grupo $T_{l}$.

Dentro de uma simetria tetraédrica trabalhamos também com células maiores (como por exemplo 54 átomos ) e interações de vizinhos de mais altia orden (chegamos interações envolvendo até quintos vizinhos) porém o processo de construçâo da matriz de Fock cristalina e similar aos casos citados.

Dentro de uma simetria diferente estivemos trabalhando com o cristal de quartzo, simetria $D_{3 h}$, com isso descreveremos esse particular caso a seguir.

\section{A.3 Simetria $D_{3 h}$ com 9 átomos na célula unitária e interação até segundos vizinhos}

A célula unitária convencional do cristal de quartzo, possui 9 átomos (3 átomos de Si e 6 átomos de O). A estrutura cristalina está apresentada na figura A.2, e as posições dos átomos da célula estão listadas na tabela A.2.

Na estrutura do cristal de quartzo cada átomo de Si "vê" como primeiro vizinho 4 átomos de $\mathrm{O}$, que formam um tetraedro quase perfeito, e como segundos vizinlos quatro átomos de Si.

Para ilustrar como podemos formar a matriz de Fock cristalina para esta estrutura, consideremos como exemplo o átomo 1 da tabela A.2. Este átomo tem como primeiros vizinhos os átomos 5, 67 e 10; os segundos vizinhos são os átomos 2, 3, 11 e 12 . Usando as propriedades de simetria encontramos:

$$
\begin{gathered}
\mathbf{F}_{\mu \nu}^{1,1}(\mathrm{~K}, \mathrm{r})=F_{\mu \nu}^{1,1} \\
\mathbf{F}_{\mu \nu}^{1.2}(\mathbf{K}, \mathbf{r})=\left(1+\mathrm{e}^{\left.\mathrm{i} \mathrm{K} \cdot \mathrm{a}_{2-11} R_{1,11}\right) F_{\mu \nu}^{1,2}}\right. \\
\mathbf{F}_{\mu \nu}^{1.3}(\mathbf{K}, \mathbf{r})=\left(1+e^{i \mathrm{~K} \cdot \mathrm{a}_{3-12}} R_{1,12}\right) F_{\mu \nu}^{1,3} \\
\mathrm{~F}_{\mu \nu}^{1,4}(\mathrm{~K}, \mathrm{r})=F_{\mu \nu}^{1,4} \\
\mathrm{~F}_{\mu \nu}^{1,5}(\mathrm{~K}, \mathrm{r})=F_{\mu \nu}^{1.5}
\end{gathered}
$$




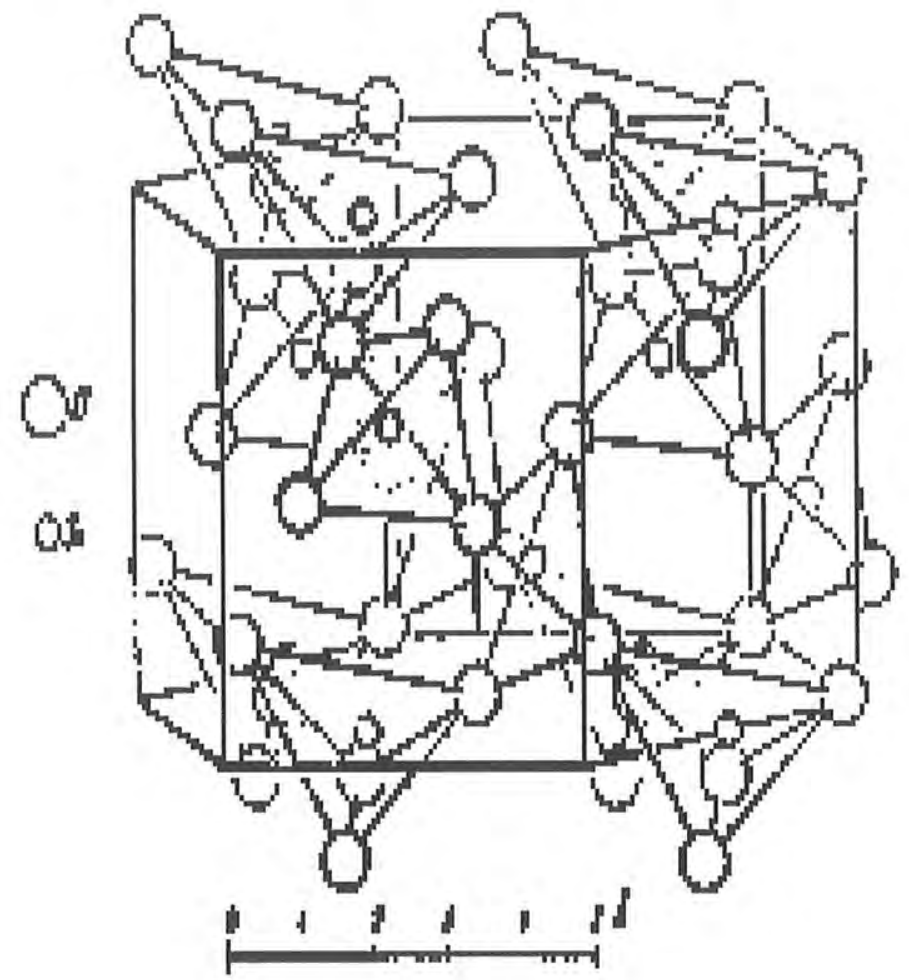

Figura A.2: Representação da estrutura cristalina do $\alpha$-quartzo. 


$$
\begin{gathered}
\mathbf{F}_{\mu \nu}^{1,6}(\mathbf{K}, \mathbf{r})=0 \\
\mathbf{F}_{\mu \nu}^{1.7}(\mathbf{K}, \mathbf{r})=F_{\mu \nu^{\prime}}^{1.7} \\
\mathrm{~F}_{\mu \nu}^{1.8}(\mathbf{K}, \mathbf{r})=\left(e^{i \mathbf{K} \cdot \mathbf{a}_{s-10}} R_{1.10}\right) F_{\mu \nu}^{1.4} \\
\mathbf{F}_{\mu \nu}^{1.9}(\mathbf{K}, \mathbf{r})=0
\end{gathered}
$$

Termos da matriz de Fock cristalina envolvendo os outros dois átomos de Si podem ser obtidos de forma idêntica.

Vejamos agora como podemos obter os termos da matriz de Fock cristalina para as interações dos átomos de O. Tomando como exemplo o átomo 4 da tabela A.2, existem dois primeiros vizinhos, átomos 1 e 2 , e seis segundos vizinhos, átomos 5 , 7 , 8, 10, 13 e 14. Assim, os elementos da matriz de Fock para o átomo 4 são:

$$
\begin{aligned}
& \mathbf{F}_{\mu \nu^{\prime}}^{4,1}\left(\mathbf{K}, \mathbf{r}=\left(\mathbf{F}_{\mu u^{\prime}}^{1.4}(\mathbf{K}, \mathbf{r})^{+}=F_{\mu \mu^{\prime}}^{1.4} ;\right.\right. \\
& \mathbf{F}_{\mu \nu}^{4.2}(\mathbf{K}, \mathrm{r})=\left(\mathbf{F}_{\mu \nu}^{2.4}(\mathrm{~K}, \mathrm{r})\right)^{+}=F_{\mu \nu}^{4.2} ; \\
& \mathbf{F}_{\mu \nu}^{4.3}(\mathbf{K}, \mathbf{r})=0 \\
& \mathbf{F}_{\mu \nu}^{4.4}(\mathrm{~K}, \mathrm{r})=F_{\mu \nu}^{4.4} \\
& \mathbf{F}_{\mu \nu}^{4.5}(\mathbf{K}, \mathbf{r})=0 \\
& \mathbf{F}_{\mu u^{\prime}}^{4.6}(\mathbf{K}, \mathrm{r})=\left(e^{i \mathbf{K} \cdot \mathbf{a}_{6-13}} R_{4-13}\right) F_{\mu \nu^{\prime}}^{7.9} \\
& \mathbf{F}_{\mu \nu}^{4,7}(\mathbf{K}, \mathbf{r})=F_{\mu \nu}^{4,7} \\
& \mathbf{F}_{\mu \nu}^{4,8}(\mathbf{K}, \mathbf{r})=\left(1+e^{i \mathbf{K} \cdot \mathbf{a}_{8-10}} R_{4-10}\right) F_{\mu \nu}^{7,9} ; \\
& \mathbf{F}_{\mu \nu}^{4.9}(\mathbf{K}, \mathbf{r})=\left(e^{i \mathbf{K} \cdot \mathbf{a}_{9-15}} R_{4-14}\right) F_{\mu \nu}^{4,5}
\end{aligned}
$$




\begin{tabular}{|c|c|c|c|}
\hline \multirow{2}{*}{$\begin{array}{c}\text { tipo de } \\
\text { átomo }\end{array}$} & \multicolumn{3}{|c|}{ coordenadas } \\
\cline { 2 - 4 } & $\mathrm{x}\left(\frac{a}{2}\right)$ & $\mathrm{y}\left(\frac{\sqrt{3} a}{2}\right)$ & $\mathrm{z}(c)$ \\
\hline 1 & 1.070 & 0.000 & 0.333 \\
\hline 2 & 0.465 & 0.465 & 0.000 \\
\hline 3 & 0.465 & -0.465 & 0.667 \\
\hline 4 & 0.687 & 0.143 & 0.12 \\
\hline 5 & 1.442 & 0.272 & 0.453 \\
\hline 6 & 0.871 & -0.585 & 0.880 \\
\hline 7 & 0.687 & -0.143 & 0.547 \\
\hline 8 & 0.442 & 0.728 & 0.213 \\
\hline 9 & -0.129 & -0.415 & 0.787 \\
\hline 10 & 1.442 & -0.272 & 0.213 \\
\hline 11 & 1.465 & -0.535 & 0.000 \\
\hline 12 & 1.465 & 0.535 & 0.667 \\
\hline 13 & -0.129 & 0.415 & -0.120 \\
\hline 14 & 0.871 & 0.585 & -0.213 \\
\hline
\end{tabular}

Tabela A.2: Posiçôes adotadas para a estrutura baseada na rede hexagonal de arestas a e c, com 9 átomos na base. Os primeiros 9 átomos pertencem à célulu unitária, os demais estão em células contíguas (ver texto).

Termos da matriz de Fock para os demais átomos de O são obtidos de maneira semelhante. Os vetores de translação são os vetores da rede hexagonal e as rotações são $C_{2}$ para as interações de primeiros vizinhos e $C_{3}$ para as interações envolvendo segundos vizinhos. 
Apêndice $B$

Parametrização NDO/Cristal para os átomos de $\mathrm{Si}$ e $\mathrm{O}$ 


\begin{tabular}{|c|c|c|}
\hline Silício & AM1/Cristal & AM1 \\
\hline$\beta_{s}(\mathrm{eV})$ & -3.9848 & -3.7849 \\
\hline$\beta_{p}$ & -1.6968 & -1.9681 \\
\hline$\alpha_{S i}$ & 2.267416 & 2.257846 \\
\hline$K_{1}$ & 0.2500 & 0.2500 \\
\hline$L_{1}$ & 9.00 & 9.00 \\
\hline$M_{1}$ & 0.911453 & 0.911453 \\
\hline$K_{2}$ & 0.061513 & 0.061513 \\
\hline$M_{2}$ & 5.00 & 5.00 \\
\hline$L_{2}$ & 1.895569 & 1.995569 \\
\hline$K_{3}$ & 0.020789 & 0.20789 \\
\hline$M_{3}$ & 5.00 & 5.00 \\
\hline$L_{3}$ & 2.99061 & 2.99061 \\
\hline$K_{4}$ & 0.0100 & 0.00 \\
\hline$L_{4}$ & 9.0000 & 0.00 \\
\hline$M_{4}$ & 3.5000 & 0.00 \\
\hline$K_{5}$ & 0.0100 & 0.00 \\
\hline$L_{5}$ & 7.0000 & 0.00 \\
\hline$M_{5}$ & 4.4000 & 0.00 \\
\hline
\end{tabular}

Tabela B.1: Parâmetros do silício: hopping ( $\beta$ ) (ver expressão 3.14), expoentes da repulsão entre caroços $(\alpha)$ (ver expressão 3.13) e parâmetros das gaussianas (ver expressões 3.16 e 3.17$)$.

Apresentamos neste apêndice apenas os valores para os parâmetros constantes nas funções que foram modificados para realizar este trabalho. Todos os demais foran mantidos como presentes no programa MOPAC para o AM1, sugeridos por Dewar e colaboradores[31], ou no programa ZINDO/CI, sugeridos por Ridley e Zerner[32].

Seguem-se as tabelas para o AM1, átomos de Si e O, e para o ZINDO, átomos de Si e O. 
Apendice B

141

\begin{tabular}{|c|c|c|}
\hline Oxigênio & AM1/Cristal & AM1 \\
\hline$\beta_{s}$ & -29.47 & -29.27 \\
\hline$\beta_{p}$ & -29.17 & -29.27 \\
\hline$\alpha$ & 4.466 & 4.455 \\
\hline$K_{1}$ & 0.280982 & 0.28092 \\
\hline$L_{1}$ & 5.000000 & 5.00 \\
\hline$M_{1}$ & 0.848118 & 0.847918 \\
\hline$K_{2}$ & 0.08133 & 0.08143 \\
\hline$M_{2}$ & 7.000000 & 7.00 \\
\hline$L_{2}$ & 1.445571 & 1.445071 \\
\hline$K_{3}$ & -0.051000 & 0.00 \\
\hline$M_{3}$ & 7.000000 & 0.00 \\
\hline$L_{3}$ & 1.85000 & 0.00 \\
\hline$K_{4}$ & 0.19000 & 0.00 \\
\hline$M_{4}$ & 5.000000 & 0.00 \\
\hline$L_{4}$ & 2.05500 & 0.00 \\
\hline$K_{5}$ & -0.3213 & 0.00 \\
\hline$M_{5}$ & 4.000000 & 0.00 \\
\hline$L_{5}$ & 3.25000 & 0.00 \\
\hline
\end{tabular}

Tabela B.2: Parâmetros do Oxigênio: hopping ( $\beta$ ) (ver expressão 3.14), expoentes da repulsão entre caroços $(\alpha)$ (ver expressão 3.13) e parâmetros das gaussianas (ver expressões 3.16 e 3.17 ). 


\begin{tabular}{|c|c|c|}
\hline Silício & ZINDO/Cristal & ZINDO \\
\hline$\beta_{s}$ & -8.50 & -9.00 \\
\hline$\beta_{p}$ & -7.50 & -9.00 \\
\hline$\Gamma_{s}$ & 7.59 & 7.57 \\
\hline$\Gamma_{p}$ & 7.55 & 7.57 \\
\hline Oxigênio & - & \\
\hline$\beta_{s}$ & -36.00 & -34.00 \\
\hline$\beta_{p}$ & -32.00 & -34.00 \\
\hline$\Gamma_{s}$ & 13.50 & 13.00 \\
\hline$\Gamma_{p}$ & 12.05 & 13.00 \\
\hline
\end{tabular}

Tabela B.3: Parâmetros para o Si e o O: hopping ( $\beta$ ) (ver a expressão 3.33) 6 integrais de repulsão de dois centros (ver expressão 3.31).

\begin{tabular}{|c|c|c|c|}
\hline & $f_{\sigma-\sigma}$ & $f_{\sigma-\pi}$ & $f_{\pi-p i}$ \\
\hline ZINDO/Cristal & 1.000 & 0.665 & 1.327 \\
\hline ZINDO & 1.000 & 0.585 & 1.267 \\
\hline
\end{tabular}

Tabela B.4: Fatores de interação (ver expressão 3.36). 


\section{Bibliografia}




\section{Bibliografia}

[1] L. Canham, Phys. World 5, 41 (março de 1992)

[2] L. Esaki e R. Tsu, IBM J. Res. Develop. 14,61 (1970).

[3] L.L. Chang e L. Esaki, Phys. Today 45, 36 (outubro de 1992).

[4] L.T. Canham, App. Phys. Lett. 57, 1004 (1992).

[5] V. Lehmann e U. Gösele, Appl. Phys. Lett. 58, 856 (1991).

[6] A. Uhli, Bell Syst. Tech. J. A53, 8 (1956).

[7] Y.H. Xie, J. Appl. Phys. 71, 2403 (1992); L.E. Friedersdorf P. C. Searson, S. M. Prokes, O. J. Glembocki e J. M. Macauly, Appl. Phys. Lett. 60, 2285 (1992).

[8] O. Tecshke, M. C. dos Santos, M. U. Klenike, D. M. Soares e D. S. Galvão, J. of Appl. Physics 78, 590 (1995); D.M. Soares, M.C. dos Santos e O 'Teschke, Chemical Physics Leet. 242, 202 (1995).

[9] R.L. Smith e R.D. Collins, J. Appl. Phys. 71, R1 (1992).

[10] K. H. Yung, T.Y. Hsich, J. Sarathy, J. C. Campbell e D. L. Kwong, Appl. Phys. Lett. 60, 1863 (1992).

[11] R. W. Fathauer, T. George, A. Ksendzov, T. L. Lin, W. T. Pike, and R. P. Vasquez, Appl. Phys. Lett. 60, 995 (1992).

[12] A.G. Cullis, L.T. Canham, G.M. Williams, P.W. Smith, e O.D. Dosser, J. Appl. Phys. 75, 493 (1994). 
[13] V. Petrova-Koch, T. Muschik, A. Kux, B.K. Meyer, e F. Koch, Appl. Phys. Lett. 61, 943 (1992).

[14] S.L. Friedman, M. A. Marcus, D. L. Adler, Y. H. Xie, T. D. Harris e P. II. Citrin, Appl. Phys. Lett. 62, 1934 (1993).

[15] J.C. Tsang, M.A. Tischler e R.T. Collins, Appl. Phys. Lett. 60 , 2279 (1992).

[16] C. Tsai, K. H. Li, D.S. Knosky, R. Z. Qion, T. C. Hsu, J. T. Irby, S.K. Banerjee, Appl. Phys. Lett. 60, 1700 (1992).

[17] R.T. Collins, Silicon Based Optoeletronics Materials Symposium, Philadelphia (1993).

[18] M.A. Tischler, Appl. Phys. Lett. 56, 2108 (1990).

[19] G. Allan, C. Delerue, e M. Lannoo, Phys. Rev. Lett. 76, 2961 (1996).

[20] A.J. Read, Q. J. Needs, K. J. Nash, L. T. Canham, P. 1). J. Calcolf e A. Qteich, Phys. Rev. Lett. 69, 1232 (1992).

[21] T. Ohno, K. Shiraishi e T. Ogawa, Phys. Rev. Lett. 69, 2400 (1992),

[22] M.S. Hybersten e M. Needels, Phys. Rev. B 48, 4608 (1993).

[23] G.D. Sanders e Y.C. Chang, Phys. Rev. B 45, 9202 (1992).

[24] F. Buda, J. Kohanoff e M. Parrinello, Phys. Rev. Lett. 69, 1272 (1992).

[25] M. Hirao e T. Uda, Surf. Sci. 306, 87 (1994).

[26] B. Delley e E.F. Steigmeier, Phys. Rev. B 47, 1397 (1993).

[27] R. Kumar, Y. Kitoh, K. Shigematsu, e K. Hara, Jpn. J. Appl. Phys. 33, 909) (1994).

[28] Tu Huaxiang, Ye Ling, e Xie Xide, Phys. Rev. B 48, 10978 (1993).

[29] J.P. Proot, C. Delerue e G. Allan, Appl. Phys. Lett. 61, 1948 (1992).

[30] M.J.S. Dewar e W. Thiel, J. Am. Chem. Soc. 99, 4899 (1976) 
[31] M.J.S. Dewar, E.G. Zoebish, E.F. Healy e J.J.P. Stewart, J. Am. Chem. Soc. 107, 39021985.

[32] J. Ridley e M. Zerner, Theoret. Chem. Acta 32, 111 (1973).

[33] C.C. Roothaan, Rev. Mod. Phys. 23, 69 (1951).

[34] Tese de Mestrado do Sr. R.J. Baierle, IFUSP (1991).

[35] L.G. Ferreira, J. Comp. Phys. 36, 198 (1979).

[36] M. Zerner e M. Hehemberg, Chem. Phys. Lett. 62, 550 (1979).

[37] P. Dèak, Comunicação Individual (1991).

[38] A. Baldereschi, Phys. Rev. B 12, 5212 (1972).

[39] D.J. Chadi e M. L. Cohen, Phys. Rev. B 8, 5747 (1973).

[40] A. Zunger, Phys. Rev. B 21, 4785 (1980).

[41] J. Thm e M.L. Cohen, Solid State Commun. 29, 711 (1979); idem, Phys. Rev. B 21, 1527 (1980).

[42] P. Ordejón e F. Induraáin, Phys. Rev. B 44, 12794 (1991).

[43] Tese de Mestrado da Sr. $\underline{a}$ C. W. Rodrigues, IFUSP (1989).

[44] M.J. Caldas, C.W. Rodrigues e P.L. Souza, Mat. Sci. Forum 83-87, 1015 (1991).

[45] R.C. Binghan, M.J.S. Dewar e D.L. Lo, J. Am. Chem. Soc. 97, 1285 (1986).

[46] M.J.S. Dewar e D.H. Lo, J.Am. Chem. Soc. 94, 5296 (1972).

[47] L. Oleari, L. DiSippio e G. DeMichelis, Mol. Phys. 10, 97, (1866).

[48] H.A. Skinner e H.O. Pritchard, Trans. Faraday Soc. 49 , 1254 (1953).

[49] G.E. Moore, "Atomic energy levels", U.S. Department of Commerce, National Bureau of Standards. Circular 467 (1949); J. Hinze e H.H. Jaffe, J. Chem. Phys. 38,1834 (1963). 
[50] J.A. Pople, D.L. Beveridge e D.L. Dobosh, J. Chem. Phys. 47, 2026 (1967).

[51] R.D. Pariser e R.G. Parr, J. Chem. Phys. 21 , 767 (1953).

[52] J.A. Pople, D.P. Santry e G.A. Segal, J. Chem. Phys. 43, S129 (1965); J.A. Pople e G.A. Segal, J. Chem. Phys. 43, S136 (1965).

[53] K. Ruedemberg, Rev. Mod. Phys. 34, 326 (1962).

[54] M.J.S. Dewar e N.L. Sabelli, J. Chem. Phys. 34, 1232 (1961); J. Klopman, J. Am. Chem. Soc 86, 4550 (1964).

[55] J.J.P. Stewart, J. Comp. Chem. 10, 209 (1989).

[56] N. Mataga e K. Nishimoto, Z. Phyz. Chem. (Frankfurt on Main), 13, 140 (1957).

[57] K. Weiss, Os autores da ref. [32] citam essa como uma comunicação individual.

[58] N. Ashroft e I. Mermin, Solid State Phys., Sanders College (Philadelphia), 1976.

[59] P. Giannozzi, S. Gironcoli, P. Pavone e S. Baroni, Phys. Rev. B 43, 7231 (1991).

[60] Landolt e Bornstein, Spring-Verlag, "Table of content semiconductors IV-IV and II-VI“, N.Y. (1982).

[61] G. Nilsson e G. Nelin, Phys. Rev. B 6 , 3777 (1972).

[62] M.D. Harmony, J. Phys. Chem. Ref. Data 813, (1979).

[63] E.G. Rochow, The Chemistry of Silica, Pergamon Press, Oxford (1973).

[64] Handbook of Chemistry and Physics, CRC Press, 73 ed. (1991-92).

[65] M. Stavola, Appl. Phys. Lett. 44, 514 (1984)

[66] B. Pajot e P. Claws, Proc. 18th Int. Conf. on the Physics of Semiconductors, Stockholm (1986).

[67] M. Gelize e A. Dargelos, Chem. Phys. 149,333 (1991). 
[68] U. Itoh, Y. Toyoshima e H. Onuki, J. Chem. Phys. 85, 4867 (1986).

[69] B. Pajot, Semiconductor e Semimetals, vol.5, 191 (1994).

[70] Y. Lee e J.W. Corbett, Phys. Rev. B 13, 2653 (1976).

[71] E. Martinez, J. Plans, e F. Indurain, Phys. Rev. B 36, 8043 (1987).

[72] J.W. Corbett G. D. Watkins, R. M. Chenko e R. S. McDonald, Phys. Rev bf 4, 1015 (1961).

[73] J.W. Corbett, R.S. Mac Donald, e G.D. Watkins, J. Phys. Chem. Solids 25, 873 (1964).

[74] L.S. Milevskii e T.A. Pagova, Soc. Phys. Semicond. 10,763 (1976).

[75] K.L. Brower, Phys. Rev. B 4, 1968 (1971).

[76] M.J. Caldas, J.R. Leite e A. Fazzio, Phys. Stat. Solidi B 98, K109 (1980).

[77] G.G. DeLeo, W.B. Fowler e G. D. Watkins, Phys. Rev. B 29, 3193 (1984).

[78] I. Ortega-Blake J. Taguerra-Martinez, R. A. Barrio, E. Martinez e F. Yndurain, Solid State Commun. 71, 1107 (1989).

[79] C. Van de Walle e P. Blochl, Phys. Rev. B 47, 4244 (1993).

[80] C. Delerue, G.Allan, e M. Lannoo, Phys. Rev. B 48, 11024 (1993).

[81] L. Wang e A. Zunger, J. Phys. Chem. 98, 2158 (1994).

[82] Y. Kanemitsu, Phys. Rev., 263 1-91 (1996).

[83] Y. Kanemitsu H. Uto e Y. Masumoto, Phys. Rev. B 48, 2827 (1993).

[84] T. Ogawa e Y. Kanemitsu, eds., "Optical Properties of Low-Dimensional Materials" (World Scientific, Singapore, 1995).

[85] L. Brus, Appl. Phys. A53 465 (1991).

[86] A.D. Yoffa, Adv. Phys. 42, 173 (1992). 
Referências

[87] D.J. Lockwwod, A. Wang e B. Bryskiewicz, Solid State Commun. 89, 587 (1994).

[88] S. Schlupper et al, Phys. Rev. Lett. 72, 2648 (1994).

[89] S. Y. Ren e J. D. Dow, Phys. Rev. 45, 6492 (1992).

[90] T. Takagahara e K. Takeda, Phys Rev. B 46, 15578 (1992).

[91] G.S. Higashi, Y.J. Chabal, G. Truks e K. Rogacachari, Appl. Phys. Lett. 56, 656 (1990).

[92] G.S. Higashi, Y.J. Chabal, R.S.Becker e A.J. Backer, Appl. Phys. Lett. 58, 1656 (1991).

[93] G. Trucks, K. Ragavachari, G. S. Higashi e Y. J. Chabal, Phys. Rev. Lett. 65, $504(1990)$.

[94] M.B. Nardelli, et al, Surf. Sci. 269-270 , 979 (1992).

[95] M. Schluter e M.L. Cohen, Phys. Rev. B 17, 716 (1978).

[96] A. Selloni e C. M. Bertoni, Solid State Commun, 45, 475 (1983).

[97] P.D.J. Calcott, K. J. Nash, L. T. Canham, M. J. Kane, e D. Brumhead, J. Phys. Condens. Matter 5, L91 (1993).

[98] R. J. Baierle, M. J. Caldas, E. Molinari e S. Ossicini, Solid. State Commun., aceito para publicação em Feveiro de 1997.

[99] S.M. Prokes, J. Appl. Phys 37, 407 (1993).

[100] M.S. Brandt, et. al, Solid State Commun. 81307 (1991).

[101] T. Oshiro, C.K. Lutrus, D.E. Hagen e S.H. Suck-Salt, Solid State Commun. 100, 439 (1996).

[102] M.R. Pedersen, W.E. Pickett e S.C. Erwin, Phys. Rev. B 4817400 (1993)

[103] A.M. Mazzone, Europhys. Lett. 35, 13 (1996).

[104] A. Borghesi, A. Sassela, B. Pivac, L. Pavesi, Solid State Commun. 87, 1 (1993). 
[105] F. Ozaman e J.N. Chazoviel, J. Electroanal. Chem. 269, 251 (1989).

[106] S. Ossicini e O. Bisi, Defects and Diffusion Forum (1997).

[107] C. Van de Walle e J.E. Northup, Phys. Rev. Lett. 70, 1116 (1993). 